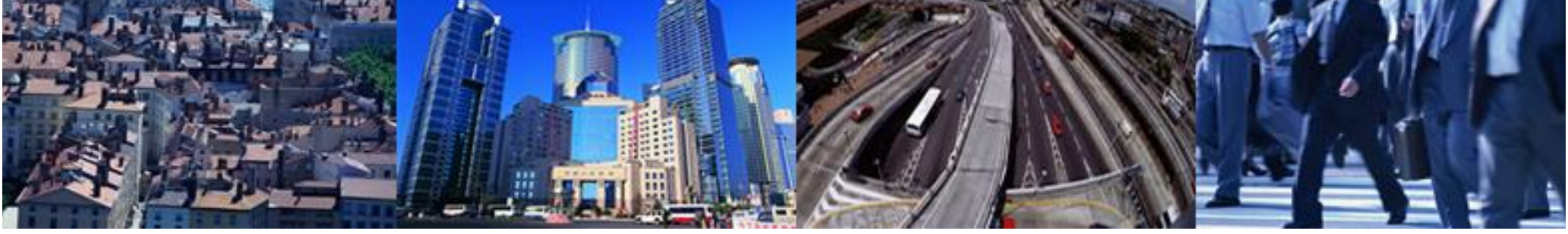

OECD Regional Development Working Papers 2009/1

\title{
Urban Trends and Policy in China
}

Lamia Kamal-Chaoui*, Edward Leman, Zhang Rufei

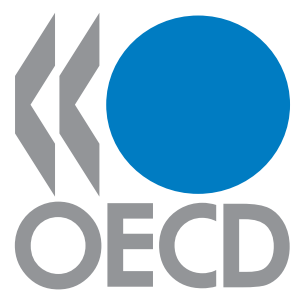

Kamal-Chaoui, L., E. Leman and Z. Rufei (2009), "Urban Trends and Policy in China", OECD Regional Development Working Papers, 2009/1, OECD publishing, (C) OECD. doi:10.1787/225205036417 


\section{OECD REGIONAL DEVELOPMENT WORKING PAPERS}

This series is designed to make available to a wider readership selected studies on regional development issues prepared for use within the OECD. Authorship is usually collective, but principal authors are named.

The papers are generally available only in their original language English or French with a summary in the other if available.

The opinions expressed in these papers are the sole responsibility of the author(s) and do not necessarily reflect those of the OECD or the governments of its member countries.

Comment on the series is welcome, and should be sent to either gov.contact@oecd.org or the Public Governance and Territorial Development Directorate, 2, rue André Pascal, 75775 PARIS CEDEX 16, France.

OECD Regional Development Working Papers are published on www.oecd.org/gov/regional/workingpapers

Applications for permission to reproduce or translate all or part of this material should be made to: OECD Publishing, rights@oecd.org or by fax 33145249930.

(C) OECD 2009 


\section{FOREWORD}

This working paper is one in a series of OECD Working Papers on Regional Development of the OECD Public Governance and Territorial Development Directorate, conducted under the responsibility of Marcos Bonturi, Head of the OECD Regional Competitiveness and Governance Division.

China has become the world's largest urban nation, with over 600 million urban citizens today. Projections indicate that this level may reach 900 million in 2030. The way this urbanisation process is managed will have important policy implications for China and beyond. This paper provides an introduction to urban trends and policies in China. It describes urban growth trends, where and in what kinds of cities growth is occurring, how China's cities are governed, and how public policy has influenced the extent, pace, and spatial distribution of urbanisation. As China continues to integrate with the globalising economy, its competitiveness will increasingly be driven by the capacities of its metropolitan regions to improve the productivity of enterprises in ever-widening supply chains. The report concludes with a description of some of the key policy challenges facing central and local urban governments in this global context, including: 1) institutional constraints to markets and factor mobility; 2) environmental challenges; 3) ensuring equity and helping vulnerable groups; and 4) metropolitan governance.

This report is part of a programme of work of the Territorial Development Policy Committee on Trends in National Urban Policies, conducted by the Urban Development Unit of the OECD Regional Competitiveness and Governance Division.

The paper has been conceived, co-ordinated and edited by Lamia Kamal-Chaoui, OECD Head of the Urban Development Unit, and produced by Edward Leman, President, Chreod Group Inc., and Zhang Rufei, Managing Director (China), Chreod Group Inc. Valuable comments were provided by Olaf Merk and Xiao Wang of the Urban Development Unit. Erin Byrne edited the language and prepared the working paper for publication.

Special thanks are given to Irène Hors (Co-ordinator of the OECD-China Program of Cooperation on Public Governance and Territorial Development) for providing suggestions and relevant contacts for the production of this paper. We are also grateful to Mrs Li Shantong, Senior Research Fellow and Former Director-General of Department of Development Strategy and Regional Economy, Development Research Center of the State Council, People's Republic of China, for her valuable comments on the paper and her participation at the 10th Session of the OECD Working Party on Urban Areas, held on 10 June 2008, at the OECD Headquarters in Paris.

For more information about this paper and on other urban development activities, please contact: Lamia Kamal-Chaoui (email lamia.kamal-chaoui@oecd.org). 


\section{TABLE OF CONTENTS}

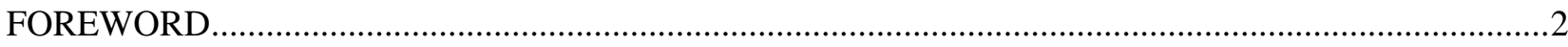

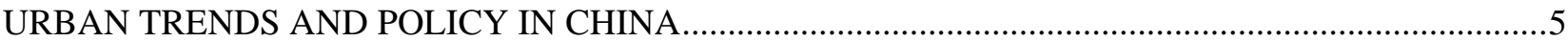

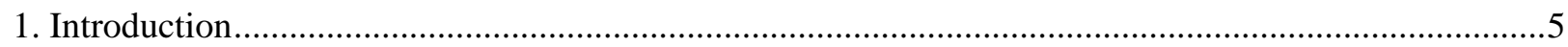

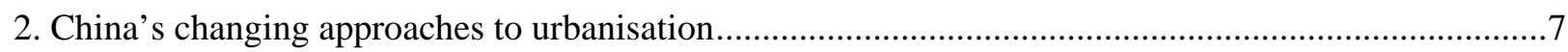

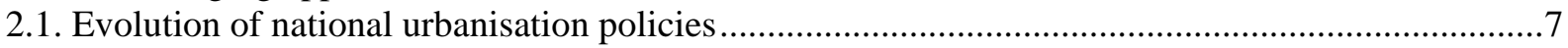

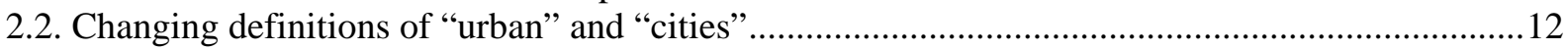

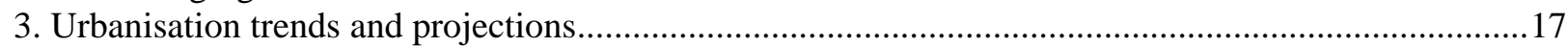

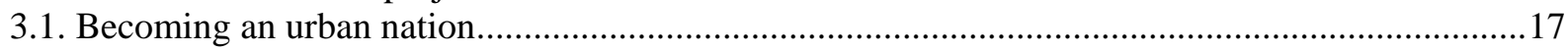

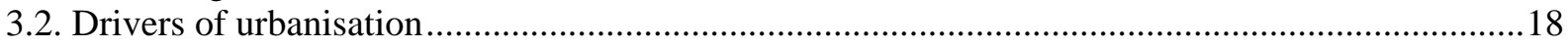

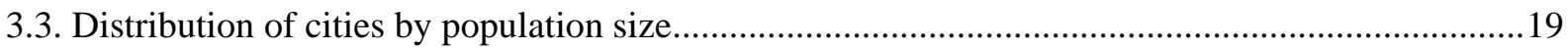

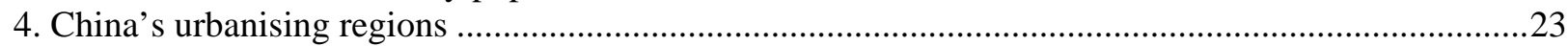

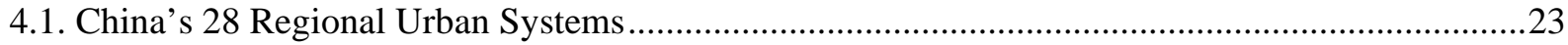

4.2. Economic performance of China's Regional Urban Systems .........................................................30

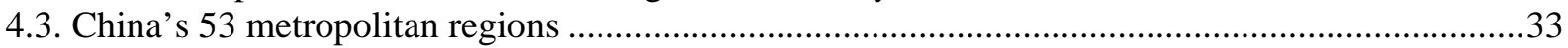

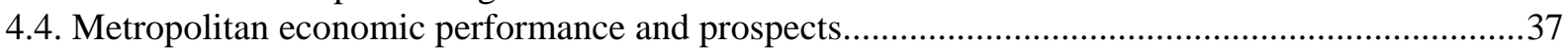

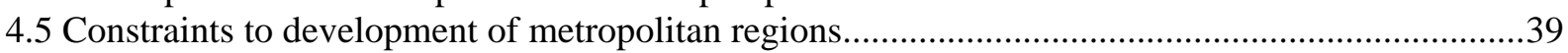

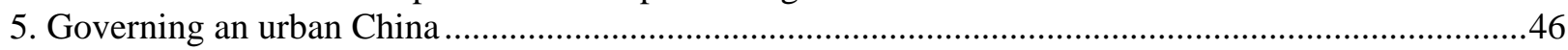

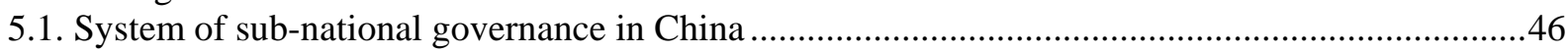

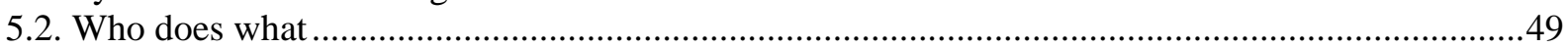

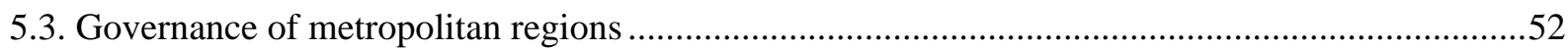

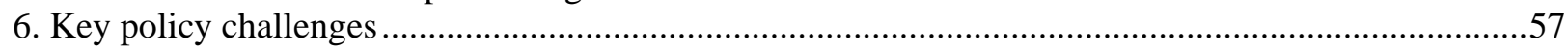

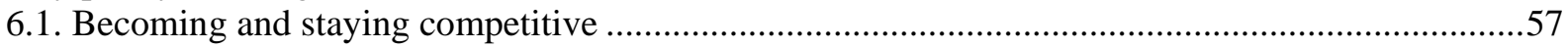

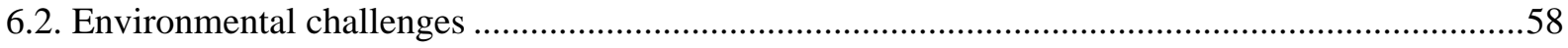

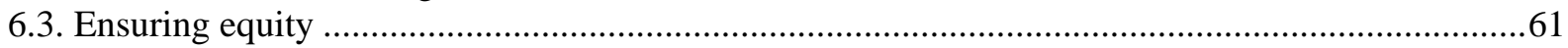

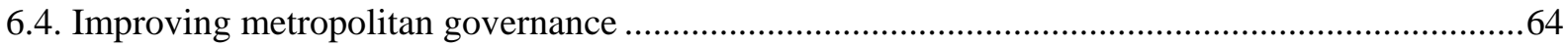

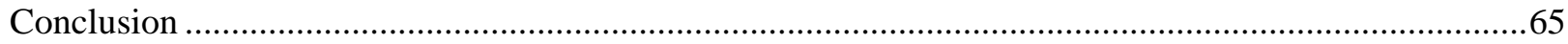

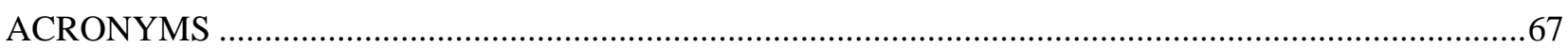

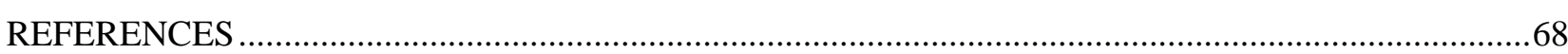

\section{Tables}

Table 1. State Council criteria for statutory designation of cities as of 1993.................................14

Table 2. $\quad$ Provisional regulations for definition of urban settlements, 1999 ...................................15

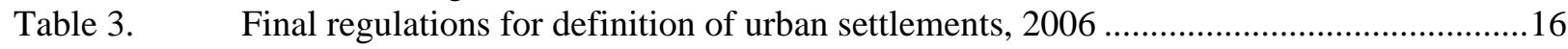

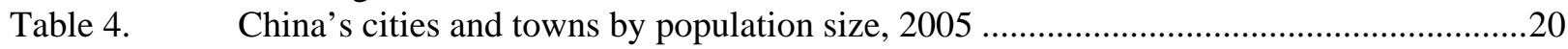

Table 5. Population changes in China's 28 Regional Urban Systems, 1998-2004 .........................29 


\section{Figures}

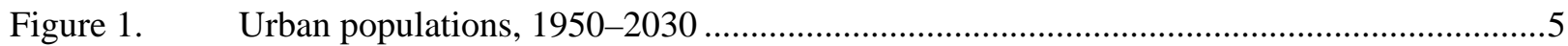

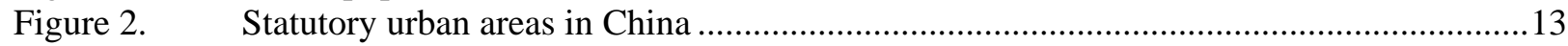

Figure 3. China's urbanisation, 1955-2020 ................................................................................17

Figure 4. Emerging disconnects between actual development and administrative boundaries in the China’s 53 metropolitan regions .......................................................................................21

Figure 5. $\quad$ Per cent of national urban population living in cities, 2005 ...........................................22

Figure 6. Generalised population densities, 2 CE (Han Dynasty) …............................................23

Figure 7. Generalised population densities, 742 CE (Tang Dynasty) ...........................................24

Figure 8. Generalised population densities, 1050 CE (Northern Song Dynasty) ............................24

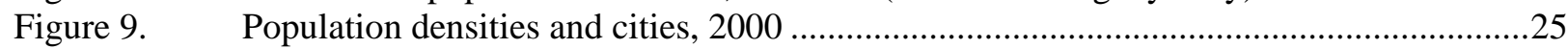

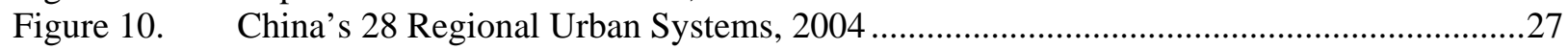

Figure 11. Economic performance of China's 28 Regional Urban Systems, 1998-2004 ...................31

Figure 12. China's 53 metropolitan regions by size of non-farming population, 2004 .....................36

Figure 13. Growing economic importance of China's 53 metropolitan regions...............................37

Figure 14. Change in metropolitan region's share of China's GDP, 1998-2004 ...............................38

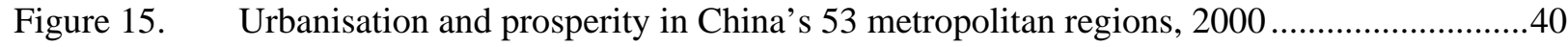

Figure 16. Educational attainment rates in China's cities (2000) .....................................................43

Figure 17. Per cent of metropolitan region population with university education, 2000/01...............45

Figure 18. Stylised model of China's governance system .........................................................46

Figure 19. Trends in sub-provincial governance under decentralisation ........................................48

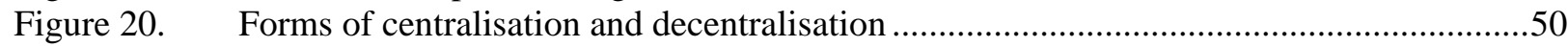

Figure 21. Generalised functional responsibilities in China's urban municipalities...........................54

Figure 22. Growth of motor vehicle population and associated NOx emissions, PRC and India

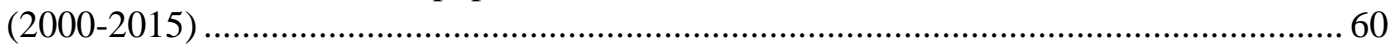

\section{Boxes}

Box 1.

Box 2.

Box 3.

Box 4.

Box 5.

Box 6.

Box 7.

Box 8.

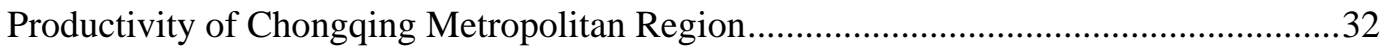

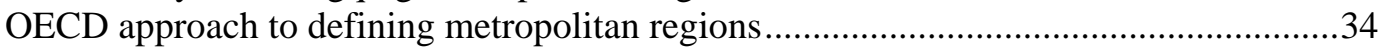

Concentrated growth urbanisation scenarios projected by the Mckinsey Report ...............39

Productivity and competitiveness in metropolitan areas ...................................................42

Higher education and human capital in Chongqing Municipality......................................4

Planning and development of metropolitan regions in Jiangsu Province.............................53

The annexation process in Chinese metropolitan regions ............................................56

Challenges from water pollution in Chongqing ……….................................................59 


\section{URBAN TRENDS AND POLICY IN CHINA}

\section{Introduction}

China surpassed the United States in the mid-1970s to become the nation with the largest number of urban dwellers in the world (Figure 1). Although still a predominantly rural country, with an urbanisation rate just under $20 \%$, in absolute numbers China had become - over 30 years ago - the world's largest urban nation in human history. ${ }^{1}$ Paradoxically, this ascendance occurred at the end of a period in which China's public policy was profoundly anti-urban. Much has changed since then. China's "opening up”, and the introduction of market-oriented reforms in the early 1980s, accelerated urbanisation across China such that, today, 600 million urban Chinese constitute $44 \%$ of the country's population. Indications are that urbanisation will continue, at even more rapid rates in parts of the country, well into this century.

Figure 1. Urban populations, 1950-2030

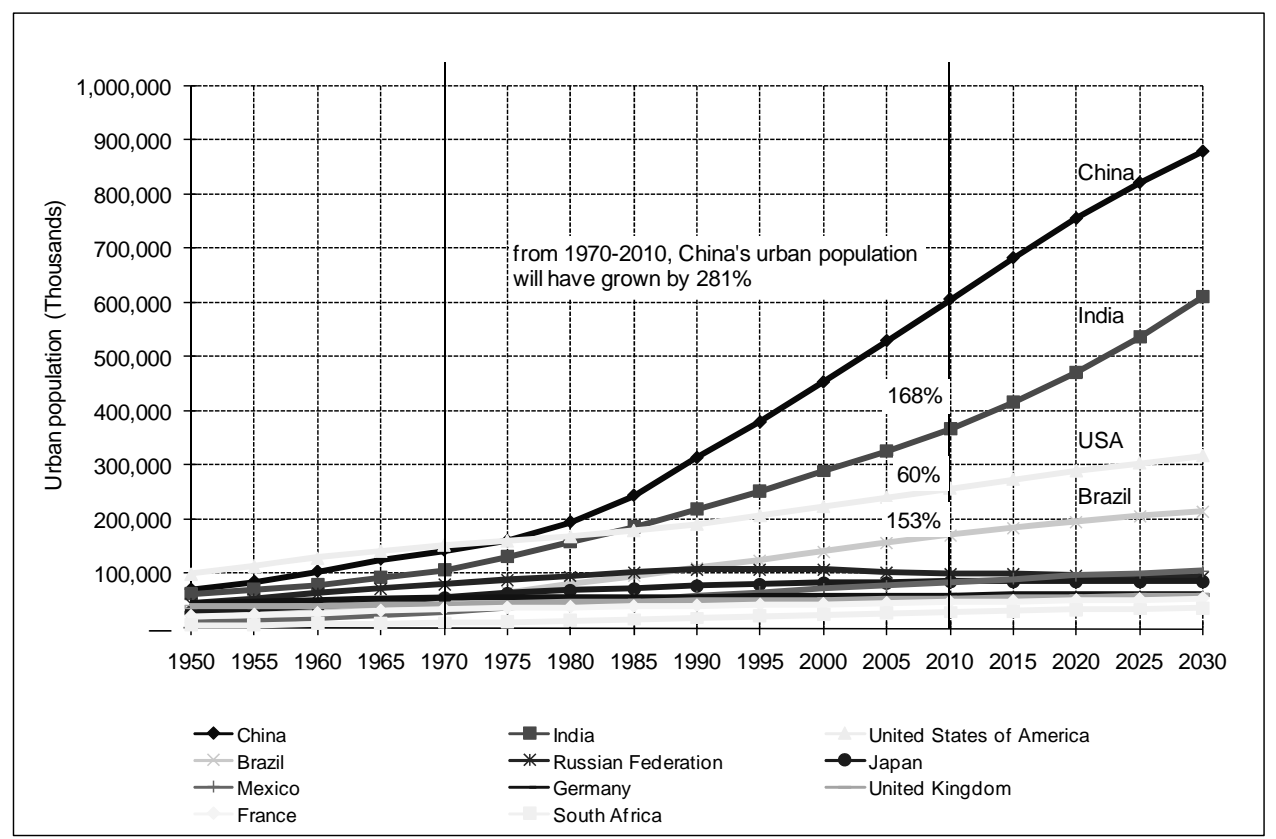

Source: UN World Urbanization Prospects - The 2007 Revision: BRICS and selected OECD countries.

1. All of the following international figures on urban population and urbanisation rates are from United Nations data; comparisons between countries need to be made with caution as national statistical agencies reporting to the UN often use different definitions for “urban”. See United Nations, Population Division, Department of Economic and Social Affairs (2007). 
Aside from the national socio-economic changes fuelled by urbanisation over the last 30 years, the growth of China's cities is starting to have major global impacts. The most obvious are environmental: pollution of coastal waters by industries and untreated urban wastewater; cross-border and inter-continental air pollution from power plants, industries, and motor vehicles; and emissions that have made the country the second largest contributor to global warming. But less obvious global linkages are equally important: China's transformation into the world's biggest consumer of steel, cement and a wide range of resource commodities, including carbon-based energy sources, that is beginning to affect availability and supply prices in other countries; the transformation of China's cities into the world's factory; and the rapid evolution of the urban populace into a consumer base that is changing what global firms produce, and how they market them. Economic changes in China's cities are fundamentally changing the global structure of flows of natural resources, products, capital, technology, information, and people. ${ }^{2}$

Many aspects of public policy in OECD countries will increasingly need to be considered within a global context influenced by China's urbanisation, and how China's government manages that urbanisation. This paper provides an introduction to urban trends and policies in China, and is largely descriptive. It describes urban growth trends, where and in what kinds of cities growth is occurring, how China's cities are governed, and how public policy has influenced the extent, pace, and spatial distribution of urbanisation. The report concludes with a description of some of the key policy challenges facing central and local urban governments in China.

- Section 2: China's changing approaches to urbanisation outlines describes key changes to national urbanisation policy since 1949, and the resulting classification and statistical issues associated with accurately measuring historical levels of urbanisation.

- Section 3: Urbanisation trends and projections present official government urbanisation estimates and projections to 2020, and the distribution of China's urban population by location and city size.

- Section 4: China's urbanising regions describes how urbanisation is consolidating 28 Regional Urban Systems across the country, some of which cross provincial boundaries, and the implications of these urban systems for national regional development policy. It also describes the emergence of 53 metropolitan regions, with populations over one million, all of which cross municipal boundaries. Their economic performance and prospects are reviewed, including issues surrounding national and global competitiveness, especially related to human capital. Key constraints to the realisation of agglomeration economies in these emerging metropolitan regions are outlined.

- Section 5: Urban governance describes the current system of sub-national governance in China, the allocation of functional responsibilities among levels of government, the need for better intergovernmental co-ordination, and resulting policy implications.

- Section 6: Key policy challenges facing concludes with a review of challenges in attaining and sustaining the global competitiveness of China's cities, managing environmental quality in cities, ensuring equity in the urbanisation process, and implementing more effective urban governance.

- The paper concludes by providing a short executive summary.

2. China had 7.25 million emigrants in 2005, or only $0.6 \%$ of the population (World Bank, 2007). However, it accounted for $8.1 \%$ of global remittances by emigrant workers in 2007, up from 1\% in 1995 (India, the largest global source of emigrant workers, accounted for 8.5\%). As China continues to integrate into the global economy, including through outward investment, it is likely to figure much more prominently in global out-migration. 


\section{China's changing approaches to urbanisation}

\subsection{Evolution of national urbanisation policies}

Current urbanisation conditions and recent trends in China are best understood within the context of a long history of public policy that separated cities from the countryside.

Historically, cities in China were called cheng which literally means "city wall”. China's ancient cities were citadels with watchtowers and city gates, often surrounded by a moat, clearly delineating city boundaries. The city had one principal role: for the capital, to house within its walls the emperor and his court, and, in other cities, the governor of the prefecture and his officials. Economic activities were considered secondary to the government function, and only a small part of the walled enclosure housed a "market" (shi in Chinese). As China began to industrialise in the late $19^{\text {th }}$ and early $20^{\text {th }}$ centuries, urban development beyond the "city wall" necessitated new forms of governance. Administrations were established to govern wider municipal areas, extending the nomenclature shi from economic to administrative use, to mean "city" in the contemporary sense. The first formal designation of a modern shi was Guangzhou in 1925.

\section{9-1957 - Initial industrialisation and urbanisation}

With the establishment in 1949 of the People's Republic of China, the government focused on transforming cities into industrial bases. After decades of civil strife and war, the country embarked on a national strategy of intensive industrialisation. Modelled on the former Soviet Union, China's national industrialisation policy focused on the development of heavy industry. A large number of mining and industrial processing cities were built in parallel with the redevelopment of selected old industrial cities in China's inland regions. As the process of industrialisation requires employing large numbers from the agriculture labour force, the national policy stance was to allow both cities and the urban population to grow. The number of statutory cities grew from 120 in 1949 to 176 by the end of 1957 and the urban population grew rapidly from $10.1 \%$ of the national population in 1949 to $15.4 \%$ in 1957 ( $\mathrm{Li}$ and $\mathrm{Yu}$, 2008).

\section{8-1963 - Unstable development of urbanisation}

A dual focus on industrialisation and the need to maintain support from the countryside led to policies that promoted industrial development in both cities and rural communities. Perhaps the most notable, the "Great Leap Forward" Campaign (1958-1960) sought to put a "steel mill in every back yard". Massive state investments were made in industrial stocks that were quickly found not to be technically or economically viable. Concentrated in cities and towns, early campaigns to promote industrialisation served to briefly accelerate urbanisation. Three years later, in 1960, the percentage of urban population had increased by $4 \%$, a stride comparable to the increase over the previous eight years.

Massive expansion of the urban population due to the influx of the rural labour force puts increasing pressure on cities. To control this movement, a critical policy measure was introduced that continues to affect urban development to this day. Regulations were promulgated in 1958 that strictly limited rural-tourban migration. ${ }^{3}$ According to these regulations, all citizens of China are assigned an agricultural or nonagricultural residency designation at birth, based on that held by parents. This residency registration (hukou)

3. Subsequent regulations issues in 1963 were even stricter, formalising a dual society of heavily subsidised non-agricultural hukou population, and a non-subsidised, rural, agriculture hukou population (albeit with land use rights; see below). In 1975, the Constitution was amended to abolish provisions related to freedom of mobility. 
is essentially permanent. Originally, residents with non-agricultural hukou were granted ration cards for a wide range of basic foodstuffs and commodities, and were entitled to employment in cities, largely with State Owned Enterprises (SOEs) or government agencies that provided full housing, healthcare, and education services. Under this two-tier management system, agricultural-registered residents were not entitled to "urban" benefits as they were assumed to be agricultural workers, and hence entitled to farm collectively owned land as the basis of their livelihoods. ${ }^{4}$ While the original rationing entitlements have by now largely disappeared as most commodities and services have been marketised over the last 25 years (including, most recently, housing), hukou is still used to preclude access by agricultural-registered citizens to subsidised healthcare, unemployment insurance, guaranteed minimum incomes and basic welfare support which are only available in cities. ${ }^{5}$

The growing pace of urbanisation was curbed by the government's tight policy control and reversed by the economic downturn resulting from flawed industrialisation campaigns and natural disasters. Commodity, food, and job shortages in cities strained the country's fragile rationing system and rekindled the anti-urban policy bias within government. Starting in 1962, the government began to reverse the statutory designation of cities back to counties, and to convert residents with non-agricultural hukou to agricultural status: the number of statutory cities dropped from 208 in 1960 to 168 in 1965 . Over 20 million urban residents were reclassified and moved to rural areas, accounting for $17.8 \%$ of China's total urban population in 1962.

\section{4-1978 - Rural re-engineering}

Responding to growing cold war tensions, in 1964 the central government launched a "third line" (sanxian) programme of relocating the country's industries from vulnerable coastal and central cities (the "first line" and "second line" respectively in national defence terms) to western regions. This "third line" programme, which guided the country's capital investment and industrial development for more than a decade and finally ended in the late 1970s, resulted in the relocation of a large number of factories, workers and their families into mountainous areas scattered across China's western region. Many of these industries ended up bankrupt, and most were closed by the government in the late 1980s.

Parallel to the third line policy, the government embarked on a large scale programme of relocating urban youth to rural areas to ease job, housing and commodity shortages in Chinese cities. The Cultural Revolution was launched in 1966 against this backdrop, and lasted for ten years. During this period, 14 to 18 million urban youth were deprived of their urban hukou and dispersed to rural areas, accounting for 10$12 \%$ of China's total urban hukou population during this period. These urban-to-rural resettlement programmes of industry and population substantially reduced the country's urban population from $20.7 \%$ of the country's total population in 1960 to $15-16 \%$ by the late 1960 s. China's urbanisation level was literally frozen at this level for well over a decade.

4. There are two types of land ownership in the People's Republic of China: the state owns all land within cities and some designated areas such as selected forests and mining areas; rural land is "owned" collectively by farmers. China's Constitution enshrines the rights of farmers to a share of collectivelyowned land which, in the absence of a rural programme covering the "five insurances", provides them with a proxy system of social security. Unlike elsewhere in Asia, the secure tenure rights to rural land are a strong incentive for most farmers to stay in the countryside.

5. The bonds of the hukou system have decreased significantly during the last five years: rural migrant workers are entitled to work in cities but they have no access to the "five major social insurances" (old age pension, medical, unemployment, worker's compensation and maternity) which are all currently reserved for registered urban residents, and to "Minimum Living Standard Insurance" (MLSI), which was introduced in the late 1990s, and now serves as the principal mechanism for alleviating poverty within the urban districts of cities. 


\section{9-1988 - Controlled urbanisation}

In late 1978 China began its far-reaching economic reform and open-door policy, starting with rural reforms that released a substantial amount of labour from farming. Urban youth dispersed to rural areas under earlier campaigns were allowed to move back to their cities of origin. However, three decades of minimal investment in urban economies and infrastructure had seriously deteriorated cities' capacities to absorb the millions of returning residents. Deteriorating performance of SOEs, and consequent underemployment, were beginning to exert pressure for urban industrial reforms.

Reflecting its rural bias, the central government partially responded with policies to support the development of collectively-owned township and village enterprises (TVEs), the only growing sector of the Chinese economy. Empowered by rural reforms, these enterprises absorbed significant surplus farm labour until the late 1980s. Again reflecting a rural bias, the government promulgated a national policy of small town development that supported "leaving the land but not the villages, entering the factories but not cities". China's national urbanisation policy evolved into three pillars: "controlling the big cities, moderating development of medium-sized cities, encouraging growth of small cities". This urban development policy was eventually codified in the National Urban Planning Law in 1989.

Government eventually found that this policy was indirectly undermined by many pro-urban policies launched in the process of opening up to the global economy. Chief among them was the establishment in 1980 of "special economic zones" in four coastal cities, followed by the designation of another 15 coastal cities in 1984 as open to foreign direct investment. By the late 1980s, the "special areas" policy had led to the rapid development of the open coastal cities, triggering a first wave of urban construction and renewed urbanisation at odds with long-standing public policy.

\section{8-2000 - Unanticipated urbanisation}

Prior to China's fiscal reforms in 1994 that decentralised the country's fiscal system and codified new fiscal arrangements between the central and local governments, Chinese cities relied for decades on limited fiscal budgets allocated from the central government to fund investment in urban housing and infrastructure. Recognising that new sources of revenue were needed by local governments to upgrade severely under-invested urban infrastructure, the central government introduced in 1988 the current system of leasing long-term rights for the use of state-owned land, allowing most revenues to be retained by municipalities. ${ }^{6}$ This soon became the principal source of off-budget revenues for municipal governments, ${ }^{7}$ and led, in many cities, to massive redevelopment of inner-city neighbourhoods, and to new residential and industrial park development in outer urban and suburban areas. The influx in the 1990s of foreign investment in manufacturing in many coastal cities, and the resulting real estate boom, has largely driven China's economic growth for the last 15 years.

China's chronic "commodity shortage" economy quietly came to an end in the mid-1990s. TVEs, which developed primarily to respond to domestic market opportunities during the "commodity shortage" period, gradually declined in the face of foreign-invested manufacturing geared towards export markets. Attracted by employment opportunities in labour-intensive manufacturing in China's coastal cities and on

6. Rural land in China is collectively-owned. Urban land is owned by the state through municipal governments. Since 1988, land use rights can be leased from municipal governments for terms up to 80 years, depending on the use of land. Land leasing income is essentially retained by local governments (90-95\%) and, until 2007, was lodged as off-budget revenue. Since 2007, the central government has required all land leasing revenues to be shown in on-budget accounts.

7. A research report published by DRC (Development Research Centre) indicates that the money coming from leasing land right could amount to $60 \%$ off-budget revenue in some local government. 
numerous urban construction sites, rural migrant workers began to move to cities that provided far higher earnings than TVEs and farming. The rapidly expanding scale of rural-to-city migration (called "wave of rural migrant workers”) soon became a major concern to the central government.

Given the historical anti-urban bias of public policy, government responded to rapidly growing ruralurban migration in a conservative way. In the national Eighth Five Year Plan for 1991-1995, "urbanisation" was explicitly addressed for the first time. The policy, however, was a reiteration of the policy orientation of the 1980s: "control the big cities, moderate development to medium-sized cities, and encourage the growth of small cities". The national Ninth Five Year Plan for 1996-2000 again repeated the central government's urban policy, but with a heavier emphasis on the control of large cities: the nuance changed to "strictly control the growth of big cities, reasonably develop medium-sized cities and small cities”.

By the end of the 1990s, the central government recognised two critical issues emerging from the pattern of the country's rapid economic growth: 1) widening regional and rural-urban disparities; and 2) stagnation and low consumption in domestic market had resulted in a heavy reliance on exports and investment to fuel the country's economy. These challenges formed the backdrop for yet another attempt at articulating a national urbanisation policy.

\section{1-2005 - Town-based urbanisation}

For the first time since 1949, the Tenth Five Year Plan explicitly placed city and town-based urbanisation as one of five key policy thrusts. It outlined three key policy measures to promote townsbased urbanisation: 1) allowing conversion of agricultural to non-agricultural hukou for rural residents permanently relocating to towns within their counties; 2) land reforms designed to create secondary markets in farming rights by allowing farmers to permanently sell off their rights to other farmers to encourage economies of scale in production; and 3) promotion of industrialisation in towns with implied approval of conversion of agricultural land to town construction land (largely for industrial parks).

These three policy measures did not have their desired effects of stimulating any significant townbased urbanisation. Farmers did not take up resettlement and hukou change since farming rights to collectively-owned land - enshrined in People's Republic Corporation's Constitution - are viewed by farmers as inviolate and secure. The permanent change to non-agricultural hukou was too uncertain, and the still limited, relatively insecure hukou-related benefits in towns were not enough to tip the balance.

The town-based industrialisation policy did, however, lead to massive illegal conversion of agricultural land by some town governments into speculative industrial parks with low levels of service and hence low occupancy rates. Another indirect result was the creation of a new rural/urban class of "landless farmers" who sold their farming rights to enable town governments to secure land for these parks but, with marginal skills for urban employment, remain under- or unemployed in towns and villages.

Halfway through the Tenth Five Year Plan, government responded to unanticipated policy outcomes by accelerating pilot projects in rural and urban social security reforms, by improving the potentials for agricultural productivity by lowering costs of production, ${ }^{8}$ and by cracking down heavily on illegal land conversion and ordering the re-conversion of unused land in many speculative industrial parks back to agricultural use.

8. Through gradual elimination of the Agriculture Tax, reductions in land fees payable by farmers, and setting price controls on fertilizers and pesticides. 
Given the low attraction of towns to industrial investment (except for polluting industries avoiding more stringent regulatory oversight in urban areas), the industrial development of rural towns under the town-based urbanisation policy was largely unsuccessful. It did not achieve the policy objective of reducing rural-urban income disparities and diverting the wave of rural surplus labour from migrating to cities.

\section{6-2010 - "Balanced development”: emergence of metropolitan regions}

After decades of policies that ranged from anti-urban to ambivalence with cities, the government appears to have recently recognised that large cities can make major contributions to the country's economic development and to sustaining China's long term growth. In the Eleventh Five Year Plan (20062010) it has placed much stronger emphasis on the development of metropolitan regions across the country, including measures to better integrate strategic towns into metropolitan economies. The Eleventh Five Year Plan is now promoting the urbanisation process through "balanced development" of cities and towns regardless of their size but it is no clear indication how it will address the issue.

By integrating national urbanisation policy under the Eleven FYP with new rural development strategies (the "new" countryside initiative directed towards increasing rural incomes, improving infrastructure services and establishing subsidised public services of education, medical and social security systems in rural areas), the government hopes to more effectively address China's growing rural-urban disparities. In part, this is being pursued through the strengthening of suburban towns in metropolitan regions. For example, Shanghai, Beijing, and Chongqing are now implementing development strategies to foster the growth of "strategic" towns into satellite cities with strong connections to their respective metropolitan centres. These are the first indications of governments' recognition of the metropolitan region scale, and the important roles that suburban towns can play in their balanced development. Rather than pursuing a rural or urban focused development policy, governments at both central and local levels appear to be now trying to plan and control development at a scale that encompasses both types of development.

The current government has placed very high priority on the conservation of agricultural land, largely for food security reasons, but also to protect farmers from being forced off their landholdings by local governments trying to convert collectively-owned land to land leasable to industrial and residential real estate developers. In 2003, the central government, through the Ministry of Land and Natural Resources (MLNR) sent out inspection teams across the country to assess the proliferation of industrial parks outside of the regulated land conversion quota system. Numerous, mostly vacant parks were ordered to be shut down and reverted to agricultural use in almost all provinces. However, actual closures were slow, and subsequent consumption of cultivated land continued at rates far higher than MLNR felt appropriate: a new land conversion control mechanism was instituted across China in late 2006.

A new Land Supervision Bureau (LSB) was established at the ministry level, reporting directly to State Council, essentially to act as the enforcement agent of MLNR (whose minister is also the director of the new LSB). Seven regional commissions were established under the LSB in nine cities (Shanghai, Nanjing, Beijing, Shenyang, Jinan, Guangzhou, Wuhan, Chengdu, and Xian). These commissions, whose job is to monitor municipal land conversion in nearby provinces, are independent of the government administration: provincial and municipal governments have no access or control over the commissions. Illegal conversions are addressed initially at local levels, but the commission can report directly to State Council which metes out stiff punishments, including removal or sanction of provincial and municipal leaders.

Conversion of agricultural land is, however, only part of the reason for the new land management regime. Given the inter-governmental system of fiscal roles and responsibilities in China, the principal source of off-budget revenues for most municipal governments since the mid- 1990s has been one-time 
leases of land use rights. Therefore, despite conversion quotas, municipalities have a strong fiscal incentive to acquire and convert agricultural land into "construction land", to try to lease off land use rights, even at steep discounts to market value, and to mortgage municipal landholdings to finance new infrastructure through loans from commercial banks. These practices have raised concerns within the central government over fiscal balance and sub-national debt.

In parallel with the establishment of the new LSB, State Council has ordered that, starting in 2007, all municipalities must: 1) record land leasing revenues and associated expenditures in formal on-budgets that are annually reviewed and approved by Municipal People's Congresses; 2) retain land leasing revenues in a declining reserve for a period of three years; 3) honor the revenue-sharing arrangement whereby 5-10\% of land leasing revenue is sent to the central government (a practice largely ignored for many years); 4) allocate a portion of their land leasing revenues to land reclamation and protection; and 5) lease all land, including industrial land, through public auction or open tenders. Since discounting of industrial land prices was apparently common practice in many cities competing for inward investment, State Council has ordered that all new industrial land leases have minimum base prices, effective 1 January 2007. These prices have been set by MLNR for all cities and counties in China, and local governments are required to publicly disclose them prior to auctions or tenders.

\subsection{Changing definitions of "urban" and "cities"}

Up until 2006, "urban” settlements in China were administratively defined as statutory cities and statutory towns. For decades, until the late 1990s, "urban” residents were those with non-agricultural hukou - regardless of whether they were farmers or dependent on non-farming sources of household income in suburban areas. The strong rural bias of government policy translated into narrow definitions and arbitrary benchmarks that make historical comparisons difficult. Exacerbating this difficulty is the panoply of administrative types of cities and towns that have evolved over the years in response to national economic and social policies.

There are three administrative types of cities in China: 1) provincial-level municipalities; 2) prefecture-level cities (PLCs); and 3) county-level cities (CLCs). In addition, 4) administrative towns are today also considered "urban” settlements.

1. The three industrial giants of Shanghai, Tianjin, and Beijing, were designated as provincial-level municipalities in the 1950s and early 1960s, reporting directly to the central government. This initially facilitated strategic industrialisation and, soon thereafter, political control and resettlement to the countryside. In recent years, the direct reporting to the central government has facilitated more direct fiscal control, and the targeting of state funds into investments with national strategic importance. Chongqing became China's fourth provincial-level municipality in 1996, reflecting its strategic importance upstream from the Three Gorges Dam.

2. Prefectures are quasi-administrative units dating back to the sub-provincial "Circuits" of the Qing Dynasty. Abolished in 1928, they were resurrected under the "city controlling county" (shi guan xian) system in the late 1950s. Counties (and later on, county-level cities) in a prefecture became subordinated to a single city that administered the entire prefecture (i.e., the Prefecturelevel City, or PLC). The reasons for which PLCs and prefectures were established in the 1950s no longer exist. Although this level of governance appears to have effectively eroded, at least in a functional sense, in many provinces since the 1980s, the administrative hierarchy is still maintained. Most prefecture-level cities report to provincial governments. ${ }^{9}$

9. The functional responsibilities and fiscal authority of prefecture-level cities over counties and county-level cities (CLCs) are undergoing major changes. In 2005, the central government introduced reforms to 
3. County-level cities (CLCs) are towns that are county administrative seats, and which meet benchmarks for designation as a statutory city by State Council; they report to PLCs. With rapid economic growth, particularly at the county level, the formerly prefecture-wide responsibilities of PLCs have been absorbed by constituent counties and CLCs. Sub-municipal structures differ between PLCs and CLCs even though they cover similar spatial territories and, in many cases, have similar sizes of population (Figure 2). Districts are administratively allowed only in PLCs. Therefore, PLCs have a de facto two-tiered administrative structure of districts reporting to the PLC’s municipal government. CLCs are single-tier administrations.

4. Administrative towns, which are also considered "urban" settlements, are former townships in which the village that served as the administrative seat has met a mix of administrative benchmarks, leading to its designation as a statutory town. Towns still report to CLCs or, if located in a district, to PLCs.

Figure 2. Statutory urban areas in China
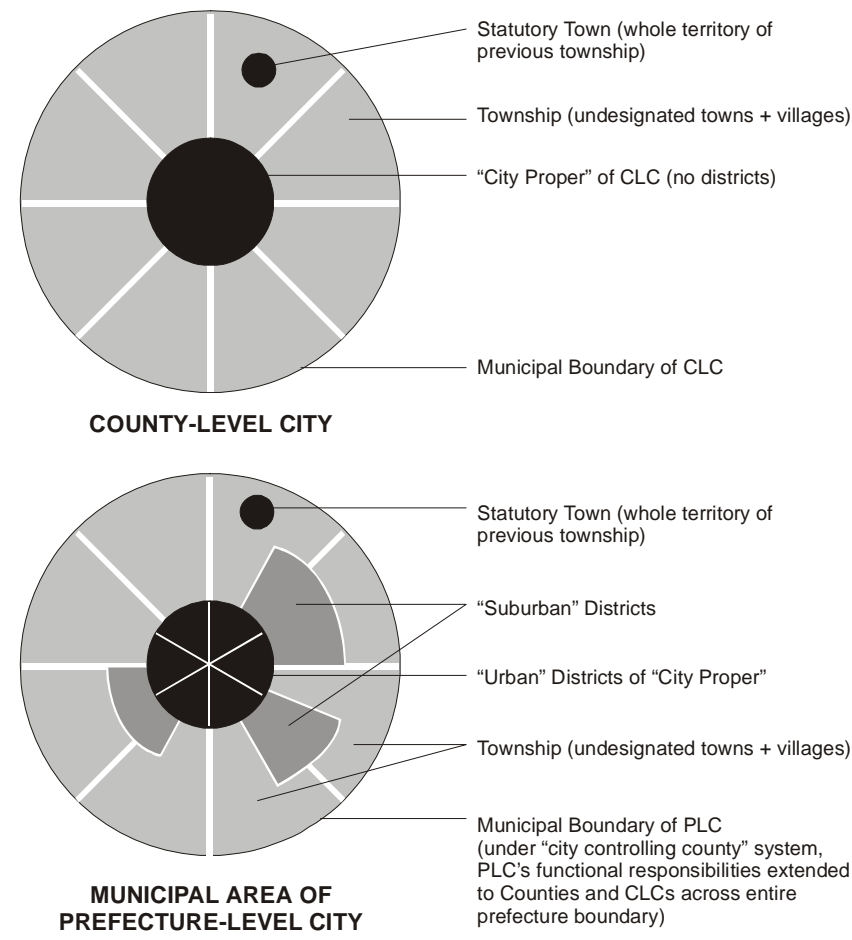

attempt to reduce the administrative hierarchy in China, and to re-design sub-provincial fiscal arrangements so that "rural" areas (counties and CLCs) can have greater financial autonomy to support growth in the countryside. A two-tier fiscal structure (county/CLC to province, bypassing the prefecturelevel city) has existed in Zhejiang Province since 1982; under the recent reforms, this system has been adopted in 18 provinces and all four provincial-level municipalities. However, while fiscal arrangements are changing, the administrative level of PLCs and prefectures has not been abolished, and likely will not be in the foreseeable future. 
The criteria for administrative designations of statutory cities and towns have diverged markedly over the past 50 years: State Council modified defining criteria in 1955, 1963, 1986, and 1993 for statutory cities, and for towns in 1955, 1963, and 1984. According to the 1993 criteria for designation of cities, almost one-third of China's cities were designated from 1994 to 1996 by reclassifying statutory towns (Table 1). ${ }^{10}$ However, since 1996 there has been a de facto moratorium on further urban re-classification, even though urbanisation has continued unabated.

Table 1. State Council criteria for statutory designation of cities as of 1993

\begin{tabular}{lll}
\hline Population & Household registration: non-agricultural & Towns: > 80 000 (CLC) \\
& registered population & County-level cities: > 205 000 (PLC) \\
\hline Economic & Urban economic functions: & Towns: >20\% (CLC) \\
& $\begin{array}{l}\text { Tertiary share of GDP } \\
\text { Size of economy (rural + urban) }\end{array}$ & County-level cities: >35\% (PLC) \\
& TDP & County-level cities: > 2.5 billion (PLC) \\
& Industrial output value & Towns: > Y 800 000 000 (CLC) \\
& GVIO: & County-level cities: > 80\% (PLC) \\
& GVIO as share of GVIAO: & Towns: > Y 40 000 000 (CLC) \\
& "Revenue" (not defined as on or off-budget; & County-level cities: > Y 200 000 000 (PLC) \\
\hline Public finance & no stated adjustments for inflation & \\
& $\begin{array}{l}\text { Tap water coverage (to non-agricultural } \\
\text { regional population) } \\
\text { "Proper" roads coverage (to non-agricultural }\end{array}$ & Towns: > 55\% (CLC) \\
& Towns: > 50\% (PLC) \\
& population) & \\
\hline Source: Administrative & Office of the State Council. &
\end{tabular}

These criteria have several limitations: 1) the population base used in calculations excludes migrants and those lacking urban hukou; 2) assessments of urban economic functions are imprecise, for example, gross GDP figures are used, which also include agriculture, mining and forestry; 4) assessments of fiscal capacity are incomplete, as off-budget revenues are not measured; and 5) arbitrary benchmarks are used for infrastructure endowments that have weak functional links to urban economic activity, or to actual demands of residents for urban infrastructure services. OECD countries typically do not differentiate between migrants and permanent residents in defining urban populations; similarly, they do not set economic benchmarks in terms of GDP or fiscal capacities in defining cities.

Given the limitations of these benchmarks, and China's rapid economic growth and urbanisation since 1996, there are likely many more villages and undesignated towns in China that would in most OECD countries be formally designated as towns, and far more towns, both statutory and undesignated, that would be administratively defined as cities. The scale of China's urbanisation is therefore likely to be considerably understated by official definitions. Moreover, spatial boundaries at the sub-municipal scale are constricted, and ignore many fast-growing suburban and semi-urban areas. These suburban communities are considered by municipal governments as outside the jurisdiction of the urban administrative region, and hence beyond operational mandates to provide service delivery.

10. The criteria for graduation of a CLC to a PLC were modified somewhat in early 2000: a CLC must be a prefecture seat of government with a non-agricultural population of at least 100000 , a non-farming population of at least 150 000, GDP of no less than RMB 2.5 billion, at least 30\% of GDP derived from the tertiary sector, and on-budget revenues of at least RMB 150 million. These amendments acknowledge that agricultural-registered residents now comprise a "non-farming” population that needs to be recognised. 
Criteria for designation of statutory towns - last amended in 1984 - are comparatively simple: "in a township with a total population of less than 20000 , the township seat may be granted town status if its non-agricultural registered population exceeds 2 000. In a township with more than 20000 persons, the township seat may become a designated town if $10 \%$ or more of the total population is non-agricultural. Other settlements that may also become designated towns include the county seat." 11

To bring China's definition of "urban" and "rural” more in line with international best practice, the National Bureau of Statistics (NBS) in 1999 released draft "Regulations on Statistical Classification of City and Town Areas" that based definitions on two spatial characteristics of "urban" and "rural" settlements: 1) contiguity of "urban construction"; and 2) population densities within municipal districts (Table 2).

Table 2. Provisional regulations for definition of urban settlements, 1999

\begin{tabular}{|c|c|c|c|c|}
\hline \multirow[t]{5}{*}{ City area } & & PLC & $\begin{array}{l}\text { If population density of PLC administrative } \\
\text { territory }>1500 / \mathrm{km}^{2}\end{array}$ & $\begin{array}{l}\text { The entire PLC territory is } \\
\text { "URBAN" }\end{array}$ \\
\hline & 2 & PLC & $\begin{array}{l}\text { If population density of PLC administrative territory } \\
<1500 / \mathrm{km}^{2}\end{array}$ & $\begin{array}{l}\text { Only the statutory street } \\
\text { committees are "URBAN" }\end{array}$ \\
\hline & 3 & PLC & $\begin{array}{l}\text { In case of } \# 2 \text {, if urban infrastructure and urban } \\
\text { public services are extended to fringe towns or } \\
\text { townships }\end{array}$ & $\begin{array}{l}\text { The entire towns or townships that } \\
\text { are connected are "URBAN" }\end{array}$ \\
\hline & 4 & CLC & Statutory street committees & $\begin{array}{l}\text { All the street committees are } \\
\text { "URBAN" }\end{array}$ \\
\hline & 5 & CLC & $\begin{array}{l}\text { If urban infrastructure and urban public services } \\
\text { are extended to fringe towns or townships }\end{array}$ & $\begin{array}{l}\text { The entire area of connected towns } \\
\text { or townships are "URBAN" }\end{array}$ \\
\hline \multirow[t]{2}{*}{ Town area } & 6 & Town & Statutory towns & The entire town area is "URBAN" \\
\hline & 7 & Township & $\begin{array}{l}\text { If urban infrastructure and urban public services } \\
\text { are extended to fringe villages in townships }\end{array}$ & $\begin{array}{l}\text { The entire village area of } \\
\text { connected villages are "URBAN" }\end{array}$ \\
\hline $\begin{array}{l}\text { Special } \\
\text { settlement }\end{array}$ & 8 & & $\begin{array}{l}\text { Independent settlement (mining fields, } \\
\text { development zones, tourist areas, university } \\
\text { cities, etc.) with a total population over } 3000 \\
\text { people }\end{array}$ & $\begin{array}{l}\text { Settlement is considered as } \\
\text { "URBAN" }\end{array}$ \\
\hline \multicolumn{5}{|c|}{$\begin{array}{l}\text { Notes: } \\
\text { Population density: refers to long stay population (registered population + migrants over six months). } \\
\text { Total population: refers to long stay population (registered population + migrants over six months). } \\
1999 \text { National Bureau of Statistics, Provisional Regulations - definition of "URBAN" = "City Area" +"Town Area" + "Special Settlement" } \\
=1+2+3+4+5+6+7+8 \text {. }\end{array}$} \\
\hline
\end{tabular}

These regulations formed the basis for defining urban populations in the 2000 National Census. In previous censuses, population statistics were generally reported according to the location in which hukou was held by the enumerated resident. This meant that migrants were not counted where they worked and lived - and therefore where they required public services - but in the village, town or city which issued their hukou. The 2000 National Census for the first time enumerated populations where they actually

11. The threshold of non-agricultural registered population size limits the number of settlements that can be designated as statutory towns. Very few village households have inherited non-agricultural status from prior generations since the principal reason that hukou was introduced in the 1950s was specifically to exclude these village residents from cities. 
resided at the time of the census, if they had maintained residence for longer than six months. ${ }^{12}$ The results are considered by many demographers to be the most accurate census conducted since the People's Republic was established.

While the 1999 definition led improved statistical reporting of populations of cities and towns, it did not define "urban construction", it set population density benchmarks that were considerably higher than in many other countries, and it continued to rely on the designation of large administrative units (Street Committees, which are designated by municipal governments) for what should be functional definitions. The result was that many towns and villages in suburban areas of cities were not statistically counted as "urban" even though they had become integral parts of the urban labour, retail and housing markets, and therefore generate demand for municipal public services.

The National Bureau of Statistics promulgated a new, fine-tuned definition of "urban" in regulations that became effective in March, 2006 (Table 3). This definition uses the smallest scale in the Chinese administrative hierarchy: statutory resident committees (under Street Committees, used in the 1999 definition), and villages (under statutory towns and townships, used in the 1999 definition). The new parameter in the 2006 definition is including villages in outer urban and suburban areas that are "directly connected" to municipal infrastructure, and that receive public services from urban municipalities.

Table 3. Final regulations for definition of urban settlements, 2006

\begin{tabular}{|c|c|c|c|c|}
\hline \multirow{2}{*}{ City area } & 1 & PLC/CLC & Statutory "resident committee" under PLC/CLC & $\begin{array}{l}\text { Only the statutory resident } \\
\text { committees are "URBAN" }\end{array}$ \\
\hline & 2 & PLC/CLC & $\begin{array}{l}\text { If urban infrastructure and urban public services are } \\
\text { directly extended to fringe villages in townships }\end{array}$ & $\begin{array}{l}\text { Connected villages are } \\
\text { "URBAN" }\end{array}$ \\
\hline \multirow{2}{*}{ Town area } & 3 & Town & $\begin{array}{l}\text { Statutory "resident committees" under statutory } \\
\text { towns }\end{array}$ & $\begin{array}{l}\text { Only statutory resident } \\
\text { committees are "URBAN" }\end{array}$ \\
\hline & 4 & Town & $\begin{array}{l}\text { If urban infrastructure and urban public services are } \\
\text { directly extended to fringe villages in townships }\end{array}$ & $\begin{array}{l}\text { Connected villages are } \\
\text { "URBAN" }\end{array}$ \\
\hline $\begin{array}{l}\text { Special } \\
\text { settlement }\end{array}$ & 5 & & $\begin{array}{l}\text { Independent settlement (mining fields, development } \\
\text { zones, tourist areas, university cities, etc ) with a } \\
\text { total population over } 3000 \text { people }\end{array}$ & $\begin{array}{l}\text { Settlement is considered as } \\
\text { "URBAN" }\end{array}$ \\
\hline
\end{tabular}

Note: Total population: refers to long stay population (registered population + migrants over six months).

Source: China National Bureau of Statistics.

Although the new definition provides for a more precise calculation of "urban" residents at finer spatial/administrative scales, the underlying premise of the definition is still supply driven. Even if nonfarming residents of suburban villages and towns have become part of urban labour and supply chains, they are not counted as urban if municipal services have not yet extended to serve them. China's current supply driven approach contrasts with the demand driven approach followed in most OECD countries where nonfarming residents, most of whom are integrated into urban labour and housing markets and therefore have needs for urban-type public services, are generally counted as “urban”.

12. The previous National Census, conducted in 1990, also enumerated migrants, but only those who had lived in the enumeration area on a continuous basis for longer than 12 months. Actual enumeration in 1990 was reportedly far less rigorous than in 2000. 


\section{Urbanisation trends and projections}

\subsection{Becoming an urban nation}

Within this context of changing policies, definitions, benchmarks, and urban entitlements, accurate calculations of "urban" and "rural" population in China have for years been constrained by official statistical reporting that preclude reliable inter-temporal comparisons. While changing statistical conventions and administrative designations of cities and towns over the past decades have made the precise definition of urban trends in China difficult, NBS has attempted to reconstruct urbanisation levels back to 1955 (Figure 3).

Figure 3. China's urbanisation, 1955-2020

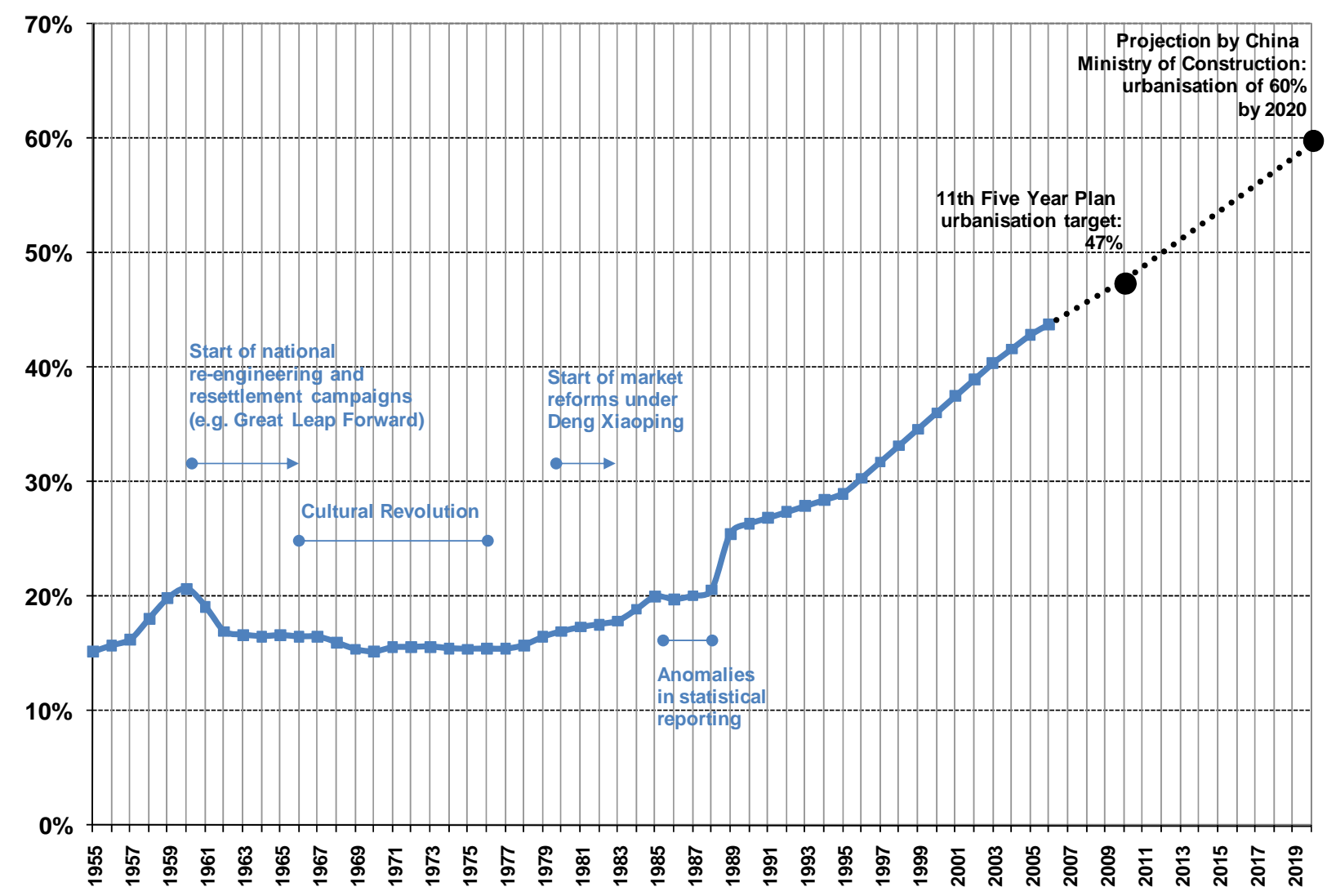

Note: Projections were made based on current trends and policy planning.

Source: China Statistical Yearbooks $(1999,2007)$; projection to 2010 from 11th Five Year Plan; to 2020 from China Ministry of Construction (2004).

Rapid urbanisation in the latter half of the 1950s peaked at $20 \%$ in 1960, and then dropped to $15-16 \%$ during the national social re-engineering campaigns from the early 1960s and throughout the Cultural Revolution period. Introduction of market reforms in the late 1970s led to a gradual rebound in the level of urbanisation to $20 \%$ (the level in 1960) in 1985. After five years of anomalies in statistical reporting, the 
rate was $26 \%$ in 1990 , and rose steadily to $30 \%$ by 1996 . According to the NBS, China was $40 \%$ urbanised in 2003 and, by 2006, 562 million residents - 44\% of the population - could be defined as "urban" (using NBS’ 1999 definition).

The Eleventh Five Year Plan (2006-2010) calls for China's urbanisation level to reach $47 \%$ by the end of 2010. The Ministry of Construction released official projections in 2004 suggesting that the country would be $60 \%$ urbanised by 2020 . Notionally, China will cross the $50 \%$ threshold and be a predominantly urban nation by 2013 at the latest. Historical patterns of development in other countries suggest that an urbanisation rate of $40-50 \%$ leads to more rapid urban growth that begins to moderate when a country becomes 70\% urbanised (World Bank, 2000). China's pace of urbanisation may well accelerate during the next ten years.

To put China's urbanisation in global perspective, by 2015 China's urban population will be between 680 and 700 million, at least 2.5 times larger than the projected urban population in the United States, and 1.6 times larger than UN projections for India. From 2005-2015 China will need to absorb an additional urban population of around 160 million people - the equivalent of almost half the entire urban population of India in 2005 (UN World Urbanization Prospects, 2007 Revision).

\subsection{Drivers of urbanisation}

Two forces are driving urbanisation in China: 1) rural-urban migration; and 2) rapid suburbanisation through in situ transformation of towns and villages into integral parts of urban economies.

The 2000 National Census counted 150 million migrants, or 12\% of the country's population. In many cities $20-35 \%$ of residents are migrants. However, $45 \%$ of migrants came from the same prefecture-level municipality, and $25 \%$ came from other parts of the same province, suggesting a relatively high degree of seasonal and temporary migration. Contrary to popular impressions of a massive wave of migrants to coastal cities from poor central and western provinces, less than a third of migrants to China's cities were from other provinces.

The 2000 Census shows that $27 \%$ of all migrants have moved, at least temporarily, into coastal metropolitan regions. Therefore, over $70 \%$ of migration has been to smaller coastal cities and to cities of all sizes in central, north-eastern, and western parts of the country. Although growing in importance, ruralurban migration has not been the principal force behind urbanisation in China since the 1980s. The major driver has been in situ suburbanisation of formerly farming populations into urban economies.

The spatial structure of urban growth in China over the last two decades has differed considerably from the pattern in North American and some European cities over the last century. The latter have traditionally grown outwards in a centrifugal way with large influxes of migrants (from the countryside, from other cities, and from other countries) accompanied by large-scale suburbanisation as many sitting residents relocated from inner city areas. In China, households and enterprises have for decades faced numerous constraints to mobility into (and out of) inner urban areas that severely limit locational choices. Aside from hukou, which limits labour mobility, the dominant enterprise structure of vertically-integrated State Owned Enterprises created supply chains that were highly localised within cities. Inner city land and housing tenure have also affected mobility. An urban housing market - that provides locational options for residents - only began to evolve in China in the late 1990s with the large-scale privatisation of state-owned housing units in favour of occupants. ${ }^{13}$ Furthermore, the decades-old administrative allocation of inner

13. Unlike previous efforts in the early 1990s, China pursued a "big bang" approach to privatisation of stateowned housing in 1997/98. Sitting households were offered their units for as little as 10\% of initial construction cost, resulting in a huge take-up across the country. The implicit, one-time public subsidy was 
urban land to state-controlled enterprises at no cost meant that, up until very recently, there had been no economic incentive for these firms to relocate to lower-cost suburban sites. Therefore, in the formal urban areas of China's cities, households and firms have been subjected to significant constraints to location and mobility that do not exist in North American and European cities.

In suburban areas where arable land is collectively-owned and far less regulated, informal shifts from farming to small-scale industrial production have been relatively simple, particularly when firms are owned, at least in part, by town/township and village administrations. Similarly, residential and labour mobility among rural residents in suburban areas, including from other towns and townships, are less constrained. Residential growth in many suburban towns and villages is supported by informal rental markets that have evolved over the last 15 years. Therefore, while household mobility and enterprise formation were tightly constrained within inner urban areas for decades, under market reforms the reverse has been true in suburban towns, townships and their constituent villages.

The growth of most cities in China, at least over the past 20 years, has largely been centripetal, through locational decisions by households and firms that circumvent administrative constraints to residency, employment, enterprise formation and land tenure in urban districts. Given the high population densities in suburban areas, and the relative ease of industrial enterprise formation, it did not take much for farming areas on the outskirts of urban districts to transform rapidly into semi-formal suburban precincts. The result has been large-scale suburban sprawl in many cities, including in central and western regions of the country.

Over the last ten years centrifugal pressures have also been building in many cities due to large influxes of migrants, industrial relocation from the central cores supported by new non-state investment in suburban industrial parks, and government efforts to reduce inner city residential densities by promoting relocation to suburban areas. Cities such as Suzhou, Qingdao, and Shenzhen are examples of predominantly centrifugal growth. In the case of Suzhou, its renowned industrial park is a site invested heavily by many multi-national corporations as manufacturing base in China.

Many cities in China - especially larger cities with over 1 million residents - are now experiencing a complex mix of both centrifugal and centripetal forms of urban growth. Shanghai, Beijing, Chongqing, Tianjin, and smaller metropolitan regions of Nanjing, Changsha, and Wuhan are all exhibiting both kinds of growth pressures.

\subsection{Distribution of cities by population size}

China's urban population is today distributed relatively evenly between towns (35\%), statutory ${ }^{14}$ cities with an urban population under 1 million (30\%), and statutory cities over 1 million (35\%) (Table 4). Unfortunately, rigorous comparisons with earlier years - to assess changes in the distribution of population by city size - is not possible since definitions of “urban” populations are not consistent. ${ }^{15}$

considered worthwhile by government as it removed growing recurrent operation and maintenance costs of a deteriorating housing stock from the books of SOEs which were in various stages of corporatisation.

14. "Statutory" is used in this report to denote cities that have been formally designated as cities by State Council.

15. Comparisons are possible only using data on registered populations (i.e., local hukou), which do not include migrants who account for over $20 \%$ of urban populations in many cities. 
Table 4. China's cities and towns by population size, 2005

\begin{tabular}{|c|c|c|c|c|c|c|c|}
\hline & \# & $\begin{array}{c}\text { Total } \\
\text { population }\end{array}$ & $\begin{array}{l}\text { Per cent of } \\
\text { total urban } \\
\text { population }\end{array}$ & $\begin{array}{l}\text { Of which } \\
\text { temporary } \\
\text { population }\end{array}$ & $\begin{array}{l}\text { Temporary } \\
\text { as } \% \text { of } \\
\text { total } \\
\text { population }\end{array}$ & $\begin{array}{l}\text { Built-up } \\
\text { area }\left(\mathrm{km}^{2}\right)\end{array}$ & $\begin{array}{c}\text { Average } \\
\text { population } \\
\text { density } \\
\left(\mathrm{inh} / \mathrm{km}^{2}\right)\end{array}$ \\
\hline Cities $>10 \mathrm{mn}$ & 2 & 33164200 & 5.9 & 8050000 & 24.3 & 2020 & 16419 \\
\hline Cities 5-10 mn & 6 & 38381800 & 6.8 & 16497800 & 43.0 & 3635 & 10558 \\
\hline Cities 1-5 mn & 61 & 123682000 & 22.0 & 15006100 & 12.1 & 9327 & 13260 \\
\hline Cities 500t - $1 \mathrm{mn}$ & 90 & 64367400 & 11.5 & 5393000 & 8.4 & 5712 & 11269 \\
\hline Cities $<500 t$ & 495 & 103451700 & 18.4 & 9555400 & 9.2 & 11675 & 8861 \\
\hline Total in statutory cities & 652 & 363047100 & 64.6 & 54502300 & 15.0 & 32369 & 11216 \\
\hline Towns* & 26959 & 198952900 & 35.4 & $\mathrm{n} / \mathrm{a}$ & $\mathrm{n} / \mathrm{a}$ & $\mathrm{n} / \mathrm{a}$ & $\mathrm{n} / \mathrm{a}$ \\
\hline Total urban & 27611 & 562000000 & 100.0 & $\mathrm{n} / \mathrm{a}$ & $\mathrm{n} / \mathrm{a}$ & $\mathrm{n} / \mathrm{a}$ & $\mathrm{n} / \mathrm{a}$ \\
\hline
\end{tabular}

* Statutory towns and street committees in towns. n/a: not available.

Data on seven cities not available.

Source: For cities, China Ministry of Construction 2006 Urban Construction Yearbook; for towns and total urban population, 2006 China Statistical Yearbook.

Shanghai and Beijing are the two statutory cities with urban populations over 10 million. The "temporary" or migrant population accounts for $24.3 \%$ of their combined population of 33 million. Six smaller metropolises (Shenzhen, Chongqing, Tianjin, Guangzhou, Dongguan, and Nanjing) with populations from 5-10 million comprise just over 38 million urban residents. The "temporary" population share of $43 \%$ in this city-size group is skewed somewhat by Shenzhen and Dongguan. Shenzhen, established in the 1980s as the early test bed of market reforms, still reports a registered population of 1.8 million but, with a predominantly migrant populace, the city's total urban population is 8.3 million. Similarly, Dongguan - a major concentration in the Pearl River Delta of migrant workers in light manufacturing - is mainly populated by migrants. Excluding Shenzhen and Dongguan, the migrant ${ }^{16}$ share of the second tier metropolises is around $20 \%$.

The much larger group of 61 small metropolises of 1-5 million residents accounts for the largest share of China's urban population. While the average share of migrants is half that of the largest metropolises, there are major differences between cities, ranging from less than 1\% in Qiqi'haer in the northeast to 40\% in Ningbo in the rapidly-industrialising Yangtze Delta Region. Although rigorous inter-temporal assessment is not possible, indications are that, as a group, the 1-5 million person metropolises have been growing the fastest in recent years for two reasons: in-migration and the ascendancy of many cities from the next lowest size class of 500000 to 1 million. The smallest size class of cities, those under 500000 residents, holds the second largest share of China's urban population, reflecting China's rural history and the preponderance of towns that met State Council's criteria for becoming statutory cities during the 1990s.

The differences in migrant share of cities' populations reflect employment opportunities and, therefore in a general sense, the recent pace of economic development in cities of different size classes.

There is an important qualification to be made when analysing statistics on China's cities. The boundaries of the vast majority of China's cities were established decades ago. Officially reported data, such as those above on population sizes, conform rigidly to these boundaries. With rapid urbanisation and the loosening of state-level controls on urban and economic development over the last two decades, larger

16. Migrants resident longer than six months. 
cities - especially metropolitan regions - have grown beyond the boundaries of the "city proper" 17 to encompass parts of suburban districts that are often not counted in official urban statistics, or into surrounding counties that, by definition, are still considered "rural" (Figure 4). Statistical reporting is therefore often distorted. ${ }^{18}$

Figure 4. Emerging disconnects between actual development and administrative boundaries in the China's 53 metropolitan regions
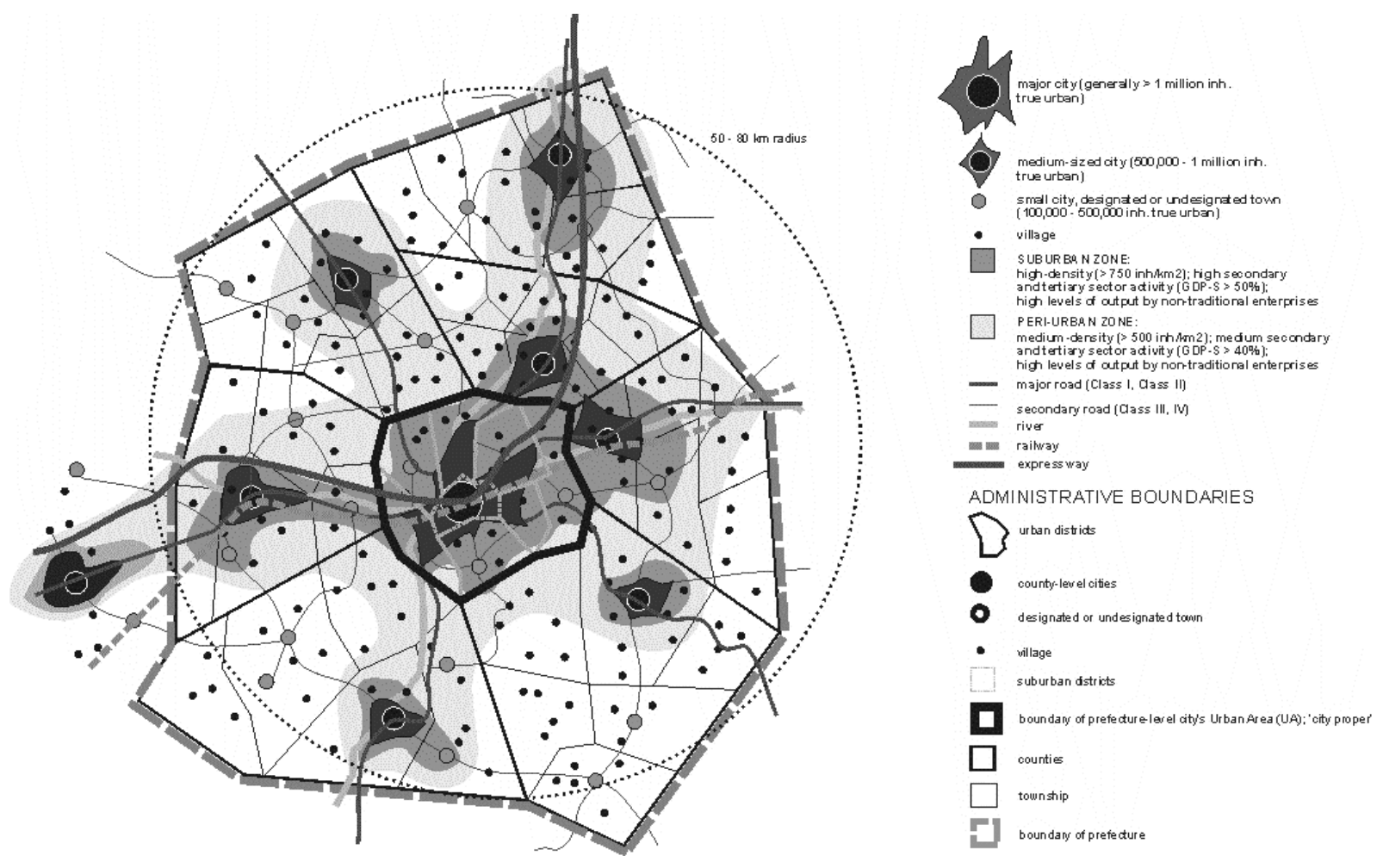

Given this important qualification, comparison of China's statutory cities with those in other countries (which follow different practices for setting administrative boundaries) needs to be done with caution. Strictly from a statutory perspective, the distribution of urban population by city size in China is similar to the United States (Figure 5), although China has twice the proportion of its urban population living in statutory cities ranging from 5 to 1 million. Differences with the Republic of Korea and Japan are instructive. Korea has a larger proportion living in cities over 1 million (63\% compared to $54 \%$ in China), and a smaller proportion in cities under half a million. Almost $75 \%$ of Japan's population lives in cities over 1 million, with about the same proportion as China in cities under half a million.

17. The term "city proper" is often used in government. It generally refers only to the urban districts in which a municipal government provides public services. Recently, some cities have added selected suburban districts to their definition of "city proper" to include those in which some municipal services have been extended. Under China's Constitution, there is no differentiation between urban and suburban districts: it sets districts at the same administrative level as counties.

18. An attempt to compensate for these distortions is described later in this report for "metropolitan regions". 
Figure 5. Per cent of national urban population living in cities, 2005

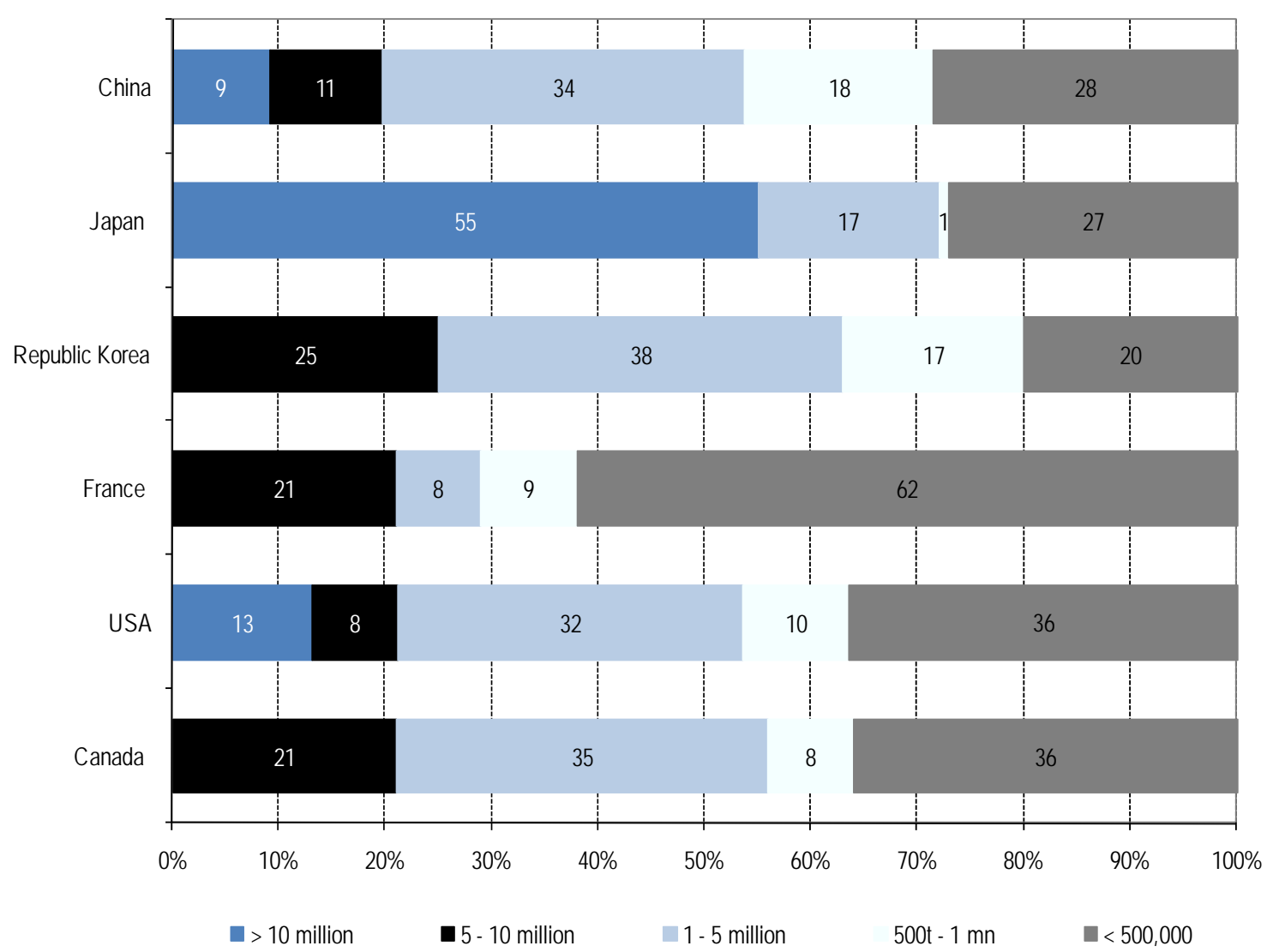

Note: To facilitate international comparisons, China data in this table are for statutory cities only, and do not include statutory towns.

Source: China data from Ministry of Construction Urban Construction Yearbook 2006; other countries from UN Global Urbanization Prospects, the 2007 Revision.

As reviewed earlier, attempts by the central government over the past six decades to promote growth of towns and small cities have not succeeded. There is no reason to believe that a policy shift back towards smaller urban settlements would have its intended effects.

As China's economy continues to globalise, the competitiveness of larger cities will increasingly be driven by the realisation of agglomeration economies intrinsic to metropolitan areas. This does not necessarily mean that urbanisation will solely focus on 10 million-plus cities (as in Japan). Rather, metropolitan areas with over 1 million residents will, depending on their location - especially their proximity to each other in wider urban systems - likely be the principal destination of rural migrants seeking non-farming employment choices as they skip over smaller cities with lower growth prospects. Both domestic and foreign firms will continue to locate in metropolitan areas as their inherent agglomeration economies manifest under market reforms. Which metropolitan areas grow the fastest will largely depend on their location and on the extent and depth of their hinterland and offshore markets. 


\section{China's urbanising regions}

\subsection{China's 28 Regional Urban Systems}

The spatial distribution of China's population today reflects a long history of internal population movements seeking to mitigate constraints of topography, land cover, and water resources. Population initially concentrated in the north China plain, fed by the Yellow River (Figure 6). By the Tang Dynasty (618-906), migration had spread southwards to the fertile Yangtze Delta and major river valleys, with growing concentration in the Sichuan Plain in western China (Figure 7). Widespread settlement of the area south of the Yangtze to the Pearl River Delta and along the South China Sea coast did not occur until the Northern Song Dynasty (960-1127); this expansion occurred in parallel with marked densification of the Sichuan Plain, and settlement farther north in the middle reaches of the Yellow River (Figure 8).

Figure 6. Generalised population densities, 2 CE (Han Dynasty)

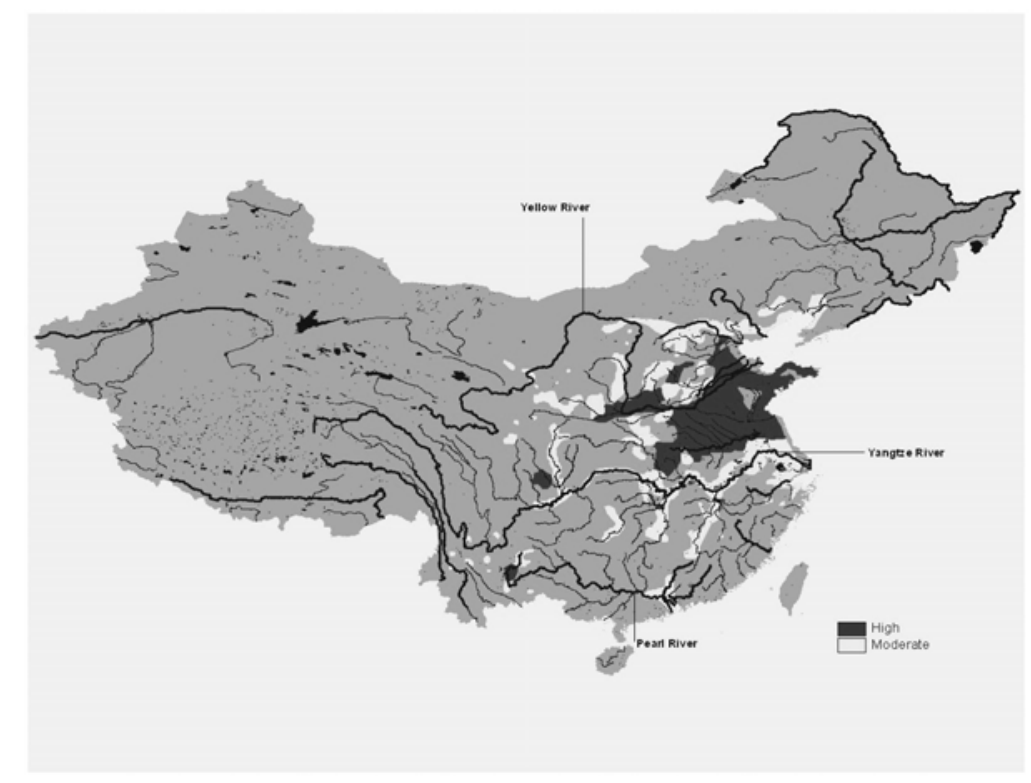

Source: Derived from Blunden, Carolin (1983), Cultural Atlas of China, Phaidon Press, Oxford. 
Figure 7. Generalised population densities, 742 CE (Tang Dynasty)

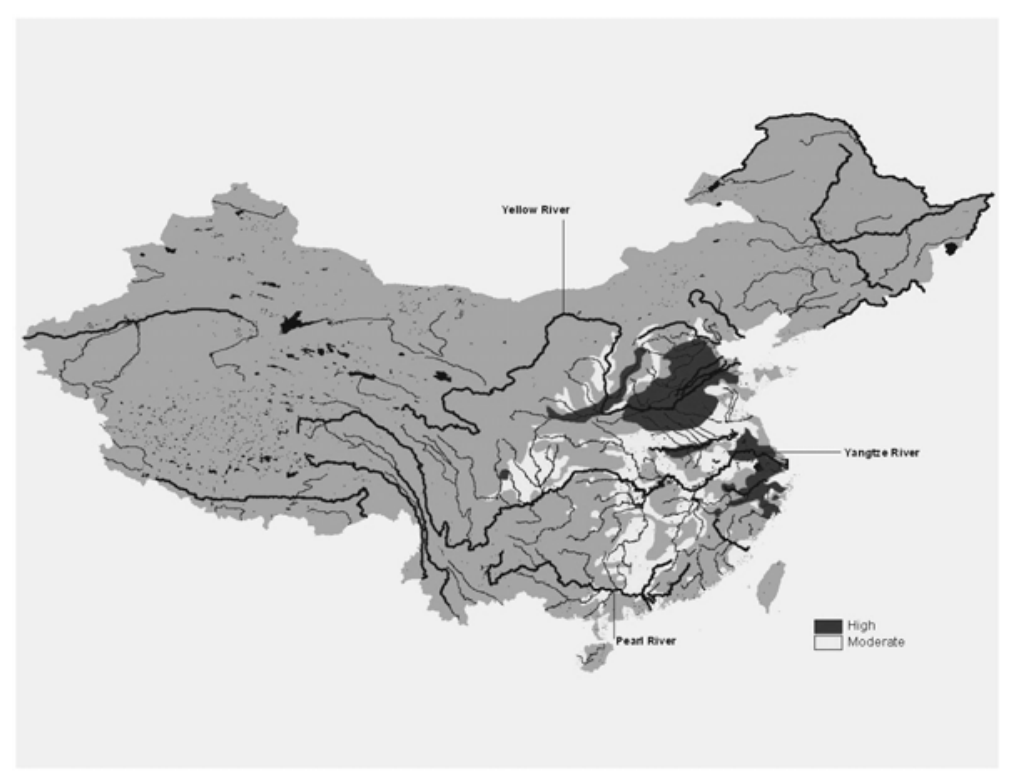

Source: Derived from Blunden, Carolin (1983), Cultural Atlas of China, Phaidon Press, Oxford.

Figure 8. Generalised population densities, 1050 CE (Northern Song Dynasty)

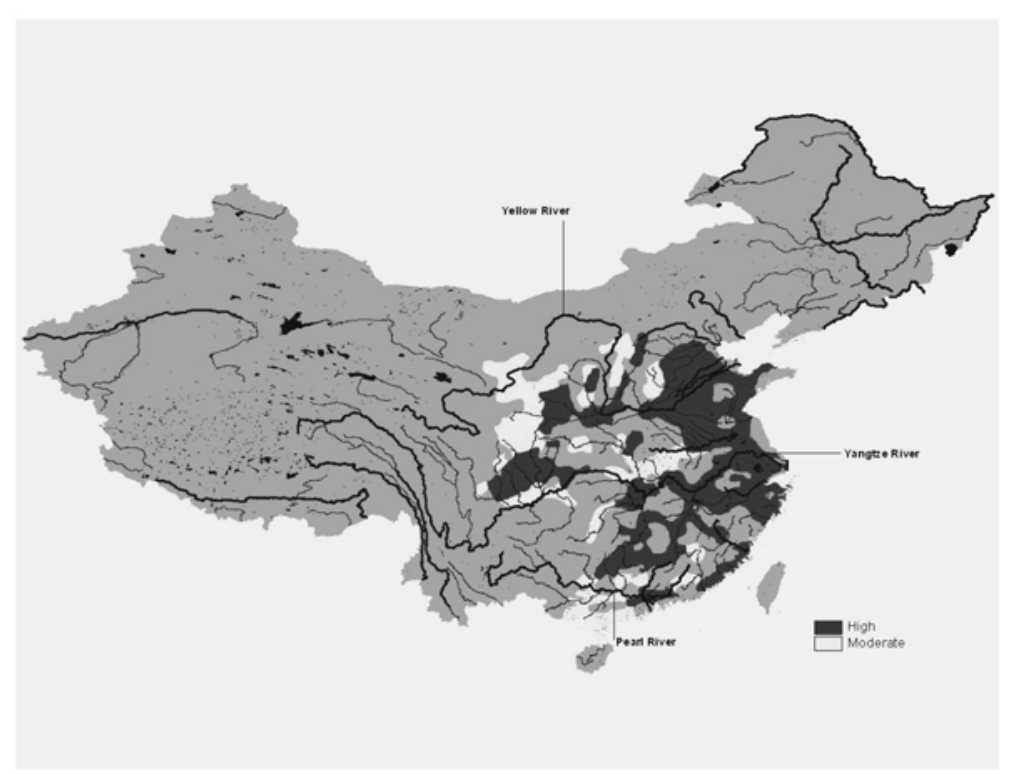

Source: Derived from Blunden, Carolin (1983), Cultural Atlas of China, Phaidon Press, Oxford.

Population dynamics since the Song Dynasties have resulted in further densification of already densely-settled areas, expansion of settlement to the northeast, and less-intensive settlement in the west, including along the Silk Road. The distribution of China's population today, including in the statutory 
cities described in the previous section, shows that the overall spatial pattern of population concentration has changed little in almost 1000 years (Figure 9).

Figure 9. Population densities and cities, 2000

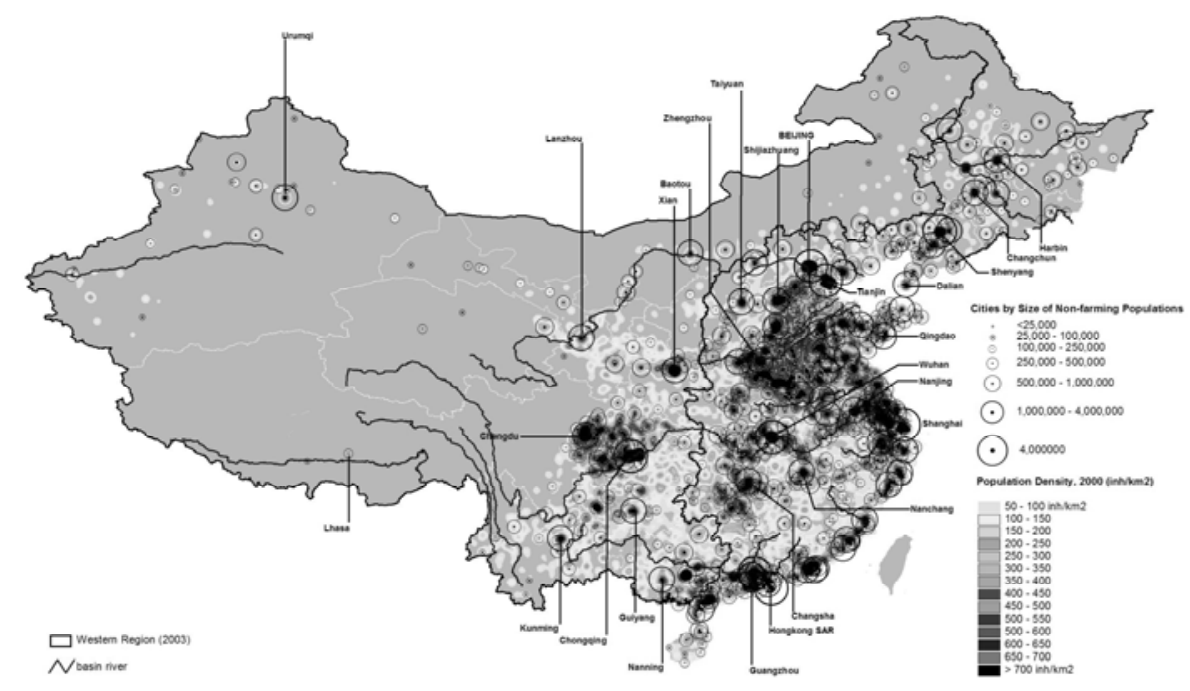

A fundamental, gradually intensifying, and historical shift in China over the last two decades has been - in relative terms - a momentous increase in factor mobility fuelled by market-oriented industrialisation, market-driven (as opposed to centrally planned) trade, the introduction of new and more accessible transport technologies along roads, rail, inland waterways, and, more recently, policy loosening under China's market and hukou reforms.

While settled regions were previously largely rural and, aside from meeting supply quotas to the Imperial Court, focused on very localised markets, recent industrialisation and mobility improvements have enabled the expansion of supply chains and the movement of goods and labour between cities across far wider spatial areas. The result has been the gradual emergence of functional market regions that are differentiating not on the basis of what is grown on or unearthed from the land but on the commodities, products, and services that are increasingly being traded across networks of cities, towns, and villages within and between regions.

Until very recently, and as in many OECD countries, government policy in China has largely not kept pace with the emergence of functional market regions in China: regional development policy has been formulated at a very coarse scale, defining "regions" as large aggregates of administratively-defined provinces that do not differentiate market regions.

- The grouping of provinces into "regions" was first made in 1986 as part of the Seventh Five Year Plan. The "region" was a very broad construct, initially formed to provide a notional spatial basis for promotion of the coastal region as a "growth pole" through which linkage and multiplier effects would trickle inland to central and western provinces.

- The Eighth Five Year Plan continued with a similar spatial thrust favouring the coast. 
- However, the Ninth Five Year Plan (1996-2000) replaced the coastal bias with recognition of the need to "pay greater attention to supporting the development of inland areas". This was to be pursued through the designation of seven economic zones across the country, a focus on development of endogenous comparative advantages, and greater co-ordination in regional economic development. However, the boundaries of the seven zones were never defined (some zones were apparently to cross provincial boundaries) and they remained elusive constructs, particularly to sub-national governments.

- A major focus of China's Tenth Five Year Plan (2001-2005) was the Western Development Strategy, an attempt to reduce economic development disparities in 12 western provinces and two adjoining Prefectures in Hubei and Hunan provinces. This was to be achieved through a combination of central government investment, directed credits from state bond issues, the introduction of preferential policies to induce non-state and foreign investment, and fiscal policies to increase local retention of state taxes.

- Halfway through the Tenth Plan period, State Council issued a new "Strategy for Developing the Old Industrial Base in Northeastern China” to address slow economic growth in Liaoning, Jilin, and Heilongjiang Provinces. Similar policy instruments used in the Western Development Strategy were applied to the northeast, although state bond issues have declined significantly since the early part of this decade.

With the "coastal region" churning ahead, and the "western region" and "northeastern region" now covered by new development "strategies", the remaining provinces were finally addressed by State Council in early 2006 through the "Suggestions Promoting the Rise of the Central Area". In most respects, these "regions" remain unchanged from those defined in the Eight Five Year Plan in the latter half of the 1980s, albeit with the addition of the northeast.

Recent experience in many OECD countries has shown that, to inform public policy, regions need to be defined far more narrowly as territories over which there are clearly identifiable daily social, cultural and economic interactions between and among settlements. Recently referred to as "functional regions"19 or "territories", they usually do not conform to administrative boundaries of provinces or municipalities.

China's central government has recently explicitly acknowledged the strategic role of regions and territories in the Eleventh Five Year Plan (2006-2010). The plan specifically mentions three areas requiring focused attention to sustain national economic development: the Yangtze River and Pearl River Delta regions, and the Binhai new coastal city area in Tianjin. This is the first time that any Five Year Plan has recognised regions smaller than large aggregates of provinces, and portends policy development at a far more appropriate regional scale.

Two scales of functional regions are evolving in China: metropolitan regions anchored on a core city with over 1 million non-farming residents; and larger Regional Urban Systems at the sub-provincial scale, anchored on metropolitan regions, but comprising a far wider network of cities, towns, and villages with comparatively strong economic linkages.

A Regional Urban System (RUS) is a construct that addresses, from a functional perspective, the bridge between settlements and central government-defined "regions" as provincial (i.e., administrative) groupings. RUS can be defined in terms of nodes, links and surrounding functional areas at a sub-national spatial scale. Nodes are cities, towns, and villages. Links are physical infrastructure and services - largely

19. See OECD (2002) for description of how OECD member countries define functional regions and territories. 
inter-city roads, railroads, navigable waterways and power grids - that connect nodes. Functional areas are the territories across which trade and other interactions occur on a regular and intensive basis.

Ongoing research on urbanisation trends in China has identified 28 Regional Urban Systems in China (see Leman, 2005) (Figure 10). Since information on economic and social flows between cities, towns, and villages is not available in China, proxies were used to approximate linkages on the basis of: 1) population densities of all counties and cities in China, and the non-farming population size of statutory cities in 2000; 2) analysis of average daily traffic volumes along more than 3000 segments of the national highway network; 3) analysis of the location and capacities of the existing and planned National Trunk Highway System; and 4) analysis of the location and capacities of the national railway network. The 28 Regional Urban Systems identified from these analyses are working hypotheses: some are clearly highly integrated while others are probably much less so.

Four types of RUS have been identified: 1) city-centred regions, which contain one metropolitan region that appears to anchor a wide hinterland of smaller cities, towns, and villages; 2) clusters, which hold at least two metropolitan regions; 3) corridors, which hold two or more metropolitan areas, and a range of smaller centres, none of which holds primacy; and 4) megalopolises, which are large, highlyindustrialising corridors with distinct metropolitan poles.

Figure 10. China's 28 Regional Urban Systems, 2004

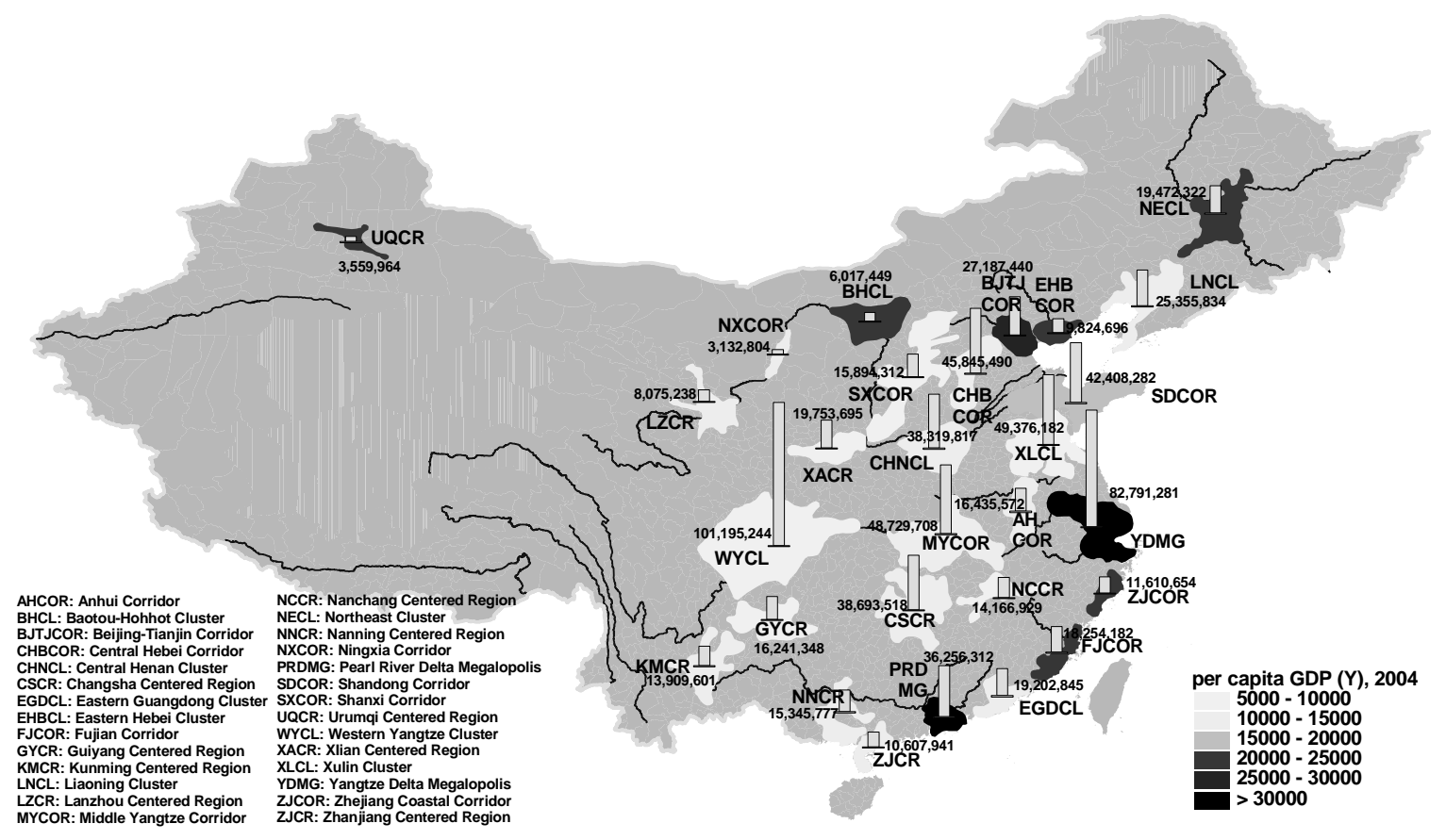


Over 750 million people, or 58\% of China's population, live in these 28 RUS. At an average annual growth rate of $0.9 \%$, the 28 RUS absorbed 38 million additional residents between 1998 and $2004 .{ }^{20}$

There are major differences in population sizes of the 28 RUS, ranging from 3.1 million in the Ningxia Corridor to 101 million in the Western Yangtze Cluster, encompassing most of Sichuan and Chongqing (Table 5). This reflects the range in geographic constraints to settlement across China, historical population concentrations, and the availability and capacities of transport systems within the Regional Urban Systems.

20. 1998 is the earliest year for which Chreod has compiled nationwide population data at the county and city scales; 2004 is currently the latest processed data. Population figures are aggregates of county and city data, and include Chreod's estimates of migrants in both years, based on GIS analysis of the distribution of migrants in 2000 as reported in the 2000 National Census for all 41636 towns, townships, and Street Committees across all of China. 
Table 5. Population changes in China's 28 Regional Urban Systems, 1998-2004

\begin{tabular}{|c|c|c|c|c|c|c|c|c|c|c|}
\hline & & $\begin{array}{l}\text { Estimated } \\
\text { total } \\
\text { population }\end{array}$ & $\begin{array}{c}\% \text { of } \\
\text { China's } \\
\text { population }\end{array}$ & $\begin{array}{c}\text { Total } \\
\text { population } \\
2000 \text { census } \\
\text { (tw/ts/sta) }\end{array}$ & $\begin{array}{c}\text { \% of } \\
\text { China's } \\
\text { population }\end{array}$ & $\begin{array}{l}\text { Migrants } \\
\text { as } \% \text { of } \\
\text { population } \\
\text { (2000 } \\
\text { census) }\end{array}$ & $\begin{array}{l}\text { Estimated } \\
\text { total } \\
\text { population }\end{array}$ & $\begin{array}{c}\% \text { of } \\
\text { China's } \\
\text { population }\end{array}$ & $\begin{array}{l}\text { Estimated } \\
\text { change } \\
\text { from 1998- } \\
2004\end{array}$ & $\begin{array}{c}\text { Average } \\
\text { annual } \\
\text { population } \\
\text { change \% } \\
1998-2004\end{array}$ \\
\hline & & 1998 & 1998 & 2000 & 2000 & 2000 & 2004 & 2004 & \# & $\%$ \\
\hline NXCOR & Ningxia Corridor & 2769423 & 0.22 & 2867219 & 0.23 & 21.41 & 3132804 & 0.24 & 363381 & 2.08 \\
\hline UQCR & Urumqi Centered Region & 3108195 & 0.25 & 3239765 & 0.26 & 34.39 & 3559964 & 0.27 & 451769 & 2.29 \\
\hline $\mathrm{BHCL}$ & Baotou-Hohhot Cluster & 5354523 & 0.43 & 5445252 & 0.43 & 31.83 & 6017449 & 0.46 & 662926 & 1.96 \\
\hline LZCR & Lanzhou Centered Region & 7524948 & 0.60 & 7683755 & 0.61 & 14.45 & 8075238 & 0.62 & 550290 & 1.18 \\
\hline EHBCL & Eastern Hebei Cluster & 9487372 & 0.76 & 9628707 & 0.76 & 8.76 & 9824696 & 0.76 & 337324 & 0.58 \\
\hline ZJCR & Zhanjiang Centered Region & 9578639 & 0.77 & 10258036 & 0.81 & 9.53 & 10607941 & 0.82 & 1029302 & 1.72 \\
\hline ZJCOR & Zhejiang Coastal Corridor & 11194796 & 0.90 & 11425392 & 0.90 & 25.44 & 11610654 & 0.89 & 415858 & 0.61 \\
\hline KMCR & Kunming Centered Region & 12694310 & 1.02 & 13322897 & 1.05 & 19.64 & 13909601 & 1.07 & 1215291 & 1.54 \\
\hline NCCR & Nanchang Centered Region & 14097676 & 1.13 & 13619054 & 1.07 & 12.82 & 14166929 & 1.09 & 69253 & 0.08 \\
\hline NNCR & Nanning Centered Region & 14241906 & 1.14 & 14792061 & 1.17 & 12.57 & 15345777 & 1.18 & 1103871 & 1.25 \\
\hline SXCOR & Shanxi Corridor & 14759985 & 1.18 & 15483545 & 1.22 & 12.36 & 15894312 & 1.22 & 1134327 & 1.24 \\
\hline GYCR & Guiyang Centered Region & 16517507 & 1.32 & 15591410 & 1.23 & 13.46 & 16241348 & 1.25 & -276159 & -0.28 \\
\hline AHCOR & Anhui Corridor & 16360365 & 1.31 & 15992432 & 1.26 & 9.84 & 16435572 & 1.26 & 75207 & 0.08 \\
\hline FJCOR & Fujian Coastal Corridor & 18002870 & 1.44 & 18086640 & 1.43 & 25.28 & 18254182 & 1.40 & 251312 & 0.23 \\
\hline EGDCL & Eastern Guangdong Cluster & 17057870 & 1.37 & 18457576 & 1.46 & 10.26 & 19202845 & 1.48 & 2144975 & 1.99 \\
\hline NECL & Northeast Cluster & 19324680 & 1.55 & 18969611 & 1.50 & 15.12 & 19472322 & 1.50 & 147642 & 0.13 \\
\hline XACR & Xian Centered Region & 18546306 & 1.49 & 18993195 & 1.50 & 8.35 & 19753695 & 1.52 & 1207389 & 1.06 \\
\hline LNCL & Liaoning Cluster & 27167168 & 2.18 & 27557665 & 2.17 & 20.45 & 25355834 & 1.95 & -1811334 & -1.14 \\
\hline BJTJCOR & Beijing-Tianjin Corridor & 25886998 & 2.07 & 26435985 & 2.09 & 27.48 & 27187440 & 2.09 & 1300442 & 0.82 \\
\hline PRDMG & Pearl River Delta Megalopolis & 32508595 & 2.61 & 33757835 & 2.66 & 30.67 & 36256312 & 2.79 & 3747717 & 1.84 \\
\hline CHNCL & Central Henan Cluster & 36298336 & 2.91 & 37120948 & 2.93 & 9.27 & 38319817 & 2.95 & 2021480 & 0.91 \\
\hline CSCR & Changsha Centered Region & 37558970 & 3.01 & 37920042 & 2.99 & 8.52 & 38693518 & 2.98 & 1134548 & 0.50 \\
\hline SDCOR & Shandong Corridor & 41169905 & 3.30 & 41600448 & 3.28 & 12.77 & 42408282 & 3.26 & 1238378 & 0.50 \\
\hline CHBCOR & Central Hebei Corridor & 43738572 & 3.51 & 44700310 & 3.53 & 7.47 & 45845490 & 3.53 & 2106918 & 0.79 \\
\hline MYCOR & Middle Yangtze Corridor & 44844703 & 3.59 & 47418340 & 3.74 & 11.53 & 48729708 & 3.75 & 3885005 & 1.39 \\
\hline $\mathrm{XLCL}$ & Xulin Cluster & 47360798 & 3.80 & 48284728 & 3.81 & 6.70 & 49376182 & 3.80 & 2015384 & 0.70 \\
\hline YDMG & Yangtze Delta Megalopolis & 76215909 & 6.11 & 76956211 & 6.07 & 23.07 & 82791281 & 6.37 & 6575372 & 1.39 \\
\hline WYCL & Western Yangtze Cluster & 96100427 & 7.70 & 97463131 & 7.69 & 9.16 & 101195244 & 7.78 & 5094818 & 0.86 \\
\hline TOTAL & & 719471751 & 57.7 & 733072190 & 57.8 & 14.5 & 757664438 & 58.3 & 38192687 & 0.87 \\
\hline
\end{tabular}


Migrants accounted for over $20 \%$ of the population in eight of the 28 RUS at the time of the National Census in 2000. Three of these are small systems anchored on Ningxia, Urumqi, and Baotou-Hohhot, which are oil, gas, and mineral extraction areas that attract both skilled and non-skilled migrants from across China. The remaining five RUS with high migrant proportions are in the coastal region. Of these, the Pearl River Delta Megalopolis (where $30.1 \%$ of the population are migrants), the Beijing-Tianjin Corridor (27.5\%), and the Yangtze Delta Megalopolis (23\%) have the largest numbers, totalling 35 million migrants, or $24 \%$ of the total migrant population enumerated in the 2000 Census. Both the Pearl River and Yangtze Delta systems experienced among the highest overall population growth rates from 1998 to 2004 .

Significantly, two of the RUS appear to have experienced small population declines: the Guiyangcentred Region in Guizhou Province (China's poorest), and the Liaoning Cluster in the northeast which experienced large-scale closures of industrial SOEs during this period.

\subsection{Economic performance of China's Regional Urban Systems}

While holding 58\% of China's population, the 28 RUS produced $88 \%$ of the country's GDP in 2004, up from $82 \%$ in 1998. Clearly, they are China's principal economic territories. They are also where the largest productivity improvements and income growth have occurred. As a group, per capita GDP in the RUS increased from 142\% of China's overall per capita GDP in 1998 to 163\% in 2004.

However, aggregation of all 28 RUS masks significant individual differences. Productivity improvements and increases in share of China's GDP have occurred in 15 of the 28 RUS (Figure 11). Seven of the RUS experienced a decline in both productivity and GDP share from 1998 to 2004. The remaining six had declines in productivity, but experienced at least a marginal increase in share of China's production. 
Figure 11. Economic performance of China's 28 Regional Urban Systems, 1998-2004

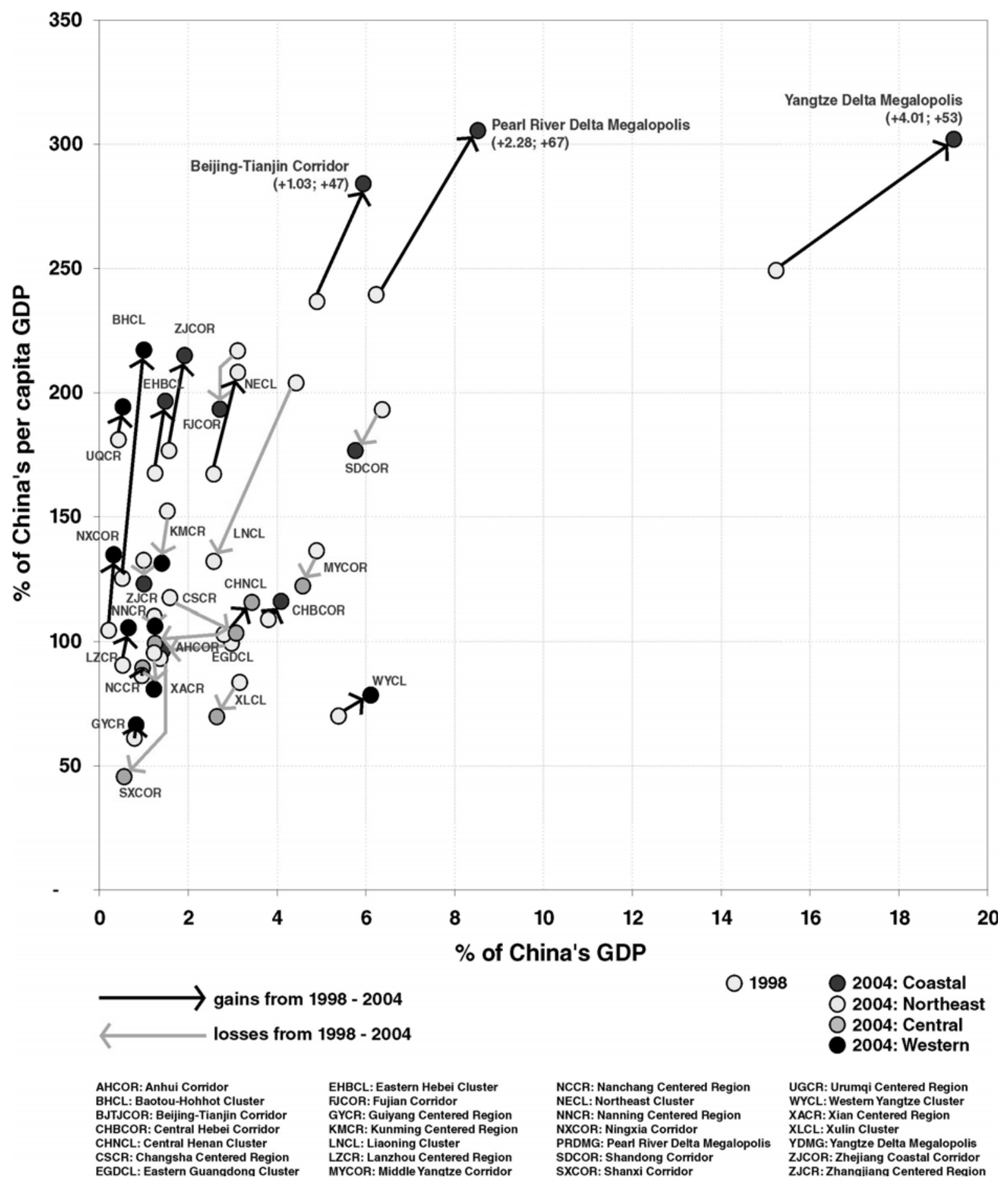

Note: Calculation from aggregated county- and city-level data, 1998, 2000, 2004 and 2008.

Several trends stand out from the analysis shown on Figure 11. First, there are major gains in both share of national GDP and relative productivity in the Yangtze Delta and Pearl River Delta Megalopolises, and in the Beijing-Tianjin Corridor. The two megalopolises are clearly the principal engines of China's growth, producing an additional 6\% of China's GDP during the six-year period. While the Beijing-Tianjin 
Corridor acquired a smaller share of $1 \%$ of national GDP, its productivity improvements approached those of the two megalopolises, reflecting growth in higher value-added industry sectors, such as ICT.

The second notable trend is that four of the remaining seven coastal RUS (the Shandong Corridor, the Fujian Corridor, the Eastern Guangdong Cluster, and the Zhanjiang Centred Region) appear to have experienced declines in share of China's GDP or a decline in relative productivity - or both. Not all coastal regions are growing equally, and some are falling behind, especially those with low levels of urbanisation and smaller cities with weak agglomeration economies.

Third, only two of the seven RUS in the "central region" had increases in GDP share and productivity - and these were only marginal. Four of the central RUS experienced declines in share of national GDP and in productivity. The Changsha Centred Region had a decline in productivity but an increase in GDP share. This could suggest either production overcapacity driven by over-investment in fixed assets during the late 1990s that was filled from 1998 to 2004, or the addition of lower value-added production during the period.

A particularly notable trend is that six of nine RUS in the "western region" had growing productivity and a slight increase in share of national GDP. Productivity increases were significant in the BaotouHohhot Cluster and in the Ningxia Corridor, likely reflecting power generation, mining, and basic mineral processing - the outputs of which are in huge demand elsewhere in China. A troubling trend is the very small increase in productivity and GDP share in China's largest RUS, the Western Yangtze Cluster comprising most of settled Sichuan and Chongqing (Box 1).

\section{Box 1. Productivity of Chongqing Metropolitan Region}

Despite being one of the largest metropolitan regions in West China, Chongqing's demographic strength and labour resources are not translated into its economic ranking, in terms of both total GDP generated and average income per capita (PPP), compared with several important Chinese and most OECD metropolitan regions. In fact, the still relatively low level of per capita income in Chongqing metropolitan region is very much due to the fact that productivity levels remain comparatively low. The OECD Chongqing report suggests that the productivity of Chongqing metropolitan region is considerably lower than China's average (about one half) and is lower than in other Chinese metropolitan regions which also perform less well in productivity terms than the entire Chinese economy (like Shantou, Changsha, Xian and Chengdu, all of which exhibit productivity levels between $60 \%$ and $80 \%$ of the national average). The causes of the lower productivity in the metropolitan region of Chongqing would have to be analysed further. $A$ priori, possible causes to be investigated could include: obsolete technology in heavy industries; inadequate training of workers and rigid employment regulations; inefficient supply chains and reliance on rather costly suppliers of inputs, parts or components; sub-optimal marketing strategies targeting markets where local products are relatively less well priced; inefficient spatial organisation of production hampering flows of people, goods and services in the metropolitan area, etc.

In any case, it would be expected that the low productivity in Chongqing metropolitan region would improve in the future, as a result from the combination of two factors: first, several reforms promoted by the national authorities, with respect to opening of markets to the international economy, direct foreign investment and modernisation of stateowned enterprises, to mention only a few; and, second, important actions considered by the local development strategy of Chongqing Municipality, such as key infrastructure projects in the transportation sector that will significantly modernise connections between Chongqing metropolitan region and other stronger metropolitan regions throughout China (like Chengdu, Guangzhou and Shanghai) and improvements in zoning and spatial organisation within Chongqing metropolitan region. However, because of the fundamental importance of productivity growth in Chongqing metropolitan region, for this engine of growth to contribute as expected to the development of larger parts of the municipality, careful analysis and implementation of sound policies to complement and reinforce those already mentioned are very much needed.

Source: OECD, Chongqing Municipality's Development Strategy: some reflections from the international experience of the Territorial Development Policy Committee of the OECD. 
An important point to keep in mind in interpreting trends is that GDP cannot be disaggregated from the data in terms of investment, consumption, and trade. A significant driver of growth in the western RUS could well be directed credits from state bond issues and public investment in support of the "Western Development Strategy'. The degree to which continued economic growth can be sustained as public investment moderates remains to be seen.

Growth of the three economically dominant regions - the Yangtze Delta Megalopolis, Pearl River Delta Megalopolis, and the Beijing-Tianjin Corridor - appears to have been driven by a combination of: 1) high levels of fixed asset investment, predominantly by domestic industrial firms, but also by government into infrastructure such as strategic ports and intercontinental airports; 2) their attraction of the bulk of direct foreign investment into China since 1990 - and the innovation attendant with this investment; 3) their strategic roles as China's trade hubs; ${ }^{21}$ 4) comparatively rapid industrial restructuring that led to closures or reorganisations of inefficient state-owned enterprises in the latter half of the 1990s; and 5) per capita consumption levels that were the highest in China in the late 1990s, and that have continued to grow relative to the rest of the country.

These four drivers of growth - investment, trade, industrial restructuring and consumption - have been comparatively weaker in the other 25 regions. Industrial restructuring is still underway in much of the northeast where trade and consumption remain low. Central regions, while benefiting from major investments in the National Trunk Expressway System, are still constrained in trade by higher logistics costs incurred by greater distance to coastal ports. Regions in the west appear to have benefited from statedirected investment in infrastructure in the first half of this decade, but their growth continues to be constrained by weak access to domestic and export markets, lower levels of investment in new industries (to replace restructured SOEs), and low levels of consumption resulting from lower household incomes.

\subsection{China's 53 metropolitan regions}

Every one of China's Regional Urban Systems contains - and is usually anchored by - at least one metropolitan region. As raised earlier, large cities in China have crossed the narrowly-defined administrative boundaries of statutory cities to encompass growing suburban areas, including small cities and towns. These are becoming the true functional areas of metropolitan China.

The challenge in demarcating the boundaries and structure of "metropolitan regions" lies in accurately capturing the extent and patterns of actual social and economic interactions that occur within them. The difficulty lies in trying to model systems of interaction that are constantly changing, and that often differ by enterprise or household. Various approaches have been developed to try to define what some call "functional urban regions" (as opposed to administrative regions). The basis of these approaches has been to define one or more of: labour markets (territories from which enterprises can, on a daily basis, draw workers), retail markets (territories over which consumers will travel to buy goods and services), housing markets (areas within which households are prepared to live while still working for enterprises in the region), and land markets (territories within which enterprises are prepared to locate to reap agglomeration benefits of localisation, urbanisation, and regionalisation economies).

The underlying principles of these approaches is that the vast majority of economic interactions are defined in markets, that the agents in these markets are located somewhere in geographic space, and that the characteristics of agents and interactions between them are affected by government policies and programme actions. Generalisation is clearly required - not every interaction of every agent can be

21. For example, exports accounted for 82\% of Shanghai's GDP in 2004 compared to 39\% in 1999. The value of foreign trade in Shanghai has more than tripled since 1998, reflecting the growing outputs of foreign manufacturers who have located in the Yangtze Delta since the late 1990s. 
defined - but there should be sufficient coverage to capture the vast majority of social and economic interactions that define the territorial extent and spatial structure of urban and metropolitan regions.

OECD has expended considerable effort to derive a definition of metropolitan regions that can form the basis for informed comparisons (Box 2). It has found that defining the boundaries and structure of a "functional metropolitan region" requires current and reliable data on the type, volume, and direction of economic and social flows. Central to the OECD definition is the demarcation of labour markets through the analysis of commuting flows.

\section{Box 2. OECD approach to defining metropolitan regions}

Metropolitan regions are generally identified as large concentrations of population and economic activity that constitute functional economic areas, typically covering a number of local government authorities. An economic area in this sense denotes a geographical space within which a number of economic links are concentrated: most obviously labour markets, but also networks of firms, important parts of supply chains, and relations between firms and local authorities.

Several methodologies have been developed to define functional metropolitan regions. While national definitions of a metro-region differ, they typically identify a core area with a significant concentration of employment or population and a surrounding area densely populated and closely linked to the core. They therefore employ at least one of three criteria: large size (in terms of either employment or population); high population density; and higher commuting within the region than between it and other surrounding areas. The European Union through the Urban Audit has proposed a definition of Larger Urban Zones for all European countries based on commuting flows. Similar to national statistical offices, scholars have used different approaches for identifying metropolitan areas. Merriman, Ohkawara and Suzuki (1995) use commuting flows and time to define Tokyo's metropolitan regions, whereas Simmie, Sennett and Wood (2002) used administrative boundaries to define London's metro-region. Dümmler and Thierstein (2002) use the metro-region's functional roles such as innovation, nodal and regulation or institutional role to define a Zurich metropolitan region. These different approaches can be summarised in five groups based on: administrative or legal boundaries, housing markets, economic activity, services provision, and labour markets. Metro-regions can also be selected on the basis of a certain critical mass that make them important as economic, social and transport centres within a national state.

Whether metro-regions are mono-centric (in strict sense or with multiple nuclei), polycentric or mega-cities, commuting flows and the labour market are important factors behind the definition of them. On the one hand, commuting flows take place between the suburbs and the core in mono-centric metro-regions. On the other hand, some suburbs around the various cities that were formerly largely residential in character, mainly dependent upon the core of the metropolitan areas to which they were attached, have ceased to be "dormitories" and have developed their own productive activities. Commuting no longer solely takes the form of journeys in and out of a central city, but many people travel between smaller cities and suburbs. In any case, commuting is at the heart of a metropolitan region as it brings together firms and workers through transport and telecommunications infrastructure.

OECD has used a methodology to gather and analyse metropolitan data. The database is based on four criteria. The first criterion is based on population size and a threshold of 1.5 million people is set to consider the region as metropolitan. Second, the density of population should exceed a critical value set at 150 people per $\mathrm{km}^{2}$. These types of regions are considered as predominantly urban; therefore, it is not only important to be a region with a large population, but it is also necessary that they concentrate in a particular place thereby accounting for higher density rates. Third, it is also fundamental that these regions with large and dense populations constituting urban areas represent a contained labour market. In order to define labour markets, commuting flows are used to calculate net migration rates. Predominantly urban areas at Territorial Level 3 (NUTS) have been selected and a process of adding and eliminating neighbouring regions based on net commuting rates has been carried out. Hence, metro-regions among predominantly urban areas (large and densely populated) are those for which the net commuting rate does not exceed $10 \%$ of the resident population.

Source: OECD (2006), Competitive Cities in the Global Economy, OECD Publishing, Paris. 
Currently, data on commuting flows in metropolitan areas are not collected in China on a consistent, comparable basis. This means that the OECD definition cannot (yet) be applied.

In China, as in other countries, data limitations force the use of proxies to identify the majority of periodic social and economic interactions occurring in metropolitan regions within a reasonable travel-time from the center of China's cities. Research in other countries suggests that a one-hour travel time is generally the limit that households are willing to spend for most journeys to work, and that most suppliers to enterprises can effectively travel for daily deliveries. Assuming motorised vehicles as the dominant mode of movement, this equates roughly to a maximum radius of $50 \mathrm{~km}$. from the urban core when accounting for lower travel speeds in more congested central areas.

China's urban regions differ significantly from North American and European cases in the distribution of places of residence and places of work. Private vehicular ownership is low, regional commuter transit (such as in Tokyo, Paris and New York) does not yet exist, and distances to work are generally much smaller in China. This is partly due to the development of large, self-contained SOE complexes that included factories, residences, and public facilities in one location, and the TVE industrialisation model in which places of work and residence are scattered in suburban towns. Therefore, in China more so than in Europe and North America, there is a much stronger correlation between population density and employment density, and hence to production.

Constraints to physical mobility mean that the $50 \mathrm{~km}$ radius is probably a maximum metropolitan catchment area in China. A one-hour drive time is possible by enterprises, most of which have access to motorised transport. But the majority of urban residents rely on inner-city public buses, bicycles and walking to get to work: their one-hour travel time distance is considerably more circumscribed. While regulatory impediments were until recently the greatest constraints to labour mobility in urban markets, physical accessibility is emerging as the most significant impediment to labour flows within China's emerging metropolitan regions, particularly to and from suburban areas.

Given these conditions, the following approach has been followed to identify and describe the spatial extent and structure of metropolitan regions in China:

- Identifying, using GIS technology, areas that are anchored on the urban districts of statutory cities with over 1 million non-farming residents;

- Identifying where these cities appear to spill over to capture non-farming populations and enterprises in towns and cities in adjacent counties and county-level cities that have population densities over $500 \mathrm{inh} / \mathrm{km}^{2}$, where non-farming GDP comprises more than $40 \%$ of total GDP, and that are connected by good quality roads (either NTHS or national highway segments with road quality above Class 3$){ }^{22}$ and

- Capturing the core city and adjacent counties or CLCs generally within a $50 \mathrm{~km}$ radius of the centre of the core city, representing a notional 1-hour travel time. Analysis of traffic volumes along the national highway network suggests that a few metropolitan regions likely spill over to capture selected counties beyond those immediately adjacent to the core city; i.e., that the reach of some is wider than $50 \mathrm{~km}$.

This method differs from the approach followed by OECD to define metropolitan regions. In terms of population thresholds, OECD uses 1.5 million total residents; i.e., not differentiating between farming and non-farming populations. The OECD definition also uses a population density threshold of $150 \mathrm{inh} / \mathrm{km}^{2}$.

22. Grade 3 roads have a design speed of 30-60 km/hr and average design capacity $1000-4000$ vehicles/day. 
China's suburban areas have very high densities - often well over 250 inhabitant $/ \mathrm{km}^{2}$ - of farming populations on small landholdings in numerous scattered villages and towns. Applying these thresholds to China would essentially capture the majority of China's cities as metropolitan regions. However, the most significant constraint to applying the OECD method in China is the absence of accurate, comprehensive, current, and comparable data on commuting flows. These have not been collected in China since commuting from suburban areas is a very new phenomenon.

The proxy approach used here identifies 53 metropolitan regions in China anchored on cities with over 1 million non-farming residents and encompassing selected adjacent counties (Figure 12). They hold over 380 million people, or almost 30\% of the country's population. The biggest metropolitan region in China is Shanghai with an urban population of over 17 million. In addition to Shanghai, Beijing and Guangzhou (Guangzhou and Foshan) metropolitan regions have non-farming populations over 10 million. ${ }^{23}$ A second tier of 13 metropolitan regions has urban populations ranging from 5 million to 10 million. A third tier with populations ranging from 1 to 5 million comprises 37 regions. While first and second tier metropolitan regions are concentrated along the coast, many of China's medium and small size metropolitan regions are located inland.

Figure 12. China's 53 metropolitan regions by size of non-farming population, 2004

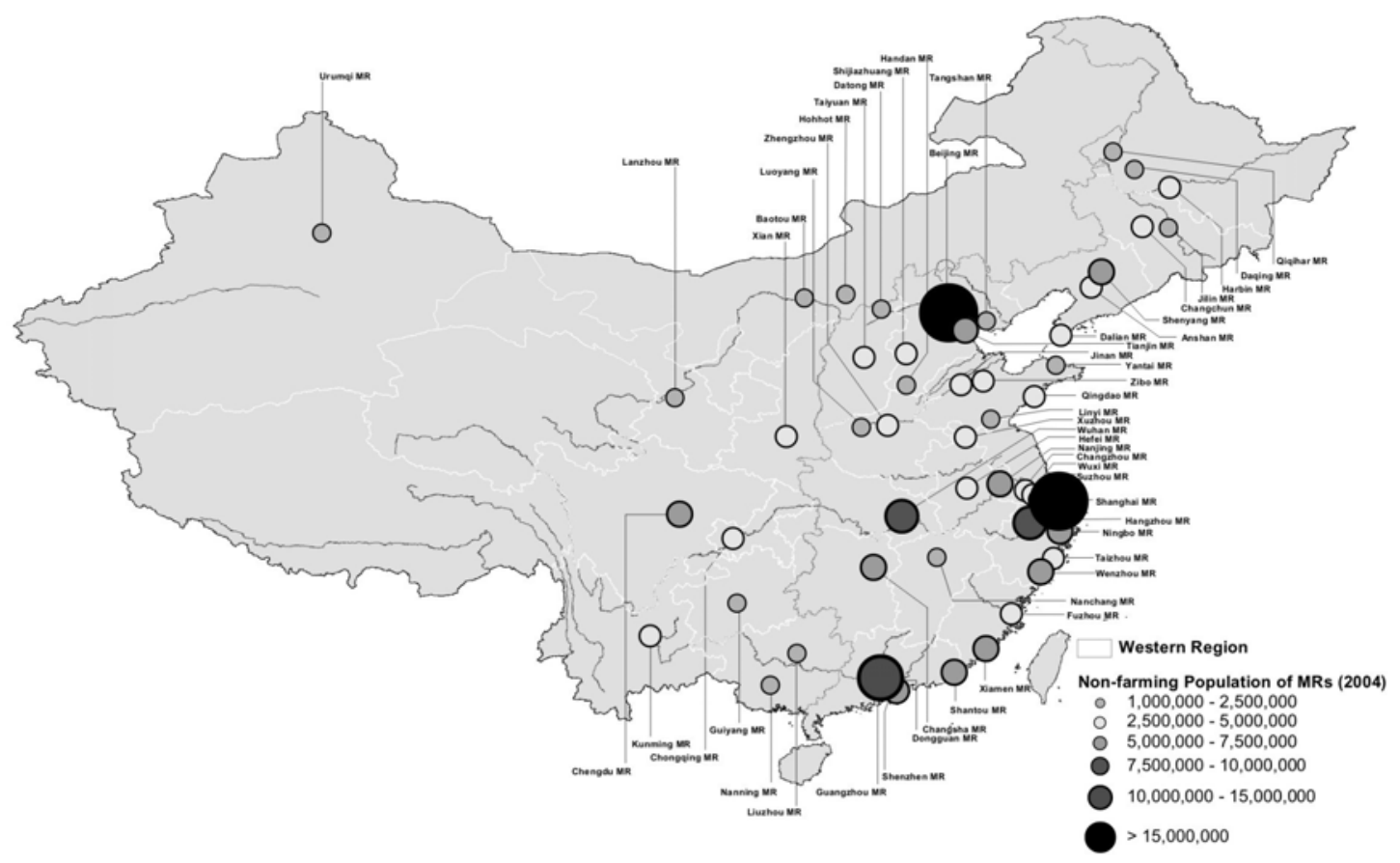

Source: Calculations from 2005 Provincial Statistical Yearbooks.

23. Metropolitan regions delineated by the proxy approach are not synonymous with the cities or regions defined by administrative boundaries. For instance, Guangzhou metropolitan region contains both the Guangzhou Prefecture and the Foshan Prefecture as a result of their close proximity. Similarly, Chongqing metropolitan region is smaller than Chongqing Municipality (Chongqing Zhi Xia Shi), as the latter is far beyond the radius of one hour's drive. 


\subsection{Metropolitan economic performance and prospects}

As a group, metropolitan regions have become the principal engines of China's fast-growing economy. Holding just under $30 \%$ of China's population, the 53 metropolitan regions produced $64 \%$ of the country's GDP in 2004, up from 55\% in 1998 (Figure 13). While China's production was largely decentralised before the mid-1990s, the country became a predominantly metropolitan economy by the late 1990s, a trend that has accelerated such that almost two-thirds of China's economic output is now concentrated in the 53 metropolitan regions. Perhaps more significantly, these metropolitan areas accounted for $77 \%$ of China's overall growth in GDP from 1998 to 2004.

Figure 13. Growing economic importance of China's 53 metropolitan regions

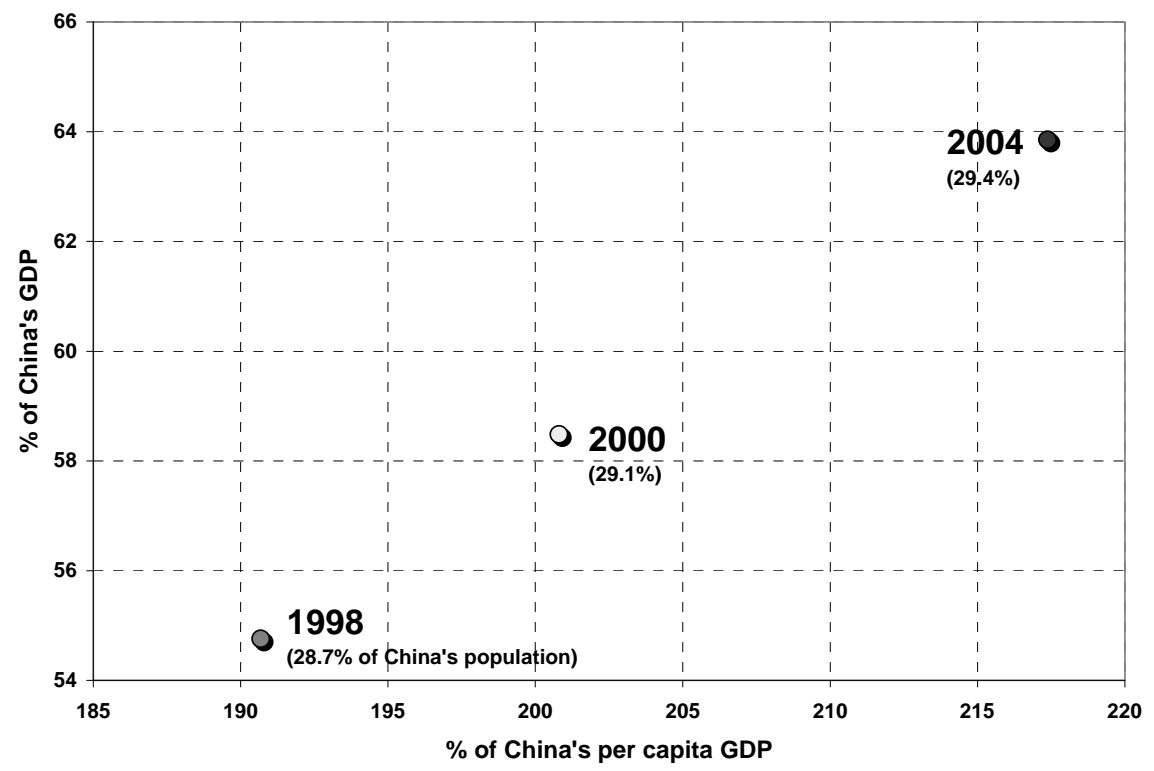

Source: Calculation from aggregated county- and city-level data, 1998, 2000, 2004.

However, as with China's Regional Urban Systems, although metropolitan economies have in aggregate grown significantly, there are wide differences in productive capacities between them. Figure 14 shows the change in share of China's GDP produced in each of the 53 metropolitan regions from 1998 to 2004. Not surprisingly, Shanghai, Guangzhou, and Shenzhen have grown in national importance, each producing almost 1\% more of China's GDP in 2004 than in 1998. Significantly, the eight metropolitan regions in the Yangtze Delta Megalopolis ${ }^{24}$ produced 17\% of China's GDP in 2004, up from 13\% in 1998. This compares with the three metropolitan regions in the Pearl River Delta Megalopolis which grew from producing 5.3\% of China's GDP in 1998 to $7.5 \%$ in 2004. Figure 14 illustrates divergent economic dynamics of China's metropolitan regions in recent years: six of 28 coastal metropolitan areas experienced declines in their share of China's production from 1998 to 2004; four of six in the northeast also had declining shares; only one of seven metropolitan regions in central China experienced a drop; and, perhaps significantly, only two of 12 in the west declined.

24. Shanghai, Hangzhou, Ningbo, Suzhou, Wuxi, Changzhou, Nanjing, Taizhou. 
Figure 14. Change in metropolitan region's share of China's GDP, 1998-2004

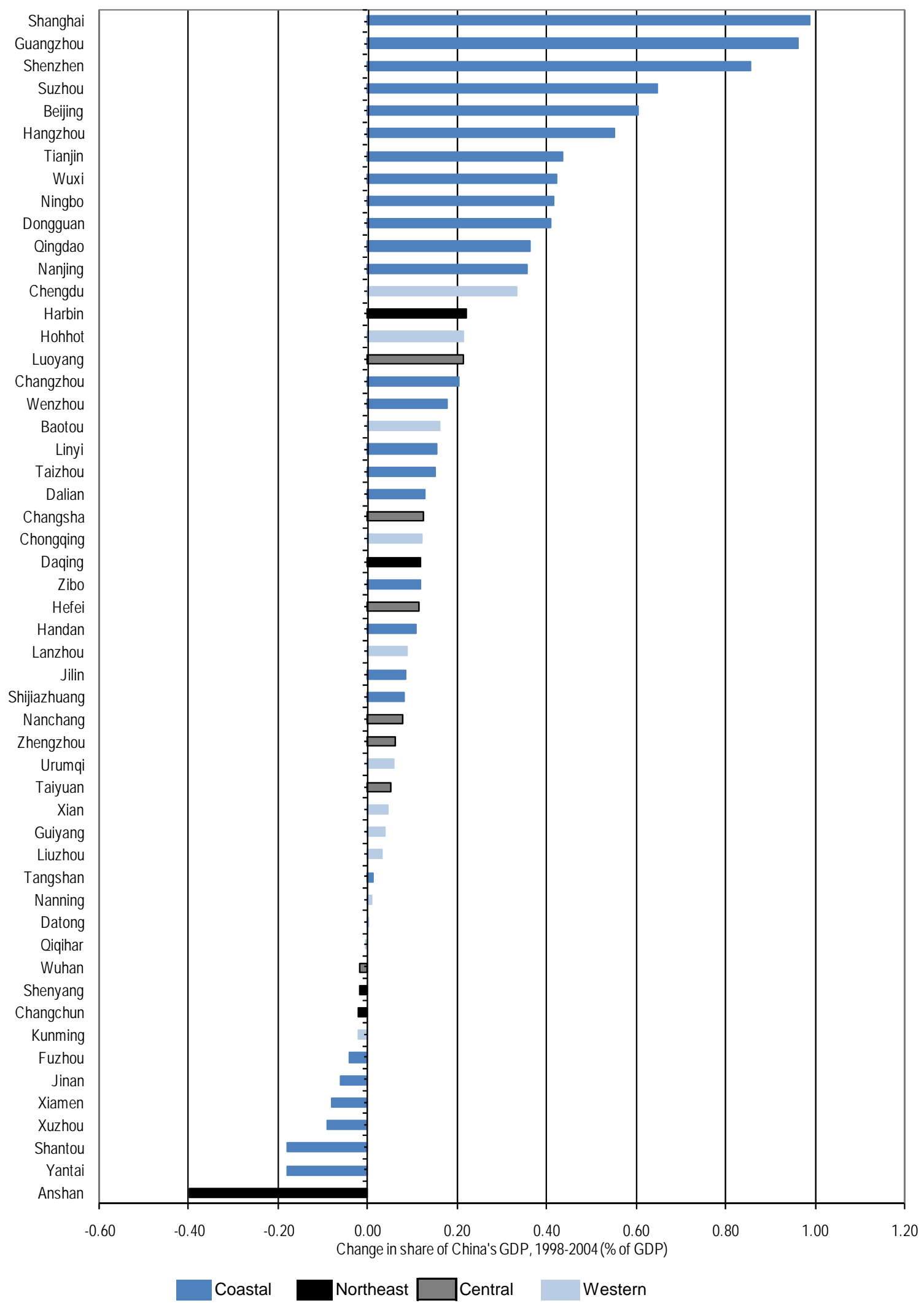

Source: Calculations from city and county-level data from Provincial Statistical Yearbooks. 
The momentum of economic growth appears to be slowing in a few coastal metropolitan regions that have either not restructured their economies from the state-sponsored heavy industry model (e.g., Xuzhou), or that have concentrated since the early 1990s on low value-added manufacturing (e.g., Shantou and Xiamen). The difficult and widespread task of restructuring old industrial economies in the northeast is still clearly unfinished: most metropolitan regions are growing at a far slower pace than elsewhere in China. Conversely, central and western metropolitan regions are now generally shouldering a growing share of China's production. Particularly notable is the increase in share of national GDP produced in the Chengdu metropolitan region - more than double the share increase of nearby Chongqing. However, the extent to which the increased shares in western and central regions have resulted from state-sponsored investment rather than consumption and trade - is unclear. Since GDP data are not disaggregated, the sustainability of production and economic growth among metropolitan regions in non-coastal areas will only become apparent over time as levels of state-induced fixed asset investment gradually subside.

\subsection{Constraints to development of metropolitan regions}

China's rapidly urbanising metropolitan regions face multiple challenges, including achieving acceptable standards of environmental quality, providing levels of infrastructure service required by residents and firms, and providing public services for all residents, including migrants. However, three constraints stand out as particularly important in facilitating the agglomeration benefits that are inherent to most metropolitan regions, particularly in OECD countries.

Most of China's metropolitan regions are under-urbanised, and hence have unrealised agglomeration economies. Only 16 of 53 MRs have urbanisation levels over 70\%. Of these, 11 MRs have per capita GDP in the top half of the range of all metropolitan regions. While just over half of China's metropolitan regions are in coastal provinces (28 of 53), half of these have urbanisation levels under $70 \%$.

Significant correlation appears to exist between the degree of urbanisation and economic prosperity of metropolitan regions in China (Figure 15). Not surprisingly, labour and spatial productivity are higher in metropolitan regions that are more urbanised. However, the population size of metropolitan regions also appears to matter: smaller MRs with under 2 million non-farming residents have lower levels of per capita GDP, reflecting lower agglomeration economies. There is considerable scope for additional urbanisation in both coastal and interior metropolitan regions, especially from integration of suburban towns into metropolitan economies. The recently published Mckinsey report confirmed this view by arguing that "a more concentrated pattern of urbanisation is the optimal path", in terms of "increase per capita GDP" and “increase overall productivity of the urban system” (Mckinsey Global Institute, 2008) (Box 3).

\section{Box 3. Concentrated growth urbanisation scenarios projected by the Mckinsey Report}

The new published Mckinsey report on "Preparing for China's Urban Billion" has projected four approaches to urbanisation, covering "concentrated growth" model and "dispersed growth" model. Two concentrated growth patterns foresee arise of gigantic cities and metropolitan regions. "Under a 'supercities' scenario, a small number of very large cities - with population of 20 million or more - could emerge. Under a 'hub and spoke' scenario, clusters of mediumsized and small cities could develop around larger ones." Two other quite different approaches would involve patterns of dispersed growth. "Under a 'distributed growth' scenario, a large number of cities with populations of 1.5 million to 5 million spread throughout China. Under a 'townisation' scenario, many smaller cities - with populations of 500000 to 1.5 million - could be the model."

Among the projected four distinct patterns of urbanisation approach, the report argues "the concentrated growth scenarios appear to be the most optimal", which would mostly apply to the case of China. Two highlighted positive economic implications include: 1) highest per capita GDP - supercities and hub and spoke scenarios, both concentrated growth models, would produce up to 20\% higher per capita GDP than trend line and more dispersed growth scenarios; 2) more efficient use of energy - energy productivity would be almost $20 \%$ higher in concentrated models of urbanisation, although hub and spoke will have the highest total energy use. 


\footnotetext{
Box 3. Concentrated growth urbanisation scenarios projected by the Mckinsey Report (cont.)

The report shows optimism in analysing the downside of the concentrated model. It argues the challenges of concentrated growth scenarios - more severe peak pollution and more intense congestion - would be more manageable, thanks to stronger economy, and effective enforcement and local level action.

Source: Mckinsey Global Institute (2008), "Preparing for China's Urban Billion”.
}

While positive correlation holds true in the context of China today, concerns for the future of mega cities may arise if comparing to OECD countries, as the OECD report Competitive Cities in the Global Economy suggested an unclear picture between city population size and income level. Data analysis of 78 metro-regions indicates bigger means richer until a certain threshold (around 7 million); i.e., the correlation between metro region size and income becomes negative. A possible explanation is the cost of congestions and diseconomies of scale in mega cities; i.e., higher commuting times, higher costs of logistics and transport, as well as land rent values and environment cost. Despite the ongoing debate on the optimum city size, which policy makers from other countries have few measures to control, challenges of mega cities mentioned above require further attention while massive urbanisation continues.

Figure 15. Urbanisation and prosperity in China's 53 metropolitan regions, 2000

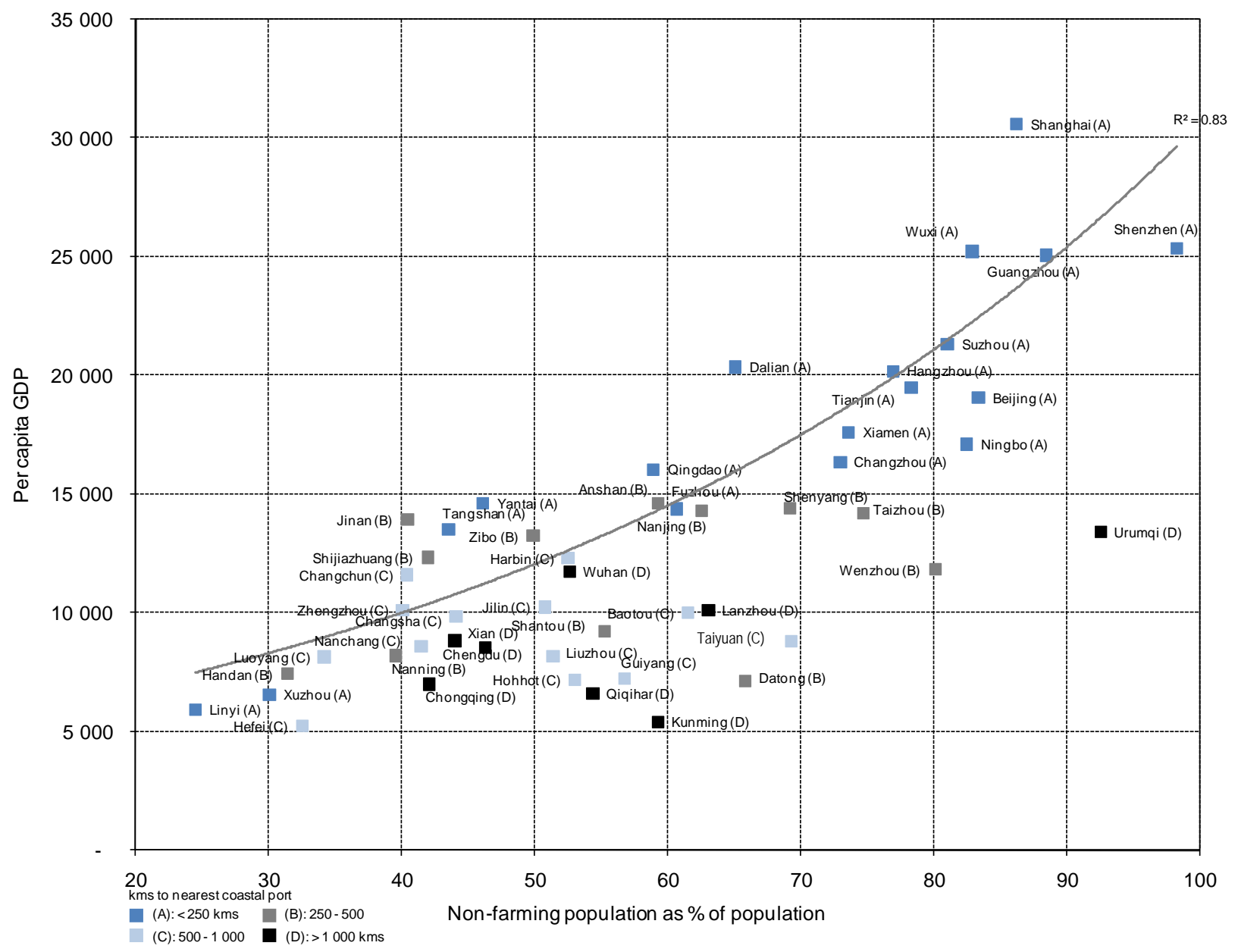

Source: Analysis of data from Provincial Statistical Yearbooks, 2001. 
In most of China's metropolitan regions well over $30 \%$ of the total population live in towns. As a whole, statutory towns now hold 52\% of China's metropolitan region population; in 27 of the 53 MRs, towns account for more than half the total number of residents. While there are certainly many exceptions, these towns are today generally characterised by: far lower population densities than the central metropolitan areas; low statutory designations of densities through town-administered development controls (e.g., floor-area ratios); comparatively weaker control over conversion of land for urban development, leading to suburban sprawl; limited and in many cases rudimentary social services; small and scattered, labour-intensive enterprises; lower levels of human capital in terms of educational and training attainment; limited fiscal capacities; and governance systems largely designed to manage farm-based rather than urbanising economies. The cases are specifically worse in towns located in some west China provinces; e.g., Chongqing, Sichuan and Guizhou, where financing capacity for public utilities and social services are weak. In the case of Chongqing, within one-hour drive cycle, while public services in nine urban districts (6 million inhabitants) in the central city are managed by sectoral agencies, each local government in the other 14 suburban counties (totalling 10.1 million inhabitants) is responsible for provision of most forms of urban services but barely receive any significant financial assistance from either the central or the municipal governments to support their urban infrastructure investment.

Recalling the UN projections of an additional 160 million urban residents in China from 2005 to 2015, assuming - in a conservative scenario - that statutory cities and counties absorb this urban population growth in the same proportion as in the year 2000 (68\% in cities; 32\% in counties), both would grow at an average annual exponential rate of $1.9 \%$, which is generally consistent with moderate urban growth rates in many developing countries during the 1980s and 1990s. However, many municipal governments, at least in the larger cities, are attempting to reduce generally high population densities within inner urban areas by promoting resettlement to suburbs. If the average densities of inner urban areas are assumed to remain stable until 2015, suburban towns and townships within statutory cities would need to absorb 117 million new non-farming residents by 2015. Such growth implies an average annual exponential suburban growth rate of 3.8\% which is at the highest end of recent urban growth rates in developing countries. If current spatial patterns of growth are allowed to continue, China's metropolitan regions will become large, sprawling urban areas with growing congestion and pollution costs that will eventually detract from the agglomeration economies inherent to well planned and well managed metropolitan regions.

Current public policy in China is to promote urbanisation in all towns (especially county seats) and small cities regardless of their competitiveness and economic sustainability. From the central government's perspective, it cannot be perceived to be picking winners. This is also true at the municipal level, but local governments often go one step further and build new towns as special districts so as not to favour one town over another, thereby adding to spatial dispersion that undermines urbanisation economies. This undifferentiated policy avoids difficult decisions and could, over time, actually undermine the urbanisation process.

Another major constraint to the development of metropolitan regions in China is their spatial structure and form: a combination of high densities in central areas (generating attendant congestion and environmental costs), and very dispersed suburban areas which together undermine urbanisation economies. There are numerous CLCs and towns in Chinese MRs that are all competing for inward investment and for spillover benefits from metropolitan economies. The capital and recurrent costs to adequately service these multiple sub-centres are often either unaffordable (and services are therefore not provided) or are high and hence drive up costs to households and firms. In either case, urbanisation economies do not accrue across the metropolitan region. This compares with spatial patterns in some highly-productive metropolitan regions outside of China, such as Paris and New York, where there are lower central core densities and far fewer sub-centres. 
The comparatively high centrality of China's metropolitan regions is a direct result of two legacies: a long tradition in which the country's few cities predominantly played governmental and administrative rather than economic roles; and the central planning tradition favouring the development of rural areas and promotion of targeted industrialisation within selected cities through strict controls on the formation and mobility of factor inputs, especially labour. Both traditions are now history, but the path dependencies are still manifested in very high central city densities, the proliferation of suburban towns (former market towns), and the comparatively low population densities within these towns.

Perhaps the single most important constraint to the sustained development of China's metropolitan regions is not related to the size and spatial structure of the urban area, but to the skills and knowledge of the people who live within them. The key driver of global competitiveness for metropolitan regions around the world is their human capital. The OECD report Competitive Cities in the Global Economy (2006) confirms that the main factor of regional competitiveness is productivity which is in turn largely explained by the educational level of the labour force (Box 4). In this respect, there are wide variations among China's cities in the levels of skilled workers.

\section{Box 4. Productivity and competitiveness in metropolitan areas}

Despite various measures for assessing city competitiveness, a commonly used definition is the aggregate indicator - GDP per capita. To explain a given region's gap in GDP per capita with other OECD metropolitan regions, the OECD has developed a cross-country comparison model, including variables like productivity per worker, efficiency of the local labour market expressed in terms of employment/unemployment, and the relative size of the labour force with respect to the population; i.e., the activity rate. Among the three explanatory factors, empirical analysis of OECD metro-regions shows productivity emerges as a key factor in metro-regional performance.

To further explain productivity, skills in metro-regions appear to be a strong factor. In Montreal, for instance, which belongs to the category of metro-regions that have specialised in high value-added sectors, relatively lower productivity was caused by lower educational attainment and insufficient investment in equipment, as well as research and development (R\&D), especially within small and medium-sized enterprises that constitute an important share of the regional fabric. In less advanced metropolitan areas, such as Mexico City and Istanbul, productivity level is highly inhibited by the relatively lower skills of the working population and the extent of the informal sector where adult education and skills training are difficult to provide. In general, lower productivity seems to be related to lower skills, not only in Turkish and Eastern European metro-regions, but also in metro-regions from more advanced countries such as Athens, Lille, Lisbon and Valencia. In spite of a few exceptions in Japan due to overall stagnating growth, however, productivity and skills seem to be related, notably so with the positive trend in London, Madrid, Oslo and Stockholm and the lagging one in Lille, Krakow and Stuttgart. In addition, countries such as Finland, Australia, the United States, France, Sweden and the United Kingdom, whose metro-regions also belong to the fast productivity-growth group, attain high productivity levels which are largely explained by skills.

Source: OECD (2006), Competitive Cities in the Global Economy, OECD Publishing, Paris.

China's education system was severely affected during the Cultural Revolution when most schools and universities were shut down, creating a generation with comparatively weak educational attainment. This generation, now 45-60 years old, absorbed the brunt of unemployment caused by SOE downsizing and closures in the 1990s since workers simply did not have the skills to apply to new jobs. In parallel, the historical disparities between urban and county/township level education continue, and very few rural or semi-rural students progress beyond the mandatory junior school level to secondary and post-secondary training. 
The results are huge differences in educational attainment across China's cities. Figure 16 shows vocational attainment along the $\mathrm{x}$-axis, and post-secondary attainment at the master's degree level or above along the y-axis. The black squares are urban areas of prefecture-level cities and lighter circles are countylevel cities. Two conditions are particularly significant. CLCs (which account for 374 of China's 657 cities) have extremely low rates of vocational attainment, and virtually no graduate-level attainment. This has serious implications for their levels of productivity and capacities to innovate, both of which are becoming important determinants of a city's national and global competitiveness. While most PLCUAs have a significant stock of vocational graduates, there is almost a ten-fold difference in levels between the lowest and highest ranked cities. Again, this suggests significant differences in labour productivity and capacity to assimilate new technologies. Also of concern, however, is the wide range among PLCUAs in residents with graduate degrees as a proportion of the city population. The human capital to exercise advanced functions in research, marketing and management are in short supply in many areas.

Figure 16. Educational attainment rates in China's cities (2000)

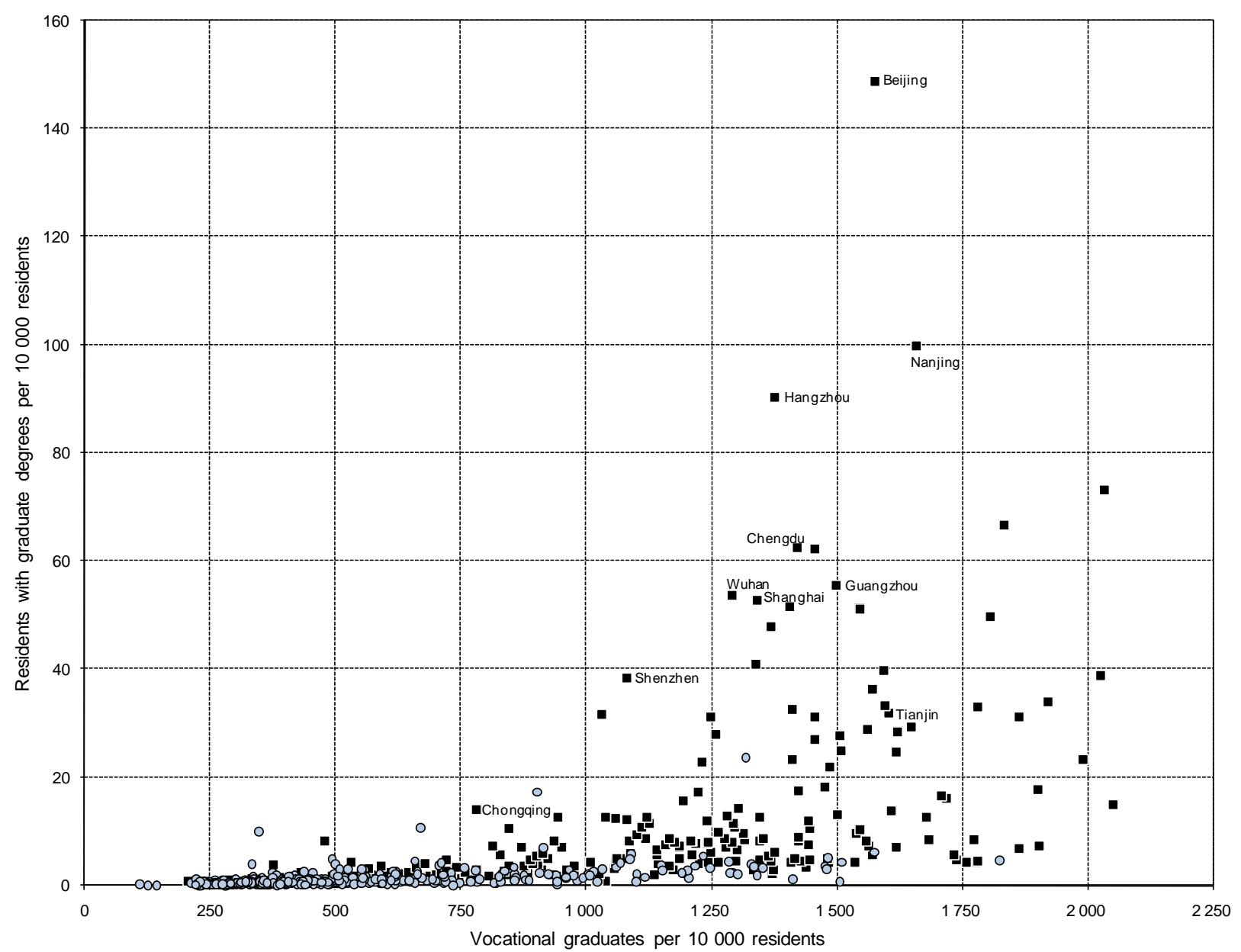

Source: Calculations from 2000 National Census of China. 
Educational attainment is likely to be the single most important constraint to fostering innovation capacities in China's cities over the next generation. Figure 17 shows the difference between university attainment in China's cities (24 top ranked metropolitan regions are shown on the graph) and selected metropolitan regions in other OECD countries. Availability of skills in Chinese cities will be probably one of the most important challenge as it is the case already in such metropolitan regions like Chongquing (Box 5).

\section{Box 5. Higher education and human capital in Chongqing Municipality}

There is significant space for improvement on the performance of accumulating human capital in Chongqing Municipality. The city's current educational efforts show shortcomings: compared to other southwest Chinese cities, the municipality is rarely among the leaders. For example, considering adults, while the proportion of university-educated workers in Chongqing Municipality $-21 \%$ - is close to the average of southwest cities, it is still lower than in close-by Chengdu; the target in this case is set in the FYP at $30 \%$, but it remains unclear how this and other education targets are to be met. Similarly, as for the younger cohorts' human capital, Chongqing's per capita spending on education is higher than that of Chengdu; nonetheless, it looks rather low compared to the national leading cities for progress towards a harmonious society. Finally, the municipality has only one institution of higher education (Chongqing University) included amongst the 106 universities considered in the national Project 211, by means of which universities gain preferential support from the central government. Moreover, Chongqing University ranks only $45^{\text {th }}$ in the Netbig Chinese University Rankings 2007 and thus stands far behind Chengdu's Sichuan University. However, Chongqing has a comparative advantage in terms of human capital with its many military research and production sites and their staff, which could in the future articulate their activities with industry even more, for instance improving the production of civilian products using military technology. It seems though that the competitiveness of these facilities products is not strong enough.

It is also not very clear whether the economy's human capital needs are to be met by Chongqing Municipality's strategy. Efforts to strengthen different fields of education, from basic primary and secondary education, over occupational education and up to higher education, are all mentioned in the official documents, such as the FYP, but precise strategic priorities are hard to identify. Administrative mechanisms to evaluate the real needs of local actors and to give directions for Chongqing's education policy are missing. It also appears that, except for automobiles and motorcycles, local enterprises suffer in their competitiveness due to a lack of senior professionals, operation management and marketing staff.

Source: OECD, Chongqing Municipality's Development Strategy: Some reflections from the international experience of the Territorial Development Policy Committee of the OECD. 
Figure 17. Per cent of metropolitan region population with university education, 2000/01

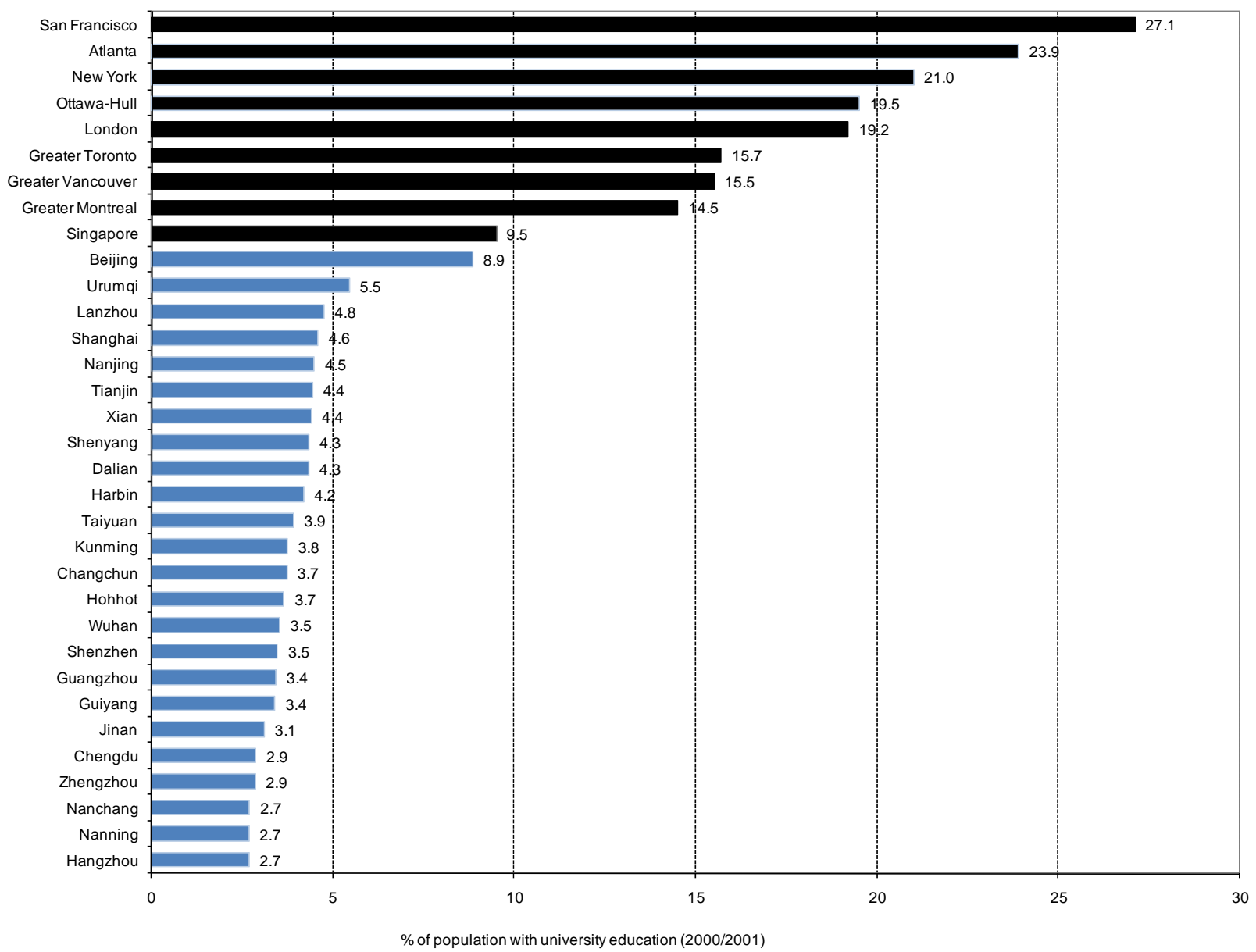

Source: For China, 2000 National Census of China data; for Singapore, 2000 Population Census; for Canada, 2001 Census; for United States, 2000 Census; for London, GLA.

The central and local governments have clearly recognised the need to improve higher education in China. They have spearheaded a massive drive to merge universities and colleges across the country, to expand university facilities (including through the construction of 'university towns' in the suburbs of many metropolitan regions), and to expand enrolment. While university enrolment is up, the delivery cycle for highly-trained technical and professional graduates is 6-10 years, and there is not likely to be a major upsurge in potential employees until 2010. A combination of new graduates and a reported increase in Chinese graduates returning from overseas institutions represent a potentially important addition to the human capital and innovation capacities of metropolitan regions. Given increased labour mobility in China over the past few years, and growing competition among metropolitan regions to attract highly-qualified graduates, most of this segment of the workforce will be able move to where career opportunities are highest. This suggests that the large and advanced metropolitan regions shouldering the biggest shares of China's GDP are likely to attract the most qualified workforce; i.e., Shanghai, Guangzhou, Shenzhen, Suzhou, and Beijing and correspondingly putting more pressure on the attraction of talents of inland and less developed metropolitan regions; i.e., Chongqing and Xi’an. 


\section{Governing an urban China}

\subsection{System of sub-national governance in China}

The pace and extent of urbanisation in China are unprecedented in the country's history, especially in metropolitan regions that invariably cross sub-municipal boundaries. Urbanisation is placing considerable stress on sub-national systems of governance by: 1) creating a myriad of new functional responsibilities for local governments; 2) increasing the scale of existing responsibilities; 3) causing serious strains on municipal public finance and on the commercial banking sector from which local government are increasingly borrowing to cover both capital and recurrent expenditures; and 4) placing pressures for the re-allocation of some responsibilities between governments on the basis of both efficiencies.

China's unitary structure of governance is a hierarchical system through which functional responsibilities are delegated from the central to provincial governments (second tier), to a third tier of prefectures and prefecture-level cities (PLCs), to a fourth tier of districts (only PLCs are permitted to have district governments), counties, and county-level cities (CLCs), and a fifth tier of towns, townships, and neighbourhood committees in cities (Figure 18). Peoples' congresses - the legislative arm of government exist at the national, provincial, city (both PLCs and CLCs), district, and county levels and operate under close guidance of local party committees. At the city level, the municipal peoples' congress and its standing committee exercise local legislative power, decision making on key local issues (including the onbudget), supervision of the executive authority, and appointment and removal of key executives (Mayor, Vice Mayors).

Figure 18. Stylised model of China's governance system

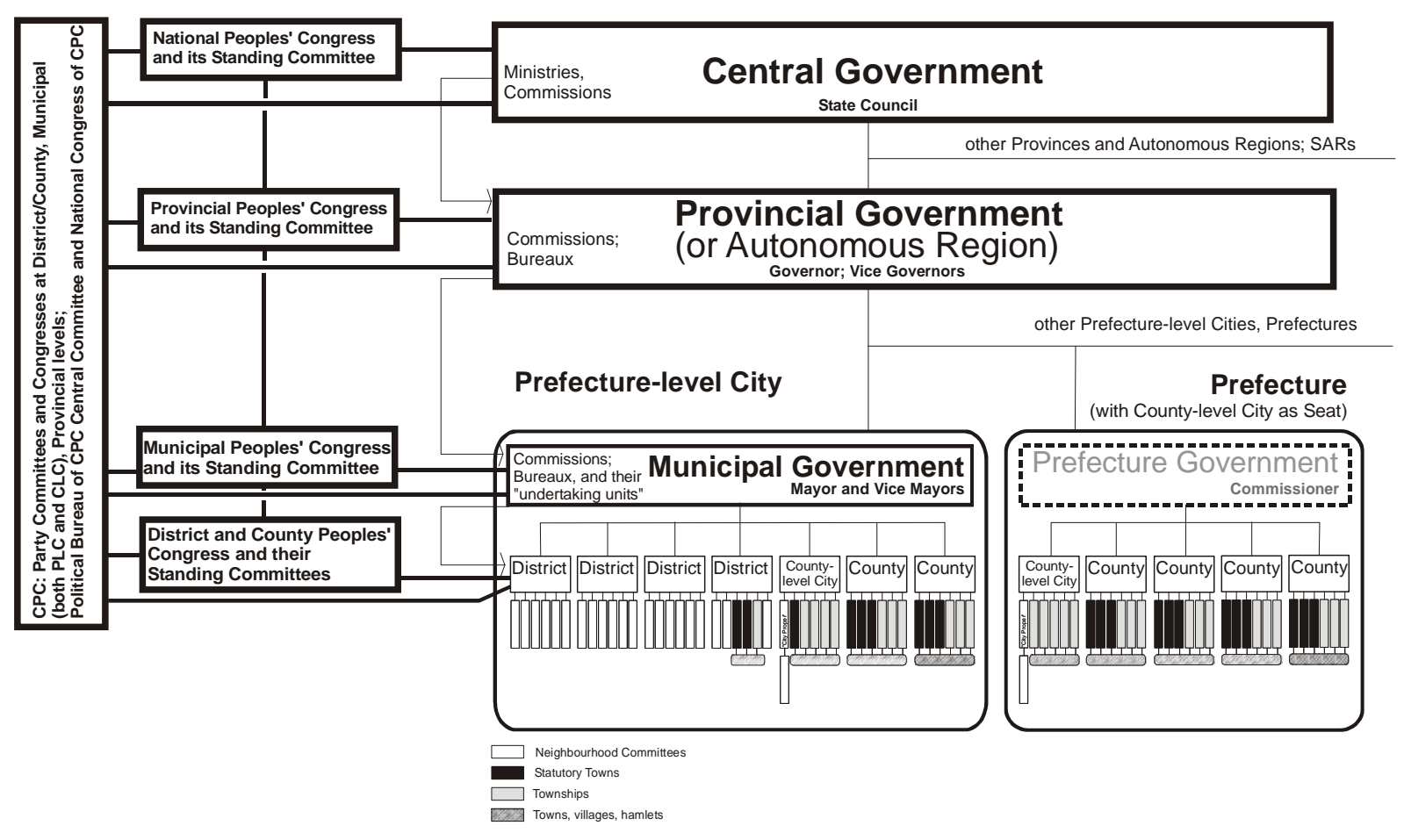


Under the unitary structure, all organs of government (party committees, peoples' congresses, executing administrations) are required to follow the directions of their higher-level counterparts. Peoples' congresses have the right to repeal legislation, regulations and directives made by the next lowest levels that are found to be inconsistent with higher level decisions. For executing administrations there is almost a complete replication of functional organisations from the central to provincial governments, and then to the municipal level: central ministries have their counterparts at the provincial level which are mirrored in the municipality (e.g., municipal finance bureaus report to provincial finance bureaus which in turn report to the Ministry of Finance). While these organisations are expected to respond to direction from senior government executives at their level, they are also required to comply with the decisions of their administrative counterpart at the next higher level. Despite this stepped authority, the Constitution provides that all levels of administration are subordinated to the State Council. Establishment of new district, county and municipal governments can only occur with the approval of the Central State Council.

Although the prefecture level has legislated functional responsibilities, as a unit of government the prefecture is not defined in the Constitution, and there is no prefecture-level peoples' congress. As noted earlier, prefectures are an administrative carry-over with some boundaries dating back at least to the early Ming Dynasty. Under the "city controlling county" system introduced in the late 1950s by the National Peoples' Congress, county-level cities and counties were subordinated to a single city that administered the entire prefecture. The subordinating cities already had demarcated boundaries (roughly equivalent to the size of counties) and municipal governments, including peoples' congresses. The "city controlling county" system essentially elevated the authority and expanded the functional responsibilities of these municipal governments to the prefecture scale. In prefectures where there is not a city of sufficient size to warrant designation of a PLC, they come under the authority of a prefecture commissioner who reports directly to the province.

Urbanisation, structural changes under market reforms, and decentralisation over the past two decades appear to be causing six stylised trends in many of China's cities that affect the mandates, structure, and functional responsibilities of municipal governments (Figure 19). 
Figure 19. Trends in sub-provincial governance under decentralisation

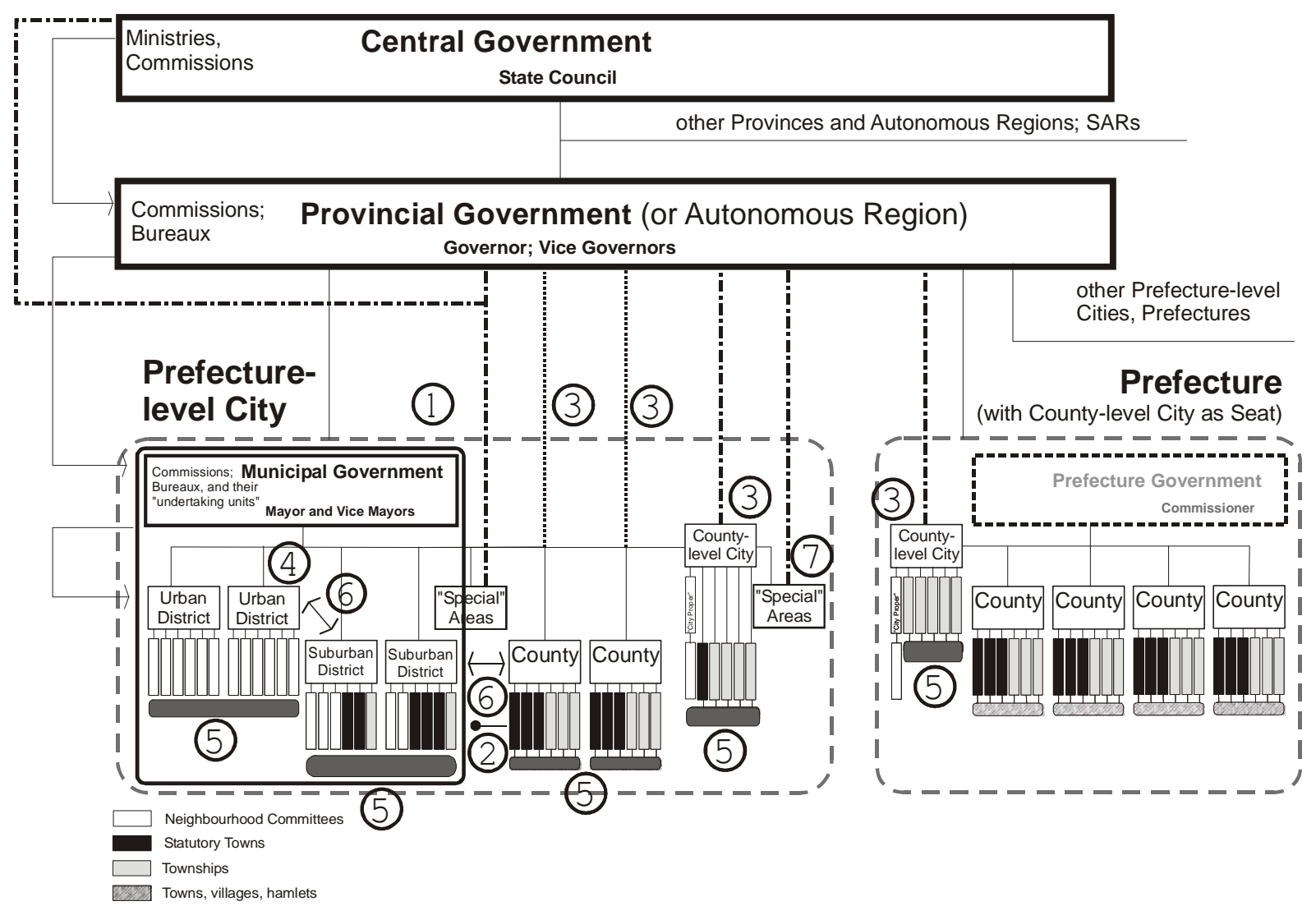

1. PLCs are focusing on issues within their own municipal boundaries. The emergence of hard budget constraints (including credit limits) growing urbanisation pressures, the erosion of functional responsibilities under the "city controlling county" system, and intense competition during the last 20 years for both domestic and foreign investment is leading PLCs to define their roles much more narrowly. They are becoming singularly aligned to the immediate boundaries of their urban municipality comprised of districts (the "urban area" of PLCs, or PLCUA or, as noted earlier, the "city proper"). While subordinated cities are still required to obtain approvals from PLC governments of master plans and major infrastructure works, since their implementation is rarely co-financed by the PLC government, approvals have become perfunctory.

2. Surrounding townships and towns are interacting more strongly with PLCUAs and, in some cases, to CLC's urban areas, but are not being adequately served by these urban governments. The transition of suburban settlements into contiguous extensions of both PLCUAs and CLCs is occurring as TVE and collective enterprises integrate into urban economies, and as former farmers enter the urban workforce. In many cases, these townships and towns are in surrounding counties or CLCs and therefore not under the jurisdiction of the municipality providing major public urban services.

3. CLCs and counties are becoming much more autonomous. The diminished role of PLCs means that CLCs and county governments will increasingly deal directly with provincial governments for policy direction, approvals, and financing. This is already occurring not only in more prosperous provinces but also in cities in the Western Region. CLCs and counties are now almost fully responsible for the delivery of all social services (health, education, welfare) and infrastructure services. 
4. "Suburban" districts are slow to integrate into municipal governments. Legally, the "district" is the only unit of government that can exist under a PLC. However, most municipal governments make a clear distinction between "urban" and "suburban" districts which appears to be linked to the prevailing type of hukou held by residents; suburban districts are still often treated as "counties" by municipal officials. Their functional responsibilities generally differ (although not always explicitly) and revenue entitlements are more limited compared to "urban" districts. Urban and infrastructure planning and investment by municipal governments generally focus on urban districts.

5. Growing numbers of residents with needs for public services are falling outside of districts and therefore of service areas. The principal demand pressures that municipal governments will face are not from rural migrants but from agricultural-registered households in suburban areas that have in fact entered the urban economy. These pressures are emerging from towns within existing districts and from surrounding townships and towns, including in adjacent counties.

6. Mechanisms for inter-jurisdictional co-ordination are not keeping up with new and expanding functional responsibilities and expenditure burdens that municipalities are facing. As in most cities around the world, co-ordination in public services planning and delivery between "urban" and "suburban" districts, between districts and counties, and between counties themselves needs to be strengthened to realise economies of scale, minimise duplication of services, and ensure equitable supply to residents and enterprises. The core issue to local administrations is that functional responsibilities of sub-provincial levels of government have not been clearly allocated and codified.

\subsection{Who does what}

Functional responsibilities for urban management need to be understood in the broader context of the "decentralisation" that has occurred in China since the introduction of market reforms. While there is no doubt that urban functional (and therefore fiscal) responsibilities of the central government are now much reduced from even a decade ago, it is important to understand what forms decentralisation has taken in China, what gaps may remain, and the scope for continued reforms in the context of the country's unitary structure of governance.

Decentralisation is widely viewed as a desirable outcome by market policy planners since it is seen to improve economic efficiency, improve cost efficiency, improve accountability, and increase resource mobilisation. However, these outcomes are neither universal nor assured: there is no single model of administrative and fiscal decentralisation that can be applied irrespective of a country's history, traditions, and specific institutional, political and economic contexts. Experience in other countries during the past decade suggests that, in general, there are three principal forms of decentralisation: 1) deconcentration; 2) delegation; and 3) devolution. They are characterised by differences in local government authority, responsibility, and fiscal autonomy. In the course of China's rapid transition, two additional (but unintended) forms of decentralisation have occurred: offloading and usurpation.

Figure 20 shows a schematic representation of six general strategies for assigning roles and responsibilities, including the centralisation model. The six are defined on three axes: the degree of local government authority as codified in constitutions and laws that define government mandates; the degree of local government responsibility as defined either by laws and regulations or, in their absence, by more informal conventions reflecting public expectations and demands for various services; and the degree of

local fiscal autonomy in making expenditure decisions and financing them from local sources and predictable transfers. 
Figure 20. Forms of centralisation and decentralisation
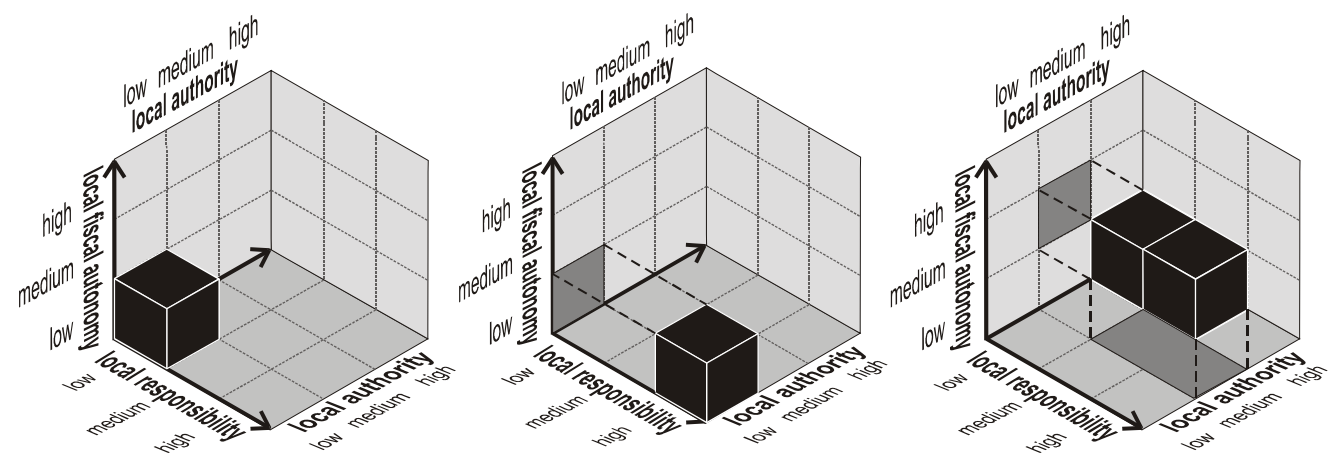

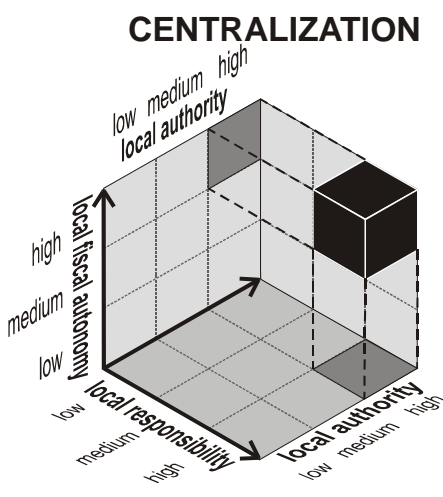

DEVOLUTION

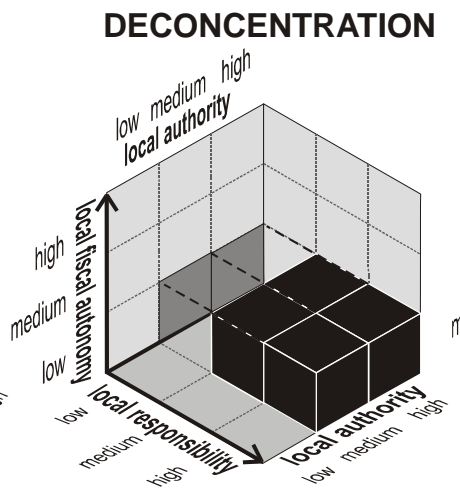

OFFLOADING

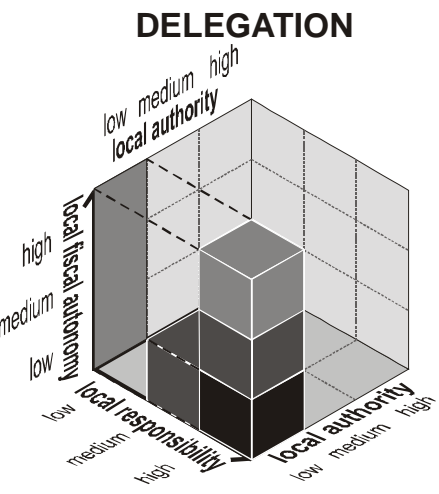

USURPATION

The centralisation option is inherent to unitary structures of governance but also is found in some federal systems, particularly in times of national crisis when central authority must supersede. The deconcentration model consists of central agencies distributing their own organisations to the local level in an effort to improve responsiveness of service delivery, or to improve monitoring and control. Both unitary and federal governance structures can deconcentrate. Some of China's central government functions have been deconcentrated to regional, provincial, and municipal governments such as customs administration and airports.

Delegation occurs when higher levels of government assign responsibilities to lower levels, most often for service delivery. While ultimate authority rests with the higher level, under delegation, conditional transfers of responsibility and authority are accompanied by increased local fiscal autonomy largely sufficient to fulfil the delegated responsibilities or by conditional fiscal transfers from the delegating level of government. Delegation is the underlying model of China's sub-national governance.

Devolution consists of the constitutional and legislative codification of authority and responsibility at the local level accompanied with almost total fiscal autonomy. This strategy by definition applies only to federal states: unitary governments cannot remain unitary under a codified model of devolution to lower levels of government.

Offloading occurs when higher levels of government assign, under their authority, functional responsibilities to lower levels but without concomitant transfer of fiscal autonomy. This is the most destabilising of decentralisation options as it invariably leads to one or more of the following outcomes: 1) failure in service delivery due to insufficient resources; 2) fiscal reallocations by local governments that 
create problems elsewhere in the system; 3) attempts by local governments to acquire capital through other means, including imprudent borrowing and illegal exactions/rent-seeking on enterprises and/or households; and 4) initially fiscal and then political conflict between levels of government. As in some OECD countries, many local governments in China consider that most of their responsibilities for social services and education have largely been offloaded from the centre.

Although certainly not a policy objective of higher levels of government, usurpation occurs when a lower level unilaterally takes over a responsibility from higher levels and asserts its fiscal autonomy by deciding on expenditures and obtaining local revenues beyond its authority. While usurpation can be avaricious, it also can occur to fill a vacuum in the absence of a higher government's capacity to exercise its responsibility (leaving local governments with little option but to usurp authority to provide services to the public), or when a new functional responsibility emerges for economic or technological reasons which was not anticipated in existing constitutional, legislative or regulatory arrangements. The latter is particularly relevant to countries in transition, such as China, without experience in anticipating outcomes of market forces.

While detailed analysis of decentralisation in China is beyond the scope of this paper, several basic observations can be made. The first is obvious: China is a unitary state and devolution of authority, responsibility and fiscal autonomy to provincial and sub-provincial levels of administration is not applicable. Decentralisation options for China are continued deconcentration of central agencies, and continued delegation to sub-national peoples' congresses and executing administrations.

Most countries are in a constant state of flux as various levels of government vie for authority, responsibility and fiscal autonomy. This is particularly true at the sub-provincial levels where institutional arrangements are typically least defined. A state of flux is certainly occurring in China today as it shifts to a market economy, and it will continue until the full impacts of market reforms are manifested. This flux will continue to be complicated by the rapid and dispersed urbanisation that is unfolding across the country which is introducing new functional responsibilities ${ }^{25}$ and expanding existing ones. ${ }^{26}$

It is not possible to capture the wide divergence in functional responsibilities among all of China's 657 cities. Figure 21 is a simplified description of current functional responsibilities affecting municipal governments in China. Most responsibilities are at the municipal level; few are today exercised directly by central government agencies (policing, tertiary education, veterans' assistance, airports, strategic ports and harbours, power generation and distribution through regional power corporations, postal services, telecommunications and radio/television (through centrally-owned corporations), and centrally-owned SOEs and zones). By and large, district responsibilities are limited to operation of enterprises owned by district governments and their undertaking units, street cleaning and solid waste collection, maintenance of local parks, land leasing (where allowed), limited primary healthcare through clinics, and some localised social welfare services. In CLCs, these functions are exercised at the municipal level.

25. For example, provision of social security benefits and education to migrant households, and provision of suburban public transport services that were previously not needed.

26. As in many other countries, the state of flux is occurring unevenly across China. Some provinces and municipalities have demonstrated their capacities to responsibly exercise increased delegated authority, responsibility and fiscal autonomy while others have not. The execution of functional responsibilities therefore varies considerably: some jurisdictions remain under heavy centralised or deconcentrated management; others have considerable delegated latitude; and others are constantly testing how much authority can be usurped. This situation applies both at the provincial level and within provinces among municipal governments (especially between PLCs and CLCs). In larger urban municipalities it is also occurring between districts, counties, and towns and townships. 
The functional responsibilities shown on Figure 21 are not universal: many cities do not exercise a number of these functional responsibilities either because the need does not exist (e.g., harbours and ports in non-coastal and non-riverine cities) or because they cannot afford to. Although most functional responsibilities have been delegated by provincial governments, a few are likely considered by some municipalities to have been offloaded (e.g., employment re-training and basic welfare support to the unemployed) while the means through which some delegated responsibilities are being exercised could be defined as usurpation of central authority (e.g., retention of all land leasing revenues).

China's "Law of The Local Peoples' Congresses and Local People's Governments" was enacted in 1979 and last revised in 1986: it does not define precise functional responsibilities that municipal governments are expected to exercise. Therefore, the delegation that is occurring is by administrative directive from the central and provincial levels. During this period of transition, understandably these directives are unpredictable and subject to modification which makes municipal planning and budgeting difficult. The delegation of responsibilities to municipal governments over the past twenty years - and uncertainty over additional responsibilities that might be delegated - has been far-reaching.

Given the differences between China's cities, at this point in the country's development it would likely be counterproductive to try to devise a model of functional responsibilities that would apply to all cities in all provinces. Rather, some latitude needs to be given to provincial governments to develop models and structures most appropriate to their particular conditions. However, to ensure basic levels of equity and efficiency, the central government needs to clearly define the lower and upper margins of municipal functional responsibilities and explicitly tie these to expenditure and revenue assignments. For this reallocation to be effective, changes must also be made to the structure of municipal and sub-municipal governance so that assignments are made to units of government that have the territorial and functional mandates to exercise their responsibilities efficiently for the benefit of all residents. This is especially true of metropolitan regions.

\subsection{Governance of metropolitan regions}

The comparatively rapid emergence of metropolitan regions in China is pushing existing forms of sub-provincial governance beyond their institutional and fiscal limits. Inefficiencies, inequities and environmental effects are incurring costs to local economies and social systems that could eventually have impacts on the speed and depth of national economic growth. Few societies in recent urban history have effectively managed the transformation from cities as islands to cities as cores of large, dynamic and complex metropolitan regions. China has the opportunity to learn from the mistakes and successes of OECD members and other countries, to modify the most relevant international practices to conform to the country's unique political, social and cultural conditions, and to apply them to harness the benefits of metropolitanisation.

Perhaps the most important task is to shift political and institutional cultures to recognise the spatial extent, complexities, and importance of the metropolitan region. This needs to be done both from the bottom up - informing local stakeholders of the benefits of metropolitan regional development and how their individual actions can incrementally strengthen or detract from efficient and effective development and from the top down, including at the highest political level. An early effort by Jiangsu province in the planning and development of metropolitan regions proved a promising start, yet challenges remain (Box 6). 


\section{Box 6. Planning and development of metropolitan regions in Jiangsu Province}

Jiangsu was the first province in China to start recognising the importance of metropolitan regions, and the first to integrate metropolitan development into its urban development strategy. The initial idea of developing three metropolitan regions in the province (Nanjing Metro-region, Xuzhou Metro-region, and Su Xi Chang Metro-region) dates back to the early 1999s and first appeared in "Urban system Planning 2001-2020, Jiangsu province". The idea, approved at the third provincial meeting on urban issues in June 2000, formed the basis of a detailed metropolitan development plan for the three metro-regions in 2002.

Perhaps the most important rationale for developing metro-regions is to extract economic spillover benefits from core municipalities serving as powerful and competitive regional centres. Jiangsu province, among others nationwide, has followed the "small city based" urbanisation strategy, which has led to an increase in the percentage of the small city urban population from 33.9\% (early 1980s) to $48.8 \%$ (1998). Large cites, on the other hand, have been excluded from the strategy and have lost much of their competitive edge compared to neighbouring Shanghai and the core cities in Zhejiang. The goal of reaping the benefits of economies of scale through agglomeration was a focus of the Provincial Master Plan 2001-2020.

Detailed metropolitan development plans have taken into consideration the contextual differences among the three metro-regions. As illustrated by Chen (2003), Xuzhou Metro-region, the recipient of limited spillover effects from the core Xuzhou municipality and with limited interactions with neighbouring urban areas and townships, is at the initial development phase. The development policy for Xuzhou focuses on cultivating the leading role of Xuzhou municipality by co-ordinating its industrial strategic planning, urban distribution, transportation networks, regional infrastructure, etc. Nanjing Metro-region, which benefits from spillover effects from Nanjing municipality, is at the growing phase. Targeting the metro-region's serious co-ordination problems, the plan aims to foster connections between leading industries in surrounding municipalities, cultivation of regional clusters, co-ordination of inter municipal infrastructure and of regional cultural amenities. Su Xi Chang Metro-region is at the mature phase. The region benefits from relatively advanced socio-economic development, yet suffers much more than either Xuzhou or Nanjing Metro-regions from coordination problems. The main problems include the identical industrial structure of surrounding municipalities, poor coordination of infrastructure development, and environmental deterioration. The primary focus of the plan is on better co-ordination with the three core surrounding municipalities (Suzhou municipality, Wuxi municipality and Changzhou municipality), in terms of regional development, city and township distribution, transportation networks, infrastructure, environmental protection, etc.

The plans have been highly regarded by the Ministry of Construction as the first attempt to tackle co-ordination problems by focusing on metro-regions. However, the results have been somewhat disappointing, particularly in terms of infrastructure construction. As pointed out by Luo and Shen (2005), 11 out of total 17 infrastructure projects in the Su Xi Chang Metro-region Plan have not been operating as smoothly as envisioned. One of the main obstacles highlighted by Luo (2005) has been competition among local stakeholders - a bottom-up force. Effective implementation has been a further challenge for developing metropolitan regions.

Source: Jian (2005), Government without Governance: Regional Governance and the Cooperative Strategies within the City-region of Changjiang Delta; Wang (2003), Exploration and Renovation of Regional Township System Planning; Luo et Shen (2005), Why Urban Region Planning Does Not Work Well? - Lessons from Suzhou Wuxi Changzhou Metropolitan Coordinating Regional Planning.

A second important consideration is to review and perhaps rationalise the number and responsibilities of administrative jurisdictions in the majority of the country's metropolitan regions. Most current administrative boundaries and governmental jurisdictions were established decades ago (in some cases, centuries ago) to govern an agrarian nation. Economic and social forces are creating a fundamentally different kind of society that will increasingly live within or near to the country's metropolitan regions. Current administrative units are extremely fragmented in many of these regions making inter-jurisdictional co-ordination and collaboration - a hallmark of well-functioning metropolitan regions - very difficult for all levels of government. In many areas, there are more than ten municipalities within a functional metropolitan region (PLCs, CLCs, and counties), and well over 100 relatively autonomous towns and townships.

Efforts are underway in some Chinese cities to rationalise the local system of government by converting counties into municipal districts, and transforming suburban towns into more formalised Street Committees, for example, in Guangzhou and Hangzhou. The process needs to be broadened to other cities and accelerated so that at least those counties within which suburban corridors and clusters are developing 
become suburban districts of the core metropolis, and under the direct governance of its municipal government. In some cases this might require annexation of parts of adjacent counties as was done in many other OECD countries (e.g., Australia, Turkey, Canada, Korea, Spain).

Figure 21. Generalised functional responsibilities in China's urban municipalities

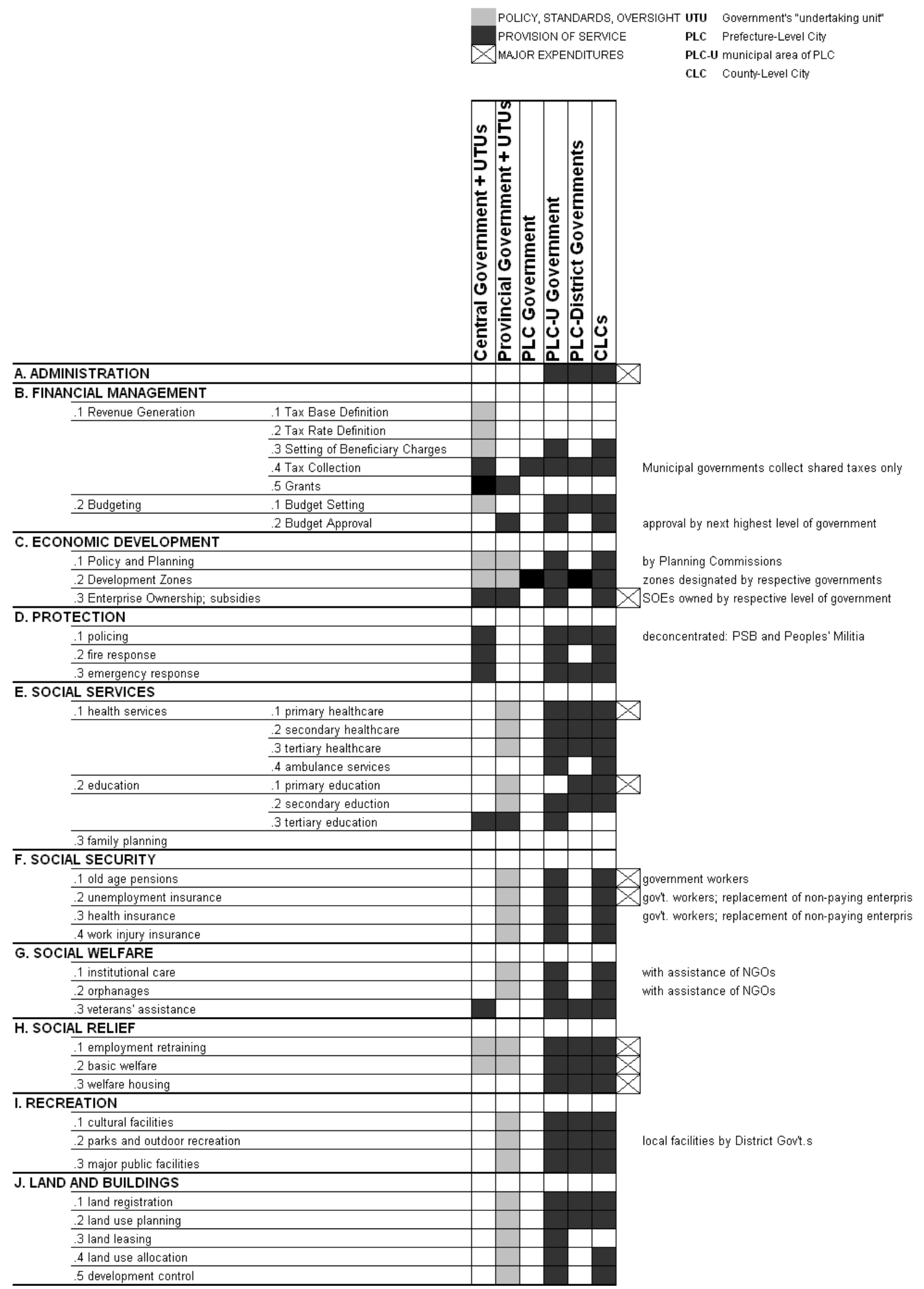


Figure 21. Generalised functional responsibilities in China's urban municipalities (cont.)

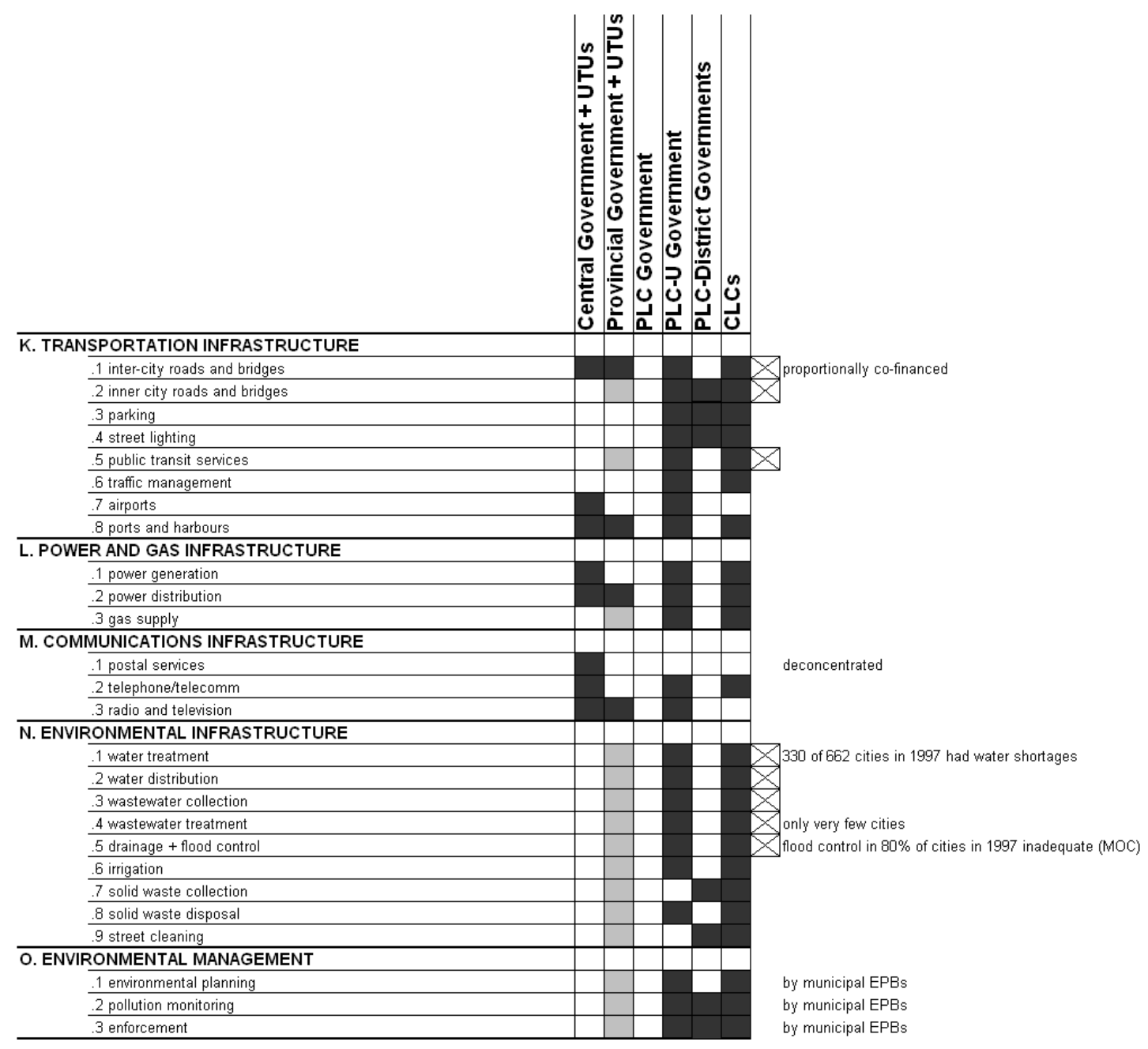

Statutory towns are another jurisdiction requiring restructuring. In many of China's metropolitan regions there are significant opportunities to generate economies of scale and improved efficiencies by amalgamating adjacent towns and townships, and converting towns and townships in districts into Street Committees (Box 7). The latter is admittedly more complex since it implies the need for municipalities or districts to eventually change collectively-owned land in towns into state-owned land. However, there are cases where the transformation has occurred without this change in land ownership, ${ }^{27}$ and it should not necessarily be a major roadblock to rationalisation of administrative units in suburban areas. The biggest challenge is widening entitlements to urban public services for residents of these towns as they become more regularised into Street Committees in districts. These Street Committees are responsible for delivery of social services, clinics, and cultural facilities. To be designated a Street Committee, land must be stateowned under the current regulatory arrangement.

27. For example, the Guangdong Provincial Government is conducting pilot projects along these lines. 


\section{Box 7. The annexation process in Chinese metropolitan regions}

The annexation of surrounding counties and statutory towns by core municipal metropolitan regions has increased in coastal China (especially the Yangtze River Delta region and the Pearl River Delta region) since 2000. This administrative restructuring is the model viewed most favorably by the government, probably because it reduces the costs associated with the negotiation and bargaining process between the municipality and neighboring towns or counties (Jian, 2005). The restructuring can also simplify administrative procedures over a larger area as these procedures are then carried out in a single municipality rather than in several separately. Moreover, as most metropolitan regions start out fairly small, the drive for industrial development encourages them to expand and gain land from the surrounding counties and towns for this purpose. Through the creation of a larger metropolitan region, the government can more easily exploit the area's potential economy of scale and enhance city competitiveness. The below table indicates that most municipalities have expanded drastically, ranging from 2.5 times (Ningbo) to 6.65 times (Changzhou) their original size. Shanghai municipality was among the first to expand in 1958, when 10 counties originally from Zhejiang and Jiangsu provinces were annexed to it under the "city controlling county" system. Since the 1980s, the process has been furthered by converting these counties into municipal districts. It is of note that the process was relatively simple in Shanghai as the provincial level municipality is far more powerful than in prefecture level cities like Guangzhou.

\begin{tabular}{|c|c|c|c|c|c|}
\hline \multicolumn{6}{|c|}{ Annexation in selected China metropolitan regions (2000-2003) } \\
\hline \multicolumn{3}{|c|}{ Prefecture-level cities } & \multicolumn{3}{|c|}{ Townships or counties } \\
\hline $\begin{array}{c}\text { Municipality } \\
\text { name }\end{array}$ & $\begin{array}{l}\text { Area (before } \\
\text { annexation) }\end{array}$ & $\begin{array}{c}\text { Area (after } \\
\text { annexation) }\end{array}$ & Name & Area & $\begin{array}{l}\text { Time being } \\
\text { annexed }\end{array}$ \\
\hline Nanjing & 1026 & 4728 & $\begin{array}{l}\text { Jiangning } \\
\text { county, } \\
\text { Liuhe county, } \\
\text { Jiangpu county }\end{array}$ & 3702 & $\begin{array}{c}2000.12 \text { and } \\
2002.4\end{array}$ \\
\hline Hangzhou & 683 & 3068 & $\begin{array}{l}\text { Xiaoshan } \\
\text { township, } \\
\text { Yuhang } \\
\text { township }\end{array}$ & 2385 & 2001.2 \\
\hline Guangzhou & 1400 & 3719 & $\begin{array}{l}\text { Panyu } \\
\text { township, } \\
\text { Huadu } \\
\text { township }\end{array}$ & 2319 & 2000.5 \\
\hline Suzhou & 392 & 1650 & Wuxian county & 1258 & 2000.4 \\
\hline Wuxi & 517 & 1631 & $\begin{array}{l}\text { Xishan } \\
\text { township }\end{array}$ & 1114 & 2000.12 \\
\hline Changzhou & 280 & 1864 & Wujin & 1584 & 2002.4 \\
\hline Ningbo & 1033 & 2560 & Jin county & 1527 & 2002.2 \\
\hline
\end{tabular}

Note: Unit: square kilometres. 
But changing boundaries and administrative designations will not, on their own, improve metropolitan governance. These actions should be viewed as a first step at rationalisation to enable the re-allocation of functional responsibilities (and hence fiscal revenue assignments and expenditure responsibilities) among levels of government to support the efficient and equitable development of China's metropolitan regions.

The third key concern involves barriers to co-ordination between metropolitan regions. A lack of co-ordination has resulted in inefficient policy making and has had detrimental impacts, such as airports being built close to neighbouring cities in both the PRD region and the YRD region. Attempts to reduce co-ordination problems are not new, as is evident from the 1982 "Shanghai Economic Zone initiative". The initiative was taken by the State Council, with the aim of breaking down administrative barriers, and fostering inter-province and inter-city co-ordination through the establishment of an Economic Integration Zone covering seven or more cities neighbouring Shanghai. Despite proactive involvement from the central government, the "Shanghai Economic Zone initiative" was never fully implemented. Perhaps the fundamental reason for its failure was the lack of incentive to broaden the scope and strategy for development beyond administrative boundaries and to further involve players from other metropolitan regions. This lack of incentive is also at the heart of the co-ordination problems within metropolitan regions. It was not until 1997 that the "Association of Economic Coordination in YRD Cities" was created, marking significant progress in regional integration in YRD cities. The Association holds regular mayoral meetings once every two years to involve local governments in the discussion and is also responsible for the co-ordination of concrete tasks. The Association has made a marked contribution to regional integration in YRD region, due to the strong commitment of local governments ( $\mathrm{Li}$ and $\mathrm{Xu}, 2005)$.

Co-ordination problems have been further complicated by the way metropolitan governance is structured in China; most notably the hierarchical arrangement which places the sub-provincial cities (which report directly to central government) at a higher level than the PLCs. Shenzhen is a case in point. In Guangdong, the provincial capital of Guangzhou enjoys privileges that Shenzhen does not, as is evident from preferential policies put in place by the provincial government to strengthen Guangzhou's central position within the province. For example, Guangdong's tenth five-year plan (2001-2005) places Guangzhou at the core of the emerging Greater PRD inter-city rapid transit system and highway network. Furthermore, in 2000, the inclusion of former county-level cities Panyu and Huadu in an enlarged Guangzhou increased the total land area from 1400 to $3719 \mathrm{~km}^{2}$. Although this favouritism is justifiable in the sense that Shenzhen has made little contribution in taxes to the provincial government over the years because of its status as "special economic zone", the lack of co-ordination and biased provincial level policies have already led to inefficiencies.

\section{Key policy challenges}

\subsection{Becoming and staying competitive}

Urban economic analysis over the last century has repeatedly identified three economic benefits to urbanisation (often called agglomeration economies): 1) urbanisation economies, in which large input (e.g., labour and land) and output markets are shared between industries; 2) localisation economies, in which firms can improve productivity through the sharing of inputs related to their specific industry (including trained labour and the tacit sharing of knowledge); and 3) economies of scale, in which the size of markets reduces input unit costs of larger means of production (including public infrastructure; e.g., a large water treatment plant rather than several smaller facilities). If they are realised, urban agglomeration benefits spawn the formation of new enterprises (including small and medium sized enterprises), increase firms' productivity, expand the scope of production, create and sustain employment, and diversify employment opportunities for a wide range of skills. They are therefore essential to achieving and sustaining cities' competitiveness in the globalising economy. 
For cities to generate agglomeration economies they must provide: 1) open access to markets, or the ability of firms and households to enter, operate within, and exit a sectoral or locational market; and 2) factor mobility, or the capacity of labour, intermediate inputs, knowledge, and capital to move unencumbered around the urban region. Both access to markets and factor mobility can be impeded by institutional constraints, such as trade barriers, constraints to business establishment, access to capital markets, and employment restrictions. In China, institutional impediments continue to be carried over from the centrally-planned era that constrain equal access to input and output markets by non state-owned firms. These include procurement policies of municipal governments and their corporations that favour locallyowned state firms, the vertical supply relationships of state-owned enterprises, business licensing requirements, employment regulations, and restricted access to credit. The weak integration of suburban enterprises into supply chains impedes the realisation of full agglomeration economies in many of the country's metropolitan regions. While the central government has been actively promoting such integration over the last few years - particularly given the growth of the non-state sector - many local governments continue to protect market access and to control the mobility of key factor inputs.

One of the most important bottlenecks to agglomeration economies in China's cities and suburban areas are distortions in land markets that constrain the availability of serviced land, drive up the price of available land, and hence limit the locational choices of enterprises and households. In core cities the old practice of administratively designating land use rights to state-owned enterprises is changing, but in many places not fast enough to respond to new demands for land. In suburban areas, the collective land ownership system precludes individual farming households from negotiating market prices directly with developers: town governments decide on what land is sold and at what price, and pay compensation to displaced households, often at rates far below market value.

Market access and factor mobility are also directly affected by physical constraints to movement within urban regions. In addition to the congestion effects raised earlier, most metropolitan regions provide very limited transport access between the core city and suburban towns, and between these towns. This limits the participation of suburban workers in metropolitan labour markets (including a growing number of migrants who would prefer to reside in lower-rent suburban areas), and constrains the development of efficient supply relationships for suburban enterprises. Aside from equity concerns, limited physical access drives up prices of inner-city labour and land - and reduces competitiveness accordingly. While institutional constraints to the realisation of agglomeration economies are complex, physical mobility constraints can be addressed through improved road connections to and between suburban towns, and the expansion and upgrading of public transport systems.

Access constraints to land and labour markets are complex institutional issues and are at the root of urban governance and fiscal arrangements in China. They are in many respects unique: very few countries have similar systems and experience that could be shared. Until these issues are resolved, agglomeration economies are not likely to reach the full potentials that would improve and sustain the global competitiveness of China's cities.

\subsection{Environmental challenges}

Air and water pollution continue to be serious problems in China's cities, and are now spreading across previously rural parts of suburban areas.

China's cities face serious challenges in the quantity and quality of water. Nationwide, there is a gap between urban water demand and supply of 6 billion $\mathrm{m}^{3}$ per year, or 16 million $\mathrm{m}^{3} / \mathrm{day}$. The Ministry of Water Resources (MWR) estimates that this costs China RMB 200-300 billion of lost industrial output value annually (Ministry of Water Resources, 2004). Of China's 657 cities, MWR reports that 420 had water shortages at the end of 2003: 110 of these have "severe" shortages. While major water diversion 
projects (and per capita demand reductions likely to be induced by higher costs of diverted water) are planned to address shortages in some northern cities during the next few years, there are many cities in central and southern China that are designated as "water shortage" cities. While these cities have enough available water, their problem is that much of it is too polluted to use.

In 2001, 53\% of monitored sections of the seven key river systems in China had water quality at Class V or lower. The regional conditions were stark: $63 \%$ of the monitored stretches of the Yellow River were Class V and worse, $60 \%$ of the Huai River system, $75 \%$ of the Hai River, and $69 \%$ of the east section of the North-South Water Diversion system. Comparatively better aggregate figures for the Pearl and Yangtze Rivers mask serious local water pollution problems in urban areas. Detailed assessments show that virtually all of the Pearl River Delta in the Guangzhou metropolitan region is below Class V in dry season; the same applies to Shanghai. Every city in China has varying levels of water pollution; no city has facilities that treat water that can be consumed directly without boiling (Box 7).

\section{Box 8. Challenges from water pollution in Chongqing}

Dynamic economic development, growth in industrial activities and urban expansion brought increasingly visible environmental problems in Chongqing Municipality. Chongqing is the largest source of water pollution upstream of the Three Gorges Dam. The pollution streams are derived from different sources (households, industrial discharges and agriculture run off). Untreated wastewater from households and agriculture run-off are the largest sources of organic pollution with high social impacts. The proximity of the Three Gorges Dam reservoir area makes water pollution particularly acute as its ecological balance is directly influenced. Industrial discharges from many metallurgy and chemical installations add to water problems as many plants employ older technologies and lack pollution prevention and abatement equipment.

In order to meet Chongqing's long-term objectives concerning health, ambient and water quality, there is a need to increase investments and management efforts in urban water supply and sanitation (including in new urban development projects). This, however, requires major legal and institutional reforms that include: 1 ) clarifying the legal status of project owners and property rights to wastewater infrastructure; 2) giving wastewater enterprises more financial and operational autonomy (e.g., a more direct access to revenue of wastewater charges) and more responsibilities (e.g., for wastewater collection); 3) making wastewater enterprises responsible and accountable for the development and operation of infrastructure; 4) clarifying division of roles and responsibilities between wastewater enterprises and municipalities through performance contracts; and 5) ensuring predictable and consistent increase of tariffs for wastewater infrastructure that would allow wastewater enterprises to pay all operating expenses, repairs, taxes and total debt service obligations.

Source: OECD, Chongqing Municipality's Development Strategy: some reflections from the international experience of the Territorial Development Policy Committee of the OECD.

These water pollution problems are not new. What is changing, however, are the contributors to urban water pollution and the extent of this pollution. The shift from farming to non-farming employment in suburban areas has been made possible by maintaining and often increasing the productivity of suburban farmland through greater use of fertilizer and pesticides, and the shifting of agricultural production into higher value-added foodstuffs such as fruits and vegetables, and poultry and livestock which create animal waste. The result has been increasing water pollution loads from non-point sources in suburban areas flowing into urban water sources, and the pollution of suburban surface and groundwater sources that are typically extracted without treatment for consumption by residents and enterprises in suburban towns. Despite the huge investments in domestic wastewater infrastructure in urban areas directed by State Council since the start of this decade, there is a strong likelihood that surface and groundwater quality will 
deteriorate in many cities because of non-point pollution in areas outside the purview of municipal governments' monitoring and control.

While progress is being made in many cities on control of $\mathrm{SO}_{2}$ through upgrades to thermal power generation infrastructure, a growing contributor to air pollution is carbon monoxide (CO) and nitrogen oxide (NOx) from motor vehicle emissions. The International Energy Agency and the World Business Council on Sustainable Development have recently prepared projections of motorisation and associated NOx from motor vehicles that show, in a conservative baseline scenario, a 72\% growth in road vehicles in China from 2005 to 2015, and a concomitant 35\% growth in NOx emissions only from light duty vehicles (Figure 22). Most of this growth will occur in and around metropolitan regions.

Figure 22. Growth of motor vehicle population and associated NOx emissions, PRC and India (2000-2015)

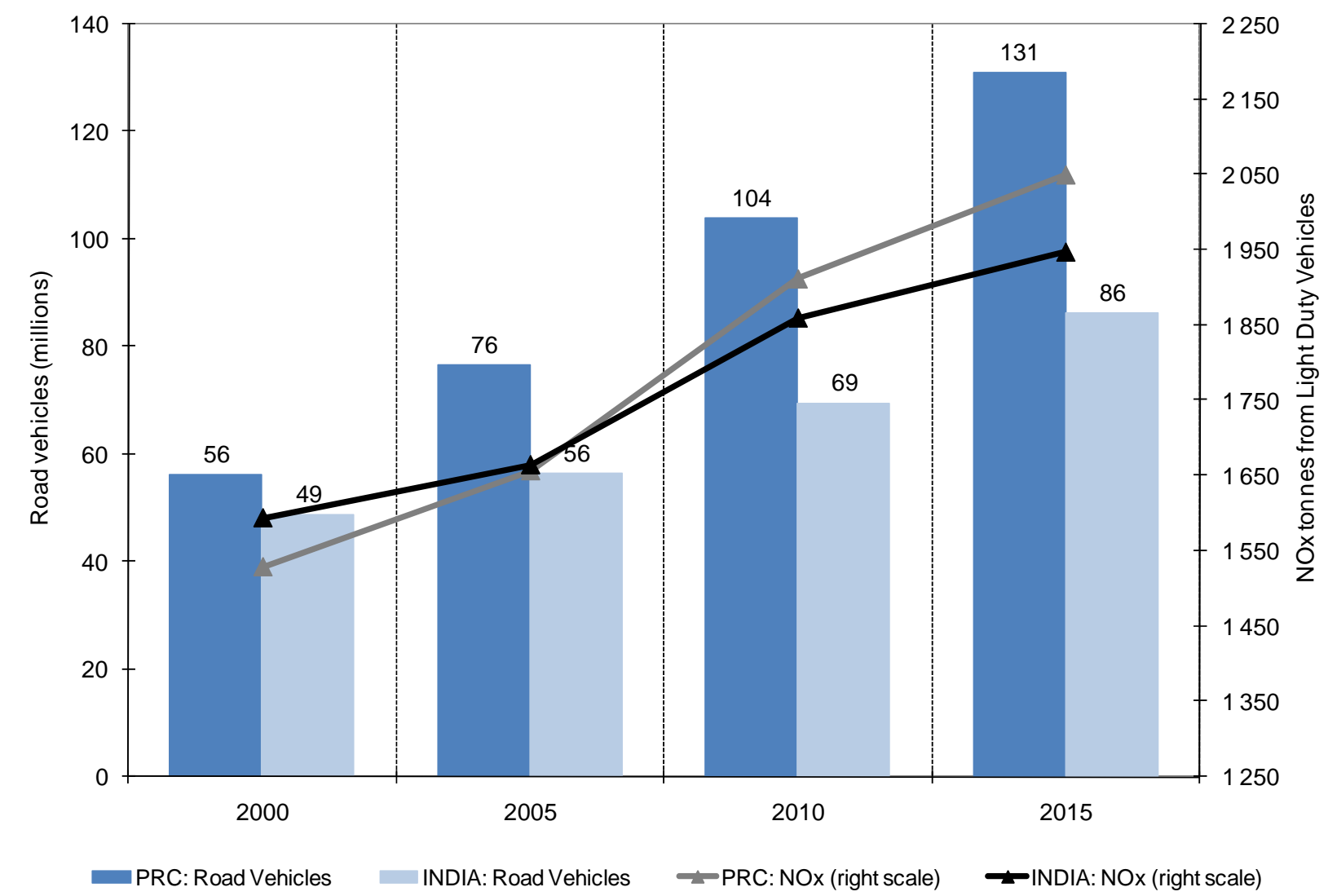

Source: Calculated from The IEA/SMP Transportation Model, World Business Council on Sustainable Development, www. wbcsd.org/plugins/DocSearch/details. asp?type=DocDet\&Object/d=MTEONjc.

Figure 21 illustrates three major negative externalities to urbanisation in China that are rapidly becoming major public policy issues: 1) rapid growth in motorised transport that will seriously exacerbate growing traffic congestion not only in central cities, but in many suburban areas as well; 2) growing air pollution from vehicular emissions; and 3) major growth in absolute and per capita consumption of energy for transport. The latter highlights additional energy demands that urbanisation will incur for electric power, 
heating, manufacturing, and construction in and around cities. As the central government has been concentrating on industrial pollution controls since the early 1990s, particularly SEPA, there has been major progress across the country on reduction of $\mathrm{SO}_{2}$ as a result. There has been no regulation on transport pollution except on fuel type and PM and NOx are getting worse in Chinese cities because of traffic.

Land consumption is also becoming a far more serious issue. With the increased mobility of factor inputs facilitated by market reforms over the last 20 years, many of China's metropolitan regions are beginning to expand rapidly through un-directed suburbanisation. The result is consumption of agricultural land and growing urban sprawl that is causing inefficiencies in land use, land markets, goods transport, public transport, and public services all of which undermine agglomeration benefits. This is occurring not only in the major coastal metropolitan regions, such as Shanghai and Guangzhou, but also inland in smaller regions such as Chengdu. For example, time-series analysis of satellite imagery shows that built-up land areas in large parts of suburban Chengdu grew by 300\% in a six-year period (1996-2002) and built-up parts of large areas of suburban Shanghai expanded by 350\% from 1988 to $2002 .{ }^{28}$ Concerns over rampant conversion of agricultural land have triggered periodic inspections and clampdowns by the Ministry of Natural Resources and Lands, but the basic problem remains that, under the current fiscal system in China, leasing of land use rights accounts for a large proportion of local government financing. ${ }^{29}$

Municipal solid waste will increasingly contribute to consumption of suburban land, and to air and water pollution. Growing purchasing power and the broadening of consumption options in urban markets will intensify the incremental volume of solid waste generated by an additional 160 million new urban residents in the next ten years. The World Bank estimates that municipal waste generation in China will grow from 195 million tons in 2005 to 306 million tons in the year 2015, partly through an increase in per capita waste generation from 1.1 to $1.3 \mathrm{~kg} /$ person/day during this period. These estimates, however, are for the urban areas of cities, and do not include waste generated in the expanding suburban areas of metropolitan regions (World Bank, 2005).

\subsection{Ensuring equity}

Of particular importance to the stable development of China's metropolitan regions is that their more vulnerable populations become better integrated into urban and suburban communities. There appear to be six major groups of vulnerable populations in many of China's metropolitan regions: 1) laid-off and unemployed urban workers; 2) newly-graduated students looking for work; 3) the chronically "old poor" who are under the support of civil affairs bureaux; 4) migrant workers and, increasingly, their families; 5) 'landless farmers' in suburban areas; and 6) over the longer term, a significantly expanded cohort of the elderly. Municipal governments are largely coming to terms with their responsibilities for the first three vulnerable groups, but significant attention has yet to be paid to the needs of migrants, "landless farmers", and the ageing population all of whom are distributed far more widely in towns and villages across metropolitan regions.

The widespread dismantling of State-Owned Enterprises (SOEs) in the 1990s and early part of this decade eroded the enterprise-based social security system through which SOEs had provided a full range of welfare coverage to all employers and their families, including housing, pensions, and health care. Millions of urban residents lost their livelihoods due to the commercialisation of non-compensatory "entitlements" resulting from SOE reforms.

28. Based on analysis of time-series satellite imagery by Chreod.

29. Revenues from leasing of land use rights accounts for $30-50 \%$ of annual fiscal revenues for most cities, and up to $80 \%$ in smaller cities (Huang Xianjin, 2005). 
In China, all "five major social insurances" (old age pension, medical, unemployment, workers' compensation, and maternity benefits) are currently reserved for residents with urban hukou, as is the "minimum living standard insurance" (MLSI). Introduced in the late-1990s to respond to SOE layoffs and closures, MLSI is now the principal mechanism for addressing the needs of China's urban poor. The subsidy is available only to urban residents with household registrations in the host urban jurisdiction with amounts set and funded by municipal governments. The cost of urban MLSI is commonly split between city governments and their constituent district governments. Local governments set their own poverty lines in accordance with different price levels: in practice, poorer cities tend to adopt stricter standards when defining "poverty". Laid-off workers from SOEs comprise 54\% of MLSI recipients, a number which is likely to increase as other avenues of welfare relief (unemployment insurance) become exhausted. While the chronically unemployed are dispersed throughout the country, they are more concentrated in the former industrial heartlands of the northeastern provinces and in the scattered military/industrial complexes of the interior provinces. Thus, a heavy social welfare burden falls disproportionately on some municipal governments, hindering their economic development and causing them to fall further behind.

Rural migrants in cities lack affordable access to adequate housing, safe and secure employment, and are rarely included in any formalised social welfare system. Although it is now being gradually addressed, the household registration system has impeded the free flow of labour into the formal employment sector. However, the dynamism inherent in a more flexible labour market has been evidenced by migrant workers making substantial contributions to metropolitan regional economies with unemployment generally at much lower rates than for registered urban residents. In some cities as much as $80 \%$ of the retail service sector is occupied by migrant labour. Such success is especially laudable in view of migrants' insecure legal status, and institutional barriers to their employment, schooling and social welfare provisions.

Urban welfare systems and rural land arrangements are the main institutional barriers to labour mobility. High costs of child-care and schooling also hinder rural families migrating to the urban areas. Because of institutionalised discrimination against migrants, they have traditionally borne heavier costs for healthcare and education. Responses by the migrant community to organise "informal" schools (offering reduced tuition rates) for their children has created a two-tiered educational system, excluding migrant children from mainstream educational opportunities. Housing costs in urban areas are also an important barrier. These existing barriers increase the migration cost, and probably dampen flows to cities and suburban areas.

Migrants are not only an issue in central cities. While the highest numbers and densities of migrants are found in the cores of metropolitan regions, high concentrations are also found in selected suburban towns. Suburban concentrations are directly related to employment locations: they are more dispersed in larger and more rapidly-expanding metropolitan regions such as Shanghai. Responding to social needs of migrants is therefore becoming a growing issue for town governments, not only for the municipal government in the core metropolis.

Local governments in metropolitan regions - including town governments - might consider exploring the introduction of a minimum set of secured and codified rights to migrants. The most basic measure is granting of urban hukou in exchange for rural migrants transferring their land use rights to collectives in locations of origin. Governments might also consider put it differently, not as a recommendation removing remaining regulatory barriers to entry into urban and suburban labour markets, such as mandatory registration and associated fees.

Migrant housing also needs to be addressed. Most migrants currently rent accommodation, including on farms in suburban areas. Minimum living standards of rental housing would protect migrants from arbitrary and usurious rent hikes. Long-term rental agreements could be structured that codify rights and responsibilities both of tenants and landlords. 
Since an increasing number of migrants are likely to move to metropolitan regions at least with their immediate families, governments in urban and suburban areas are facing the challenge to address the education needs of migrant children. The informal migrant schools that are springing up, particularly in suburban areas, need to become integrated into the formal education system to ensure that minimum standards are maintained and that affordable access is assured for all families.

Affordable employment training for migrant workers - which is responsive to needs of urban and suburban employers - needs to be provided in metropolitan regions and not, as is the case today in a few areas, through minimal orientation training of prospective migrants in their original towns and villages. While the minimal, village-based orientation is useful, it does not come close to meeting the training required of a skilled metropolitan workforce.

While the government has repeatedly called for the acceleration of urbanisation to towns and small cities (as recently as in the Tenth Five Year Plan), the biggest constraint still appears to be the absence of social safety nets for migrants to urban and suburban areas. Migrants are reluctant to make permanent moves when the only social security they have is their rural landholding. China's existing social security system in urban areas was largely designed to support the huge SOE workforce that was being exposed to unemployment from SOE restructuring reforms started in the 1990s. As formation of foreign-invested enterprises began to increase, they were added to the system along with government employees, many of whom were laid off or re-assigned during the massive downsizing of the public service several years ago. This system now apparently serves $45 \%$ of the eligible urban workforce. It is a very generous system, and carries high costs to local governments (many of which require annual bailouts through ad hoc transfers from the central government to meet payouts). It is highly unlikely that this existing system will become affordable to small, domestic enterprises and new workers (migrants, landless farmers, graduating students). Governments simply do not have the fiscal capacity to provide for universal coverage across metropolitan regions at current benefit levels.

In addition to the rural social security programme with which the central government has experimented over the last several years, consideration needs to be given to establishing a new, scaleddown social security system to meet the growing needs of unserved populations within metropolitan regions. Additional participation in the expensive, existing urban social security system should be limited to the comparatively few remaining SOE workers, and then gradually phased out as needs decline. A new system could provide coverage to all workers in the metropolitan region at lower benefit levels that are affordable to firms and users. Aside from providing wider coverage and at least a minimum standard of security to migrants (which should help to loosen their bonds on rural landholdings), the new, lower-cost system would decrease the often onerous business operating costs across metropolitan regions.

The promotion of urbanisation in strategic towns and smaller cities in metropolitan regions will largely depend on the removal of constraints to migration posed by: 1) labour mobility restrictions still pervading from the hukou household registration system; 2) shortage of affordable housing for migrants in suburban towns and their often uncertain tenure; 3) limited access to and inconsistent availability of affordable social services at acceptable standards, especially education and health; 4) lack of access to at least a basic level of social security; and 5) in some areas, formal and informal constraints to migrants entering the town-based labour market. Constraints to in-situ urbanisation also need to be removed, particularly the arbitrary compensation paid by town governments to farmers for conversion of their land to urban uses (creating the new non zhuan fei population of "landless farmers" who are no longer farming, but are not integrated into urban/suburban non-farming labour markets), the absence of training mechanisms to support the transition of these farmers to non-farming occupations, and, in bigger towns and those now within suburban districts, the limited access to affordable public services that are available to more established "urban" neighbours. 
A final group of vulnerable residents emerging in many of China's metropolitan regions are the elderly. While current systems appear to be providing most of the needs of the existing aged population, few municipal government and stakeholders are aware of a profound and inexorable shift in the country's demographic pattern that will unfold over the next 15-20 years. China's population is ageing rapidly. By 2020, a fundamental change will have occurred with a shrinking of the population under 40 years of age, and the expansion of the proportion over 50 years. This will have major impacts on demand for health services, for social services for an ageing population, and on the planning and design of land uses and transport systems. Municipal governments in metropolitan regions might begin now to model and analyse these likely impacts, and to develop strategies that gradually address them. In addition, governments need to start assessing the fiscal impacts of this demographic shift, and how they will finance the more complex demands of an increasingly aged population.

Achieving equity among diverse populations in urban areas is a challenge facing city governments across the world. OECD member countries have experimented with a wide range of policies and instruments directed specifically towards the needs of vulnerable urban residents. These efforts are ongoing, but experiences so far might serve to inform the relatively new public policy challenge in China of ensuring equitable access to the economic and social benefits offered by urbanisation, especially in metropolitan regions.

\subsection{Improving metropolitan governance}

The core public management issue in metropolitan regions is ensuring that planning and service areas are congruent with areas of market demand. The key constraints to the emergence of agglomeration benefits across China's metropolitan regions today are the gaps in planning and provision of urban-type services in suburban areas. The standard practice in China's cities is for municipal governments to provide services to a narrowly circumscribed population within urban districts, often defined physically by a ring road. This conventional view contrasts sharply with the pattern of new demand for public services in suburban parts of emerging metropolitan regions.

The public policy dilemma is therefore two-fold: providing to former farming households and new, largely informal enterprises public services at higher standards (and cost); and providing new regional public services that generate and sustain agglomeration benefits at a scale that transcends the jurisdictions of current forms of sub-provincial governments. Applying the principle of subsidiarity within metropolitan regions can ensure that management and service-delivery take place at the government level closest to the user of the service. In this way, government services that traverse districts, such as metropolitan planning and the provision of public transit and wastewater treatment, are administered at the metropolitan region level, while local services such as community planning and solid waste collection are the responsibility of local service providers. Governments in metropolitan regions elsewhere in the world have addressed these issues in various ways.

All of these options have been applied with varying degrees of success in other countries. All may have some relevance to management practices within China, but the application and potential effectiveness will vary, depending on the specific context of each metropolitan region. Some municipalities may find that sets of services are most effectively delivered in differing ways, for example water and wastewater services through a federated model, public transport through public-private partnerships, and solid waste treatment through inter-municipal service agreements.

Whatever the best combination, each metropolitan region needs to develop strategies and actions plans for the planning and delivery of regional public services across their demand areas, including to outlying, more vulnerable populations. This is also needed to ensure economies of scale in the regional delivery of social and infrastructure services. Current trends in a number of sectors - especially water 
supply, wastewater management, and solid waste management - are that individual jurisdictions are investing in their own small, inefficient infrastructure facilities to address market demands within their narrowly-defined administrative boundaries. This contrasts starkly with approaches in more integrated and efficient metropolitan regions in OECD countries.

A final challenge is for governments to structure mechanisms through which a far wider range of stakeholders can be given the chance to participate in the monitoring and analysis of social, economic, urban development and environmental trends in metropolitan regions, in the setting of development and management policies, and in the review of investment and service delivery programmes.

\section{Conclusion}

Although China became the world's largest urban nation more than thirty years ago, urbanisation only began to gradually accelerate ten years later. The growing speed and momentum of urbanisation over the last 20 years has been such that more than half of the country's people will live in urban areas by the early part of the next decade. This is less than most OECD countries but in absolute term, this represents the largest urbanising nation ever in human history. A growing proportion of urban residents will live and work in metropolitan regions - a form of settlement that is relatively new to China, but that is now clearly driving the country's explosive economic growth. As China continues to integrate with the globalising economy, its competitiveness will increasingly be driven by the capacities of its metropolitan regions to improve the productivity of enterprises in ever-widening supply chains. These metropolitan capacities are not only in the bricks and mortar of infrastructure. More importantly, they include the knowledge and skills of workers, and the social capital needed to trigger and sustain innovation that is shared among firms. But China's cities are more than economic engines. They are places in which families are raised, where children are educated, and where the elderly expect to live in good health and with dignity. They are also places where many farmers and their families will increasingly want to create their futures.

After four decades of slow - and at times declining - urbanisation, China is now irrevocably set on a trajectory of urban growth such that more than $50 \%$ of the country's population will live in cities by the end of this decade. Its national economy is already concentrated in cities: almost 65\% of China's GDP is now produced in its 53 metropolitan regions, a share that grew from 55\% over the last ten years. These metropolitan regions form the cores of 28 larger Regional Urban Systems that hold almost $60 \%$ of China's population and produce almost $90 \%$ of the country's GDP in increasingly interconnected networks of large and small cities, towns, and rural villages.

The size and speed of China's urbanisation are having growing impacts on global flows of capital, commodities, products, technology, and people, and on the global environment. OECD countries will increasingly need to consider these impacts on a broad range of national and international policies.

This report reviews urban and regional development trends and the evolution of public policies and governance structures that have both contributed and responded to these trends. Urbanisation policy has evolved from a decidedly anti-urban stance in the 1950s and 1960s to measures favouring small cities and towns in the last two decades, to recognition at the start of this decade that urban growth, and the agglomeration attractions of metropolitan regions, are both inexorable and essential if China's rapid development is to be balanced and sustained. In historical terms, urbanisation is a relatively new phenomenon in China, and government is still seeking to better understand its scale, underlying processes, stimuli, impacts, costs, and benefits to inform more effective public policy.

While the scale of China's urbanisation - and the growing number of metropolitan regions within which this urbanisation is concentrating - are unprecedented globally, the issues confronting all levels of government in managing this growth are not unique. Most OECD countries have needed to address a wide 
range of metropolitan management challenges, and are continuing to acquire valuable experience in doing so. A key challenge in many countries has been to define the most effective and efficient allocation of functional responsibilities among various levels of government in the metropolitan context. Defining who does what provides the framework through which the structures and processes of metropolitan governance can be refined, realigned, or even entirely re-designed.

China has, in its long history, dealt with enormous challenges, and will do so again in maximising national benefits of urbanisation and mitigating its negative impacts. What is unclear today, however, are the economic, social, and environmental costs of meeting these challenges, the higher costs incurred by lagging, uncoordinated and piecemeal actions, and which generations will ultimately pay these costs. Successes and failures in other countries, including members of OECD, could inform public policies for China that minimise the costs and maximise the benefits inherent to well-managed cities. 


\section{ACRONYMS}

CLC County-level city

CPC Communist Party of China

FYP Five Year Plan

GDP Gross Domestic Product

GIS Geographic Information System

ICT Information and Communications Technology

LSB Land Supervision Bureau

MLNR Ministry of Lands and Natural Resources

MLSI Minimum Living Standard Insurance

MR Metropolitan region

NBS National Bureau of Statistics

NTHS National Trunk Highway System (expressways)

PLC Prefecture-level city

PLC-UA Urban area (districts) of PLC

PRC People's Republic of China

RUS Regional Urban System

SEPA State Environmental Protection Administration

SOE State-Owned Enterprise

RMB Yuan (unit of Renminbi, national currency) 


\section{REFERENCES}

Blunden, Carolin (1983), Cultural Atlas of China, Phaidon Press, Oxford.

Huang Xiajin (2005), “The Relationship of Housing Price and Land Price in China: Observation and Policies” (in Chinese), accessed from website of Nanjing Municipal Land Reservation Center, www.nj-tudi.com/html/special-news-details.php?news_id=90.

Jian (2005), Government without Governance: Regional Governance and the Cooperative Strategies within the City-region of Changjiang Delta (in Chinese).

Leman, Edward (2005), “Metropolitan Regions: New Challenges for an Urbanizing China”, paper presented to World Bank/IPEA Urban Research Symposium, 4 April 2005, Brasilia, Brazil.

Li, Shantong (2008), “The Choice of Pattern of Urbanization in China” (in Chinese), background report for the 2008 China Development High Level Forum, Beijing, China.

Luo and Shen (2005), Why Urban Region Planning Does Not Work Well? - Lessons from Suzhou Wuxi Changzhou Metropolitan Coordinating Regional Planning (in Chinese).

Mckinsey Global Institute (2008), “Preparing for China’s Urban Billion”, www.mckinsey.com/mgi/reports/pdfs/China_Urban_Billion/MGI_Preparing_for_Chinas_Urban_Bil lion.pdf.

Ministry of Construction, China (2006), Urban Construction Yearbook 2005, Ministry of Construction, Beijing.

Ministry of Water Resources, China (2004), “Water Supply and Demand in China’s Cities 2003” (in Chinese), www.mwr.gov.cn.

National Bureau of Statistics, China (various years), Statistical Yearbook of China, NBS Press, Beijing.

OECD (2002), Redefining Territories: The Functional Regions, OECD Publishing, Paris.

OECD (2006), Competitive Cities in the Global Economy, OECD Publishing, Paris.

OECD (2007), Chongqing Municipality’s Development Strategy: some reflections from the international experience of the Territorial Development Policy Committee of the OECD.

United Nations, Population Division, Department of Economic and Social Affairs (2007), World Urbanization Prospects: The 2007 Revision, POP/DB/WUP/Rev.2007/1, United Nations, New York.

Wang (2003), Exploration and Renovation of Regional Township System Planning (in Chinese).

World Bank (2000), “Urbanization: Policy Note to Government” (internal communication), World Bank, Washington, DC. 
World Bank (2005), Waste Management in China: Issues and Recommendations, World Bank, Washington, DC.

World Bank (2007), World Remittances Database, World Bank, Washington, DC. 